Florida International University FIU Digital Commons

4-27-2016

\title{
Characterizing the Molecular Structure and Reactivity of Natural Organic Matter in The Everglades
}

Wenxi Huang

whuan011@fiu.edu

DOI: $10.25148 /$ etd.FIDC000689

Follow this and additional works at: https://digitalcommons.fiu.edu/etd

Part of the Chemistry Commons

\section{Recommended Citation}

Huang, Wenxi, "Characterizing the Molecular Structure and Reactivity of Natural Organic Matter in The Everglades" (2016). FIU Electronic Theses and Dissertations. 2636.

https://digitalcommons.fiu.edu/etd/2636 


\title{
FLORIDA INTERNATIONAL UNIVERSITY
}

Miami, Florida

\section{CHARACTERIZING THE MOLECULAR STRUCTURE AND REACTIVITY OF NATURAL ORGANIC MATTER IN THE EVERGLADES}

\author{
A thesis submitted in partial fulfillment of \\ the requirements for the degree of \\ MASTER OF SCIENCE \\ in \\ CHEMISTRY
}

by

Wenxi Huang 
To: Dean Michael R. Heithaus

College of Arts, Sciences and Education

This thesis, written by Wenxi Huang, and entitled Characterizing the Molecular Structure and Reactivity of Natural Organic Matter in The Everglades, having been approved in respect to style and intellectual content, is referred to you for judgment.

We have read this thesis and recommend that it be approved.

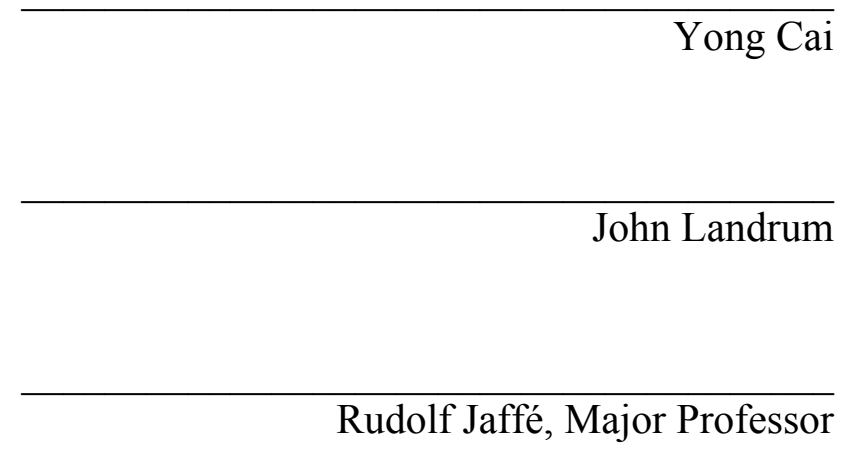

Date of Defense: April 27, 2016

The thesis of Wenxi Huang is approved.

Dean Michael R. Heithaus

College of Arts, Sciences and Education

Andrés G. Gil

Vice President for Research and Economic Development and Dean of the University Graduate School

Florida International University, 2016 
C Copyright 2015 by Wenxi Huang

All rights reserved. 


\section{DEDICATION}

I dedicate this thesis to my beloved parents, Ms. Ailing Deng and Mr. Zhuguang Huang. Without your endless love, support and encouragement, the completion of this work would not have been possible. This dissertation is also dedicated to the memory of my grandmother Wanhao Zhang (1929-2014). 


\section{ACKNOWLEDGMENTS}

I want to thank a number of people who I am greatly indebted.

My deepest gratitude is to my advisor Dr. Rudolf Jaffé. I sincerely appreciate his guidance and support throughout this study. I would also like to thank the rest of my

thesis committee: Dr. Yong Cai, Dr. John Landrum for their encouragement and insightful comments.

My sincere thanks also go to my collaborators Garrett Mckay, Fernando RosarioOrtiz and Cristina Romera-Castillo. I would also like to acknowledge Rafael Travieso, Adam Hines, Sandro Stumpf and Pedro Lorenzo for the access and assistance in order to make my fieldwork possible.

Special thanks go to my fellow labmates Peter Regier, Alan Rocebuck, Chao Ya, Sasha Wagner and Ding He. I am also thankful to Chemistry and Biochemistry department-FIU and FCE-LTER Grant for their support to this research.

Last but not least, I want to express my warm thanks to my family and friends for their love and encouragements. 


\title{
ABSTRACT OF THE THESIS \\ CHARACTERIZING THE MOLECULAR STRUCTURE AND REACTIVITY OF NATURAL ORGANIC MATTER IN THE EVERGLADES
}

\author{
by
}

Wenxi Huang

Florida International University, 2016

Miami, Florida

\section{Professor Rudolf Jaffé, Major Professor}

Mangroves are the dominant vegetation in Everglades estuarine environment and are known to contain polyphenols such as tannins, which present similar fluorescence properties as some amino acid fluorophores. In the present study, gas chromatographymass spectrometry (GC/MS) was used to quantify gallic acid, which is a normal monomer of polyphenols. The quantitative GC/MS analytical method was developed using gallic acid and tannic acid standards to quantify the false 'protein-like' fluorescence in DOM.

The present study also compared the optical properties, reactive species (RS) production and radical scavenging ability of DOM from different regions of the Everglades and a correlation was observed between DOM composition and its photoproductivity. In general, the reactive species quantum yield decreased with increased DOM redox potential. The RS formation rates were controlled by the DOC and CDOM abundace. Normalized RS formation rates were shown to be influenced by DOM aromaticity and molecular weight characteristics. 


\section{TABLE OF CONTENTS}

CHAPTER

PAGE

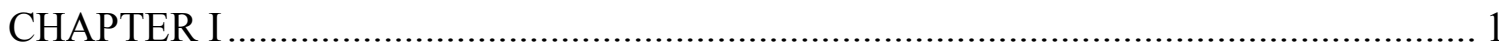

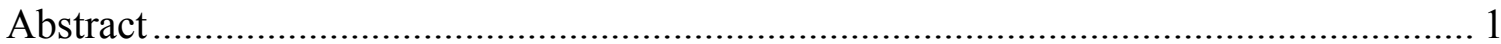

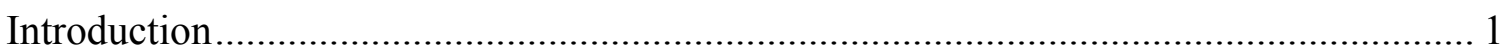

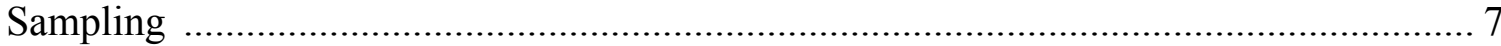

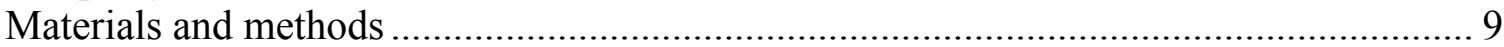

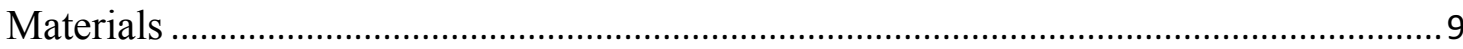

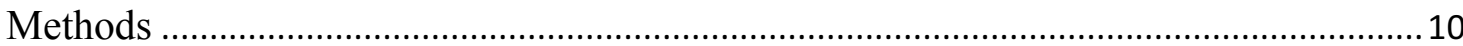

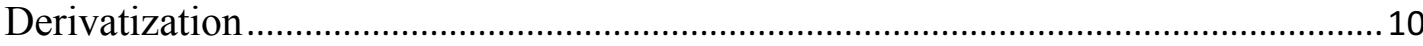

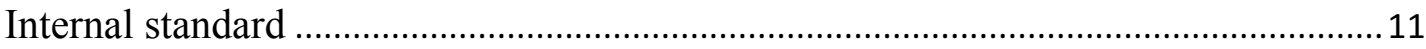

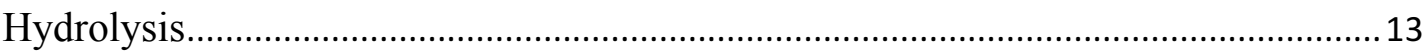

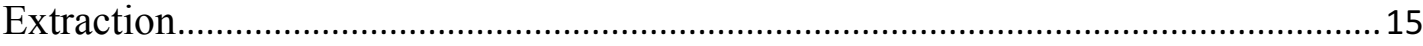

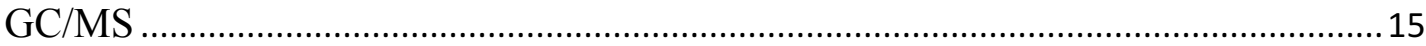

Analytical measurements of UV-vis, EEMs (Emission Excitation Matrix), DOC …16

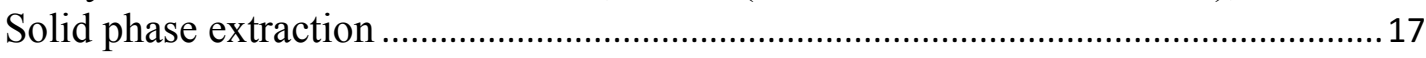

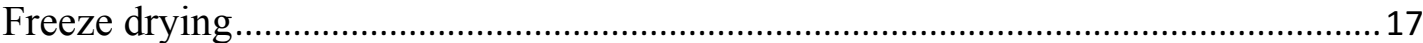

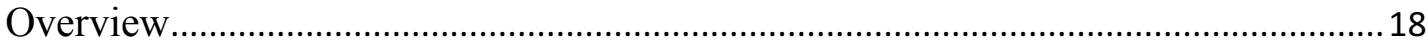

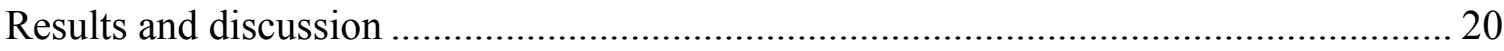

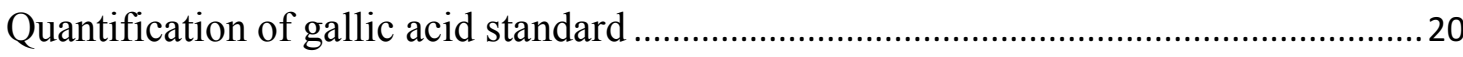

Quantification of gallic acid standard using internal standard........................................25

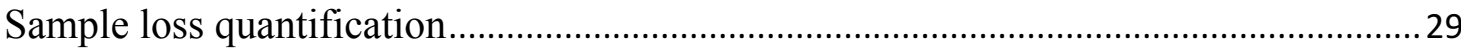

Tannic acid (hydrolyzable tannin) standard ...................................................................29

Floc sample (Environmental sample).............................................................................

Fluorescence quantum yield and DOC ………………............................................

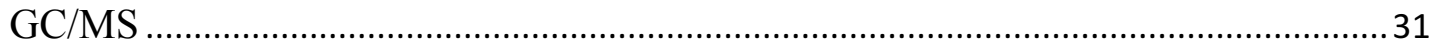

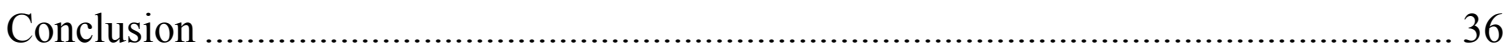

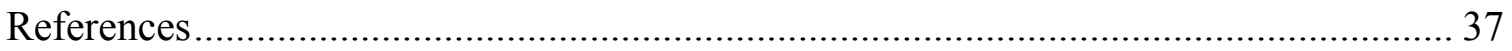

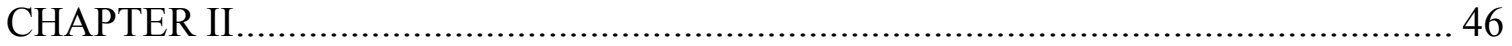

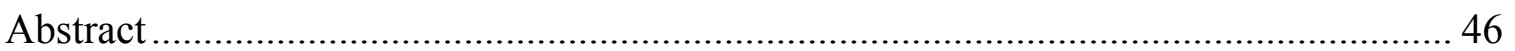

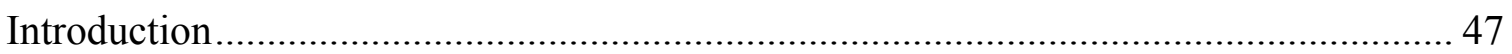

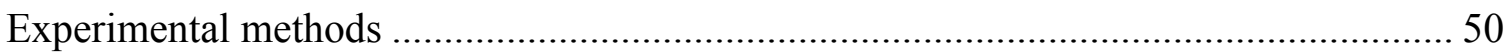

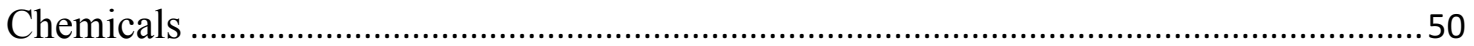

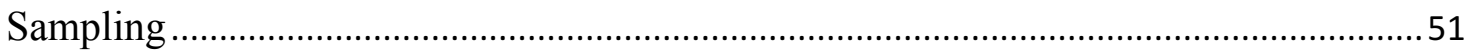

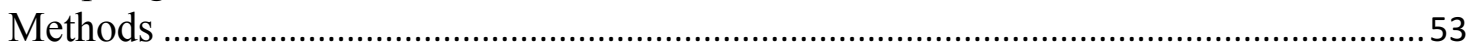

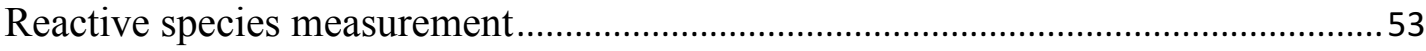

Antioxidant activity measurement ...........................................................................5

Dissolved organic carbon and optical properties measurements ..................................57

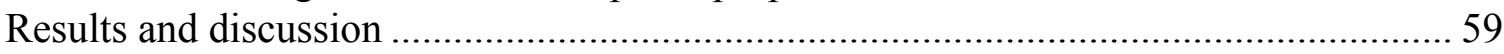

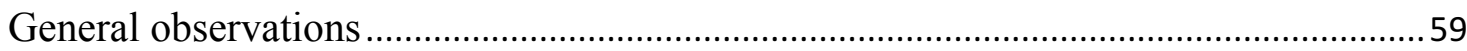

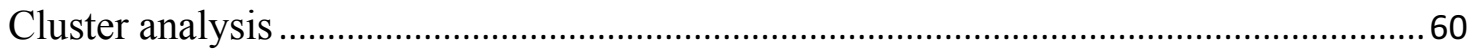

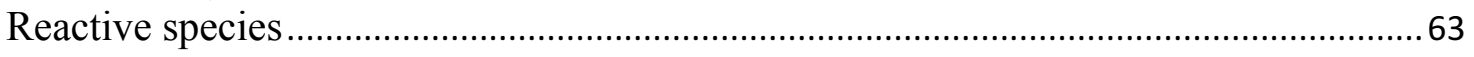




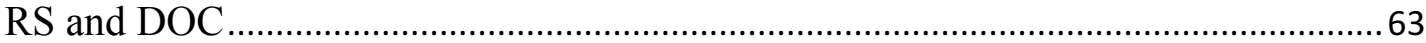

RS and CDOM (chromophoric dissolved organic matter) .........................................68

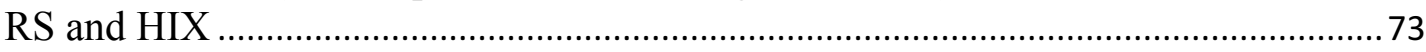

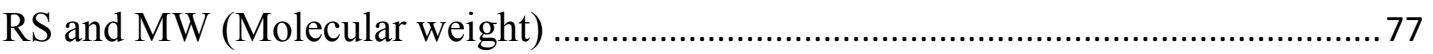

RS and redox potential (IP100)

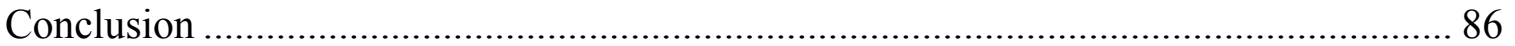

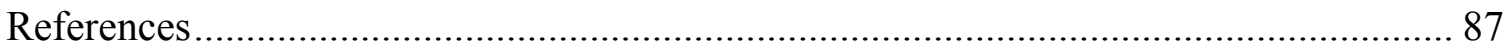

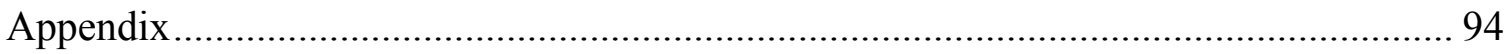




\section{LIST OF FIGURES}

FIGURE

PAGE

\section{CHAPTER I}

Figure 1-1. Size distribution diagram of natural organic matter (Aiken et al., 2011) ....... 3

Figure 1-2. Chemical structures of typical condensed and hydrolyzable tannins (Hernes et al., 2001)

Figure 1-3. Excitation emission matrix fluorescence spectra of Gallic acid (left) and tannin acid (right) 7

Figure 1-4. Sampling site SRS6 location in the Everglades National Park ...................... 8

Figure 1-5. The chemical reaction of tannic acid hydrolysis ..................................... 14

Figure 1-6. Flow diagram of the overall analytical procedure. Numbers in the scheme indicated the beginning of an independent experiential procedure.

Figure 1-7. Total ion chromatogram spectrum of gallic acid using fragment ion $\mathrm{m} / \mathrm{z}=281$

Figure 1-8. Standard MS spectrum of gallic acid from literature (Tor et al.,1996)......... 21

Figure 1-9. MS spectrum of peak $16.86 \mathrm{~min}$ in Figure 1-7 (MS spectrum of incomplete derivatized GA).

Figure 1-10. MS spectrum of peak 16.97 min in Figure 1-7 (MS spectrum of complete derivatized GA).

Figure 1-11. Total ion chromatogram spectrum of gallic acid using fragment ion $\mathrm{m} / \mathrm{z}=281$

Figure 1-12. The calibration curve of gallic acid using external standard. The blue line is a linear prediction and the blue shade is its $95 \%$ confidence zone. 26

Figure 1-13. Total ion chromatogram spectrum of DMBA and gallic acid.................... 26

Figure 1-14. MS spectrum of the peak at 16.25 min in Figure 1-13 (MS spectrum of DMBA)

Figure 1-15. MS spectrum of the peak at $16.52 \mathrm{~min}$ in Figure 1-13 (MS spectrum of GA) 
Figure 1-16. The calibration curve of gallic acid using internal standard 28

Figure 1-17. Fluorescence EEMs of floc extract before (left) and after (right) Varian Bond Elut PPL cartridges. 32

Figure 1-18. Fluorescence EEMs of gallic acid before (left) and after (right) Varian

Bond Elut PPL cartridges. 32

Figure 1-19. GC/MS of hydrolyzed floc sample (TIC) 34

Figure 1-20. GC/MS of hydrolyzed floc sample (MS). 35

\section{CHAPTER II}

Figure 2-1. Sampling sites along Shark River Slough (SRS-2/4/6), Taylor Slough (TS2/3/7) and Florida Bay (FB21).

Figure 2-2. Cluster analysis with RS quantum yields, antioxidant activity and optical properties data reorganized into monthly averages of each site.

Figure 2-3. Cluster analysis with monthly data. Sample name is a combination of sampling site and month.

Figure 2-4. Reactive species quantum yields versus DOC concentration..................... 65

Figure 2-5. Reactive species formation rates versus DOC concentration. ...................... 66

Figure 2-6. Scatter plots showing significant correlation between ${ }^{3} \mathrm{DOM}^{*}$ and ${ }^{1} \mathrm{O}_{2}$ formation rate

Figure 2-7. Reactive species quantum yields versus absorbance coefficient.. 70

Figure 2-8. Reactive species quantum yields versus SUVA value.............................. 71

Figure 2-9. Reactive species formation rate versus $a_{255}$ and SUVA value. .................. 72

Figure 2-10. Reactive species quantum yields versus HIX value............................. 75

Figure 2-11. Reactive species formation rate and DOC normalized formation rate versus HIX value. 76

Figure 2-12. Scatter plots showing significant correlation between DOM slope ratio and E2:E3 ratio. 79

Figure 2-13. Reactive species quantum yields versus slope ratio. 80 
Figure 2-14. Reactive species formation rate and DOC normalized formation rate versus

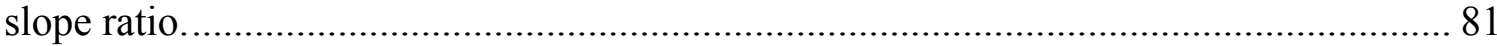

Figure 2-15. Reactive species quantum yields versus IP100_...................................... 84

Figure 2-16. Reactive species formation rate and DOC normalized formation rate versus

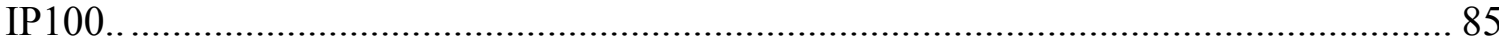




\section{ABBREVIATIONS AND ACRONYMS}

Hydroxyl radical

$\cdot \mathrm{OH}$

Hydroxyl radical quantum yield

$\cdot O H \_$QY

Singlet oxygen

${ }^{1} \mathrm{O}_{2}$

Singlet oxygen quantum yield

${ }^{1} \mathrm{O}_{2} \mathrm{Q} \mathrm{Y}$

Excited triplet states of dissolved organic matter

${ }^{3} \mathrm{DOM}^{*}$

Excited triplet states of dissolved organic matter quantum yield

${ }^{3} \mathrm{DOM}^{*}{ }_{\mathrm{Q}}$

The absorption coefficient at wavelength $254 \mathrm{~nm}$

$a_{254}$

The absorption coefficient at wavelength $255 \mathrm{~nm}$

$a_{255}$

N,O-Bis(trimethylsilyl)-acetamide

BSA

(N, O-Bis(trimethylsilyl) trifluoroacetamide)

BSTFA

Chromophoric dissolved organic matter

CDOM

Carboxylic acid

$-\mathrm{COOH}$

3,4-Dihydroxy-5-methoxybenzaldehyde

DMBA

3,4-Dihydroxy-5-methoxybenzaldehyde

DMBA

Dissolved organic matter

DOM

2,2-diphenyl-1-picrylhydrazyl

$\mathrm{DPPH} \bullet$

Ratio of a sample's absorbance at $254 \mathrm{~nm}$ to that at $365 \mathrm{~nm}$

E2:E3

Excitation emission matrix fluorescence with parallel factor analysis

EEM-PARAFAC

EEMs

Emission excitation matrices

Everglades national park

ENP 
Ethyl acetate solution $\quad$ EtAc

Ethanol

$\mathrm{EtOH}$

Florida bay

FB

Florida coastal everglades long term ecological research

FCE-LTER

Furfuryl alcohol

FFA

Fresh-water

FW

Gallic acid

GA

Gas chromatography-mass spectrometry

$\mathrm{GC} / \mathrm{MS}$

Humification index

HIX

The antioxidant activity for $100 \mathrm{mg} / \mathrm{L}$ methanol extracted

IP100

DOC on the basis of the calibration curve

IS

Internal standard

NIST

National Institute of Standards and Technology

NMR

Nuclear magnetic resonance

NOM

Natural organic matter

$-\mathrm{OH}$

Hydroxyl

POM

Particulate organic matter

PPLs

Varian Bond Elut PPL cartridges

RS

Reactive species

Solid phase extraction

SPE

Slope ratio

$\mathrm{S}_{\mathrm{R}}$

Shark river slough

SRS

Specific UV absorbance

SUVA 
Tannin acid

Trifluoroacetamide

Total ion chromatogram

Trimethylchlorosilane

2,4,6-trimethylphenol

Trimethylsilyl

Taylor slough

Ultraviolet-visible

Percentage by weight
TA

TFA

TIC

TMCS

TMP

TMS

TS

UV-vis

$\mathrm{wt} \%$ 


\title{
CHAPTER I
}

\begin{abstract}
'Protein-like' fluorescence has been used as a bio-reactivity proxy in many estuarine studies, under the assumption that amino acids are easily bioavailable to bacteria. However, polyphenols including tannins present similar fluorescence properties to some amino acid fluorophores. This potential interference is rarely considered in the literature related to 'protein-like' fluorescence. Mangroves, a major vegetation type of tropical estuarine environments contain significant amounts of tannin. Since tannins are primarily composed of gallic acid monomers, the goal of this study is to re-evaluate the contribution of such polyphenols to 'protein-like' fluorescence in natural organic matter. Besides dissolved organic carbon concentration and optical properties, gas chromatography-mass spectrometry (GC/MS) was used to quantify gallic acid, which is a normal monomer of polyphenols. A quantitative GC/MS analytical method was developed using gallic acid and tannic acid standards. Mangrove floc was collected from an estuarine mangrove forest in the Everglades to serve as an environmental sample. Advances and difficulties during the development of this method for environmental samples measurement are described in the thesis.
\end{abstract}

Introduction

Photo-reactivity and bio-reactivity are important focus areas of natural organic matter (NOM) research. Natural organic matter, which is comprised of dissolved organic 
matter (DOM) and particulate organic matter (POM), is defined as detrital material derived from plants and animals, and their degradation products occurring in aquatic systems (Riley and Chester, 1971). Historically, NOM has been divided into DOM and POM depending on filtration (Figure 1-1) usually using $0.7 \mu \mathrm{m}$ glass fiber filters (Morel and Gschwend, 1987; Lead and Wilkinson, 2007; Aiken et al., 2011). 'Protein-like' fluorescence is often observed both in DOM (Coble et al., 1990; Maie et al., 2007) and base-extracts of POM (Osburn et al., 2012; Brym et al., 2014).

Our study of NOM focused on the Everglades ecosystem. Everglades National Park (ENP) is the largest subtropical wetland in the United States (Davis and Ogden, 1994). It comprises one of the largest freshwater marshes on the North American continent and contains the largest single body of organic soils in the world (Stephens 1956). Surface waters naturally drain to Florida Bay and Florida Shelf through a landscape of broad shallow sloughs (Gooselink and Turner, 1978). The seasonal climate in the Everglades is divided into clear wet (between June and November) and dry seasons (December to May) with about $80 \%$ of total annual precipitation occurring during the wet season. In the dry season, freshwater in-flows are reduced and the estuarine residence time increases, altering processes responsible for nutrient availability and water quality (Childers, et al., 2006). The seasonal changes affect DOM residence times and its reactivity. One of the primary drainages of the Everglades National Park (ENP) is Shark River Slough (characterized as a long hydroperiod region). The Shark River Slough estuary is connected to the Gulf of Mexico and receives significant tidal influence (Fourqurean et al. 1993). 


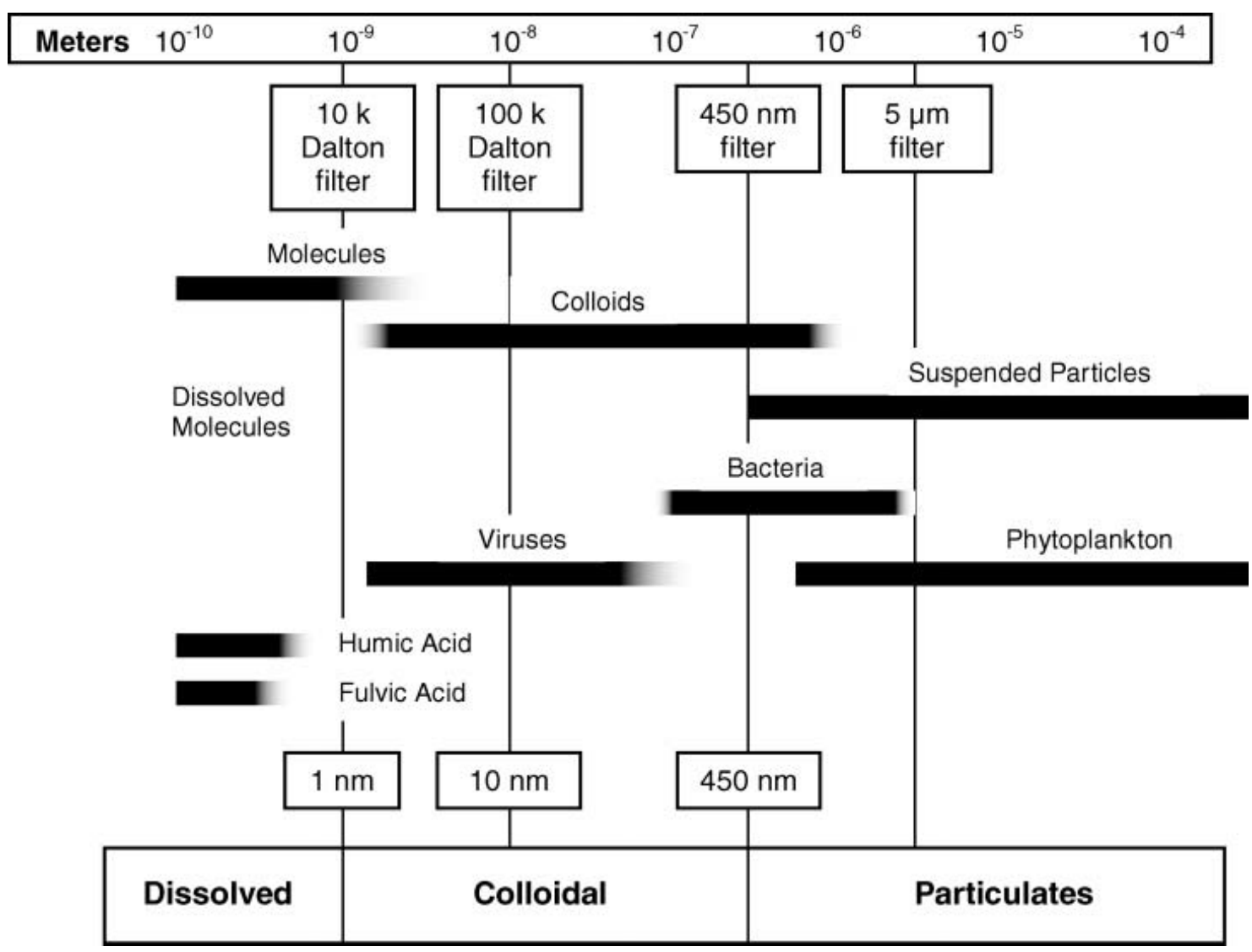

Figure 1-1. Size distribution diagram of natural organic matter (Aiken et al., 2011)

Dissolved organic matter characterization studies have used a wide variety of techniques, including optical properties (Twardowski et al., 2004; Helms et al., 2008), nitrogen and carbon stable isotopes (Banner et al., 1997), and radioisotopes (Benoit et al., 2001). For characterization of the molecular constituents of DOM, such as amino acids, proteins, carbohydrates and lignins, methods including nuclear magnetic resonance (NMR) and mass spectrometry have been applied (Gélinas, et al., 2001; Kujawinski, et al., 2002; Maie et al., 2005; Hertkorn et al., 2015). Fluorescence has been used as a qualitative and semi-quantitative method for characterizing optical properties for decades (Kalle, 1949; Godshalk et al., 1978). Excitation emission matrix fluorescence with 
parallel factor analysis (EEM-PARAFAC) makes fluorescence spectroscopy a more efficient method to study the dynamics of bulk DOM in aquatic ecosystems (Stedmon, et al., 2003). Coble, et al. (1990) characterized dissolved organic matter as 'humic-like' and 'protein-like' fluorophores. While the former are mainly derived from soil OM and plants, the latter may be plankton-derived and positive correlation between the 'protein-like' fluorescence and DOM bioavailability have been reported (Hood et al., 2009; Fellman et al., 2011). Therefore, 'protein-like' fluorescence has been applied as a proxy for bioavailable DOM (Fellman et al., 2009) and an indicator for biological reactivity of DOM (Parlanti, et al., 2000). Natural DOM with 'protein-like' fluorophores has been further classified as 'tryptophan-like' (with an emission wavelength peak around $350 \mathrm{~nm}$ ) and 'tyrosine-like' (with an emission wavelength peak around $300 \mathrm{~nm}$ ) (Coble, 1996) and fluorescence intensities have been shown to correlate significantly with tryptophan and tyrosine concentrations as hydrolyzable amino acids (Yamashita, and Tanoue, 2003). 'Protein-like' fluorescence peaks have also been observed in base-extracted POM (Osburn et al., 2012; Brym et al., 2014).

While it is usually assumed that the 'protein-like' fluorescence is mainly due to amino acids, Maie, et al. (2007) determined via size exclusion chromatography that the tryptophan-like peak was composed of two compounds with distinct molecular weights (MW) and suggested that one of them might be composed of polyphenols and not amino acids. In addition, only a weak correlation between 'protein-like' florescence intensity and the hydrolyzable amino acid concentrations in the Everglades has been reported (Chen and Jaffe, personal communication), which suggests reconsidering use of the 
'protein-like' peak florescence intensity as a proxy for bioavailable dissolved organic nitrogen at least in ecosystems where polyphenols such as tannins are abundant.

Tannins (polyphenols) are polymeric plant derived phenolic compounds with high molecular weight (Robinson, 1980). The term 'phenolic' indicates any compound with a hydroxyl-substituted benzene ring. Tannins are a ubiquitous group of plant phenols and present in significant amounts in the wood, bark, and leaves of woody plants (Brouillard et al., 1994). Tannins are generally classified as hydrolyzable tannins and condensed tannins (Figure 1-2). The hydrolyzable tannins contain gallic acid or hexahydroxydiphenic acid and their derivatives. The condensed tannins consist of flavonoid polymers (Roux et al., 1975). Hydrolyzable tannin is more soluble than the latter and could be hydrolyzed to gallic acid (Gross et al., 2012). Gallic acid (GA) consists of a benzene ring directly bonded to a carboxyl group and three hydroxyl groups and has been reported to feature 'protein-like' fluorescence.

'Protein like' fluorescence, with an excitation / emission wavelength maximum of $275 \mathrm{~nm} / 310$ or $340 \mathrm{~nm}$ corresponds to tyrosine-like or tryptophan-like DOM fluorescence peaks respectively (Coble, 1996). Gallic acid and tannic acid both exhibit an excitation wavelength maximum around $275 \mathrm{~nm}$ and emission wavelength maximum around $340 \mathrm{~nm}$ (Figure 1-3). The EEM spectra of diagenetic products of tannins were detected to have fluorescence signals. Tannins were estimated to account for about $20 \mathrm{wt} \%$ of mangrove (Rhizophora mangle) leaf tissues using solid-state ${ }^{13} \mathrm{C}$ nuclear magnetic resonance (Benner et al., 1990). 
It is therefore critical to characterize the molecular composition of the "proteinlike" fluorescence in DOM to quantitatively assess the actual contributions of amino acids and polyphenols. While polyphenols such as tannins have been linked with 'protein-like' fluorescence (Maie et al., 2008), in samples with high abundance of these compounds, the 'protein-like' fluorescence should be considered carefully before using as a DOM bioavailability proxy. Many measurements of 'protein-like' fluorescence could be wrongly assumed to be tyrosine and tryptophan protein, leading to erroneous interpretation. However, little is known about this topic. Therefore, this thesis aims to provide a critical evaluation of this traditionally defined fluorescence EEM component.

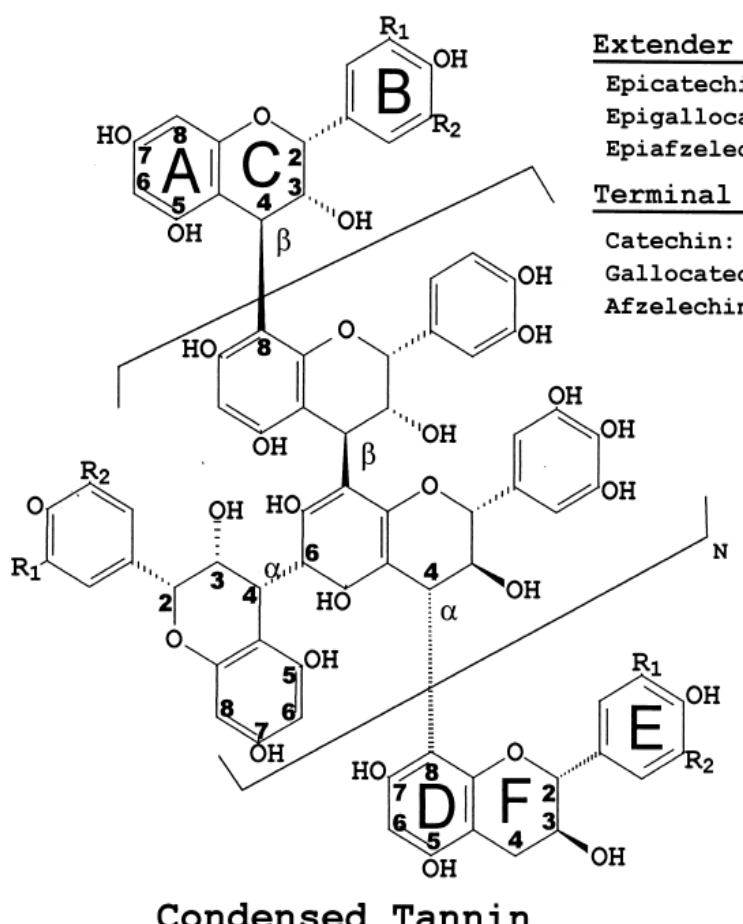

Condensed Tannin

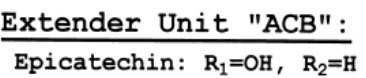

Epigallocatechin: $\mathrm{R}_{1}=\mathrm{R}_{2}=\mathrm{OH}$

lechin: $R_{1}=R_{2}=H$

locatechin: $R_{1}=R_{2}=O H$

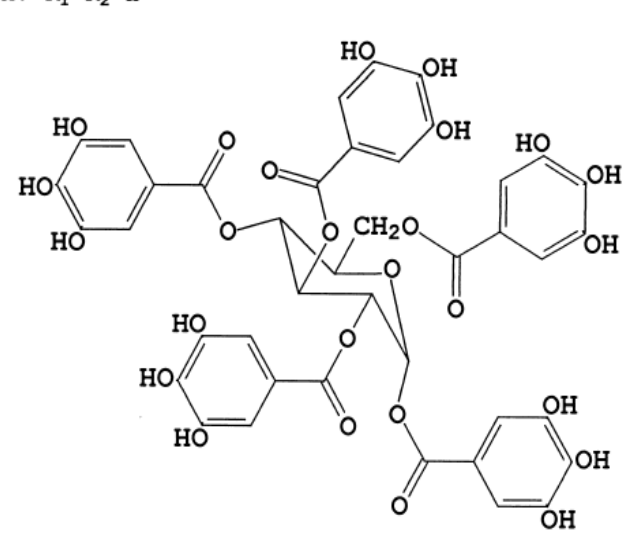

Hydrolyzable Tannin

Figure 1-2. Chemical structures of typical condensed and hydrolyzable tannins (Hernes et al., 2001) 

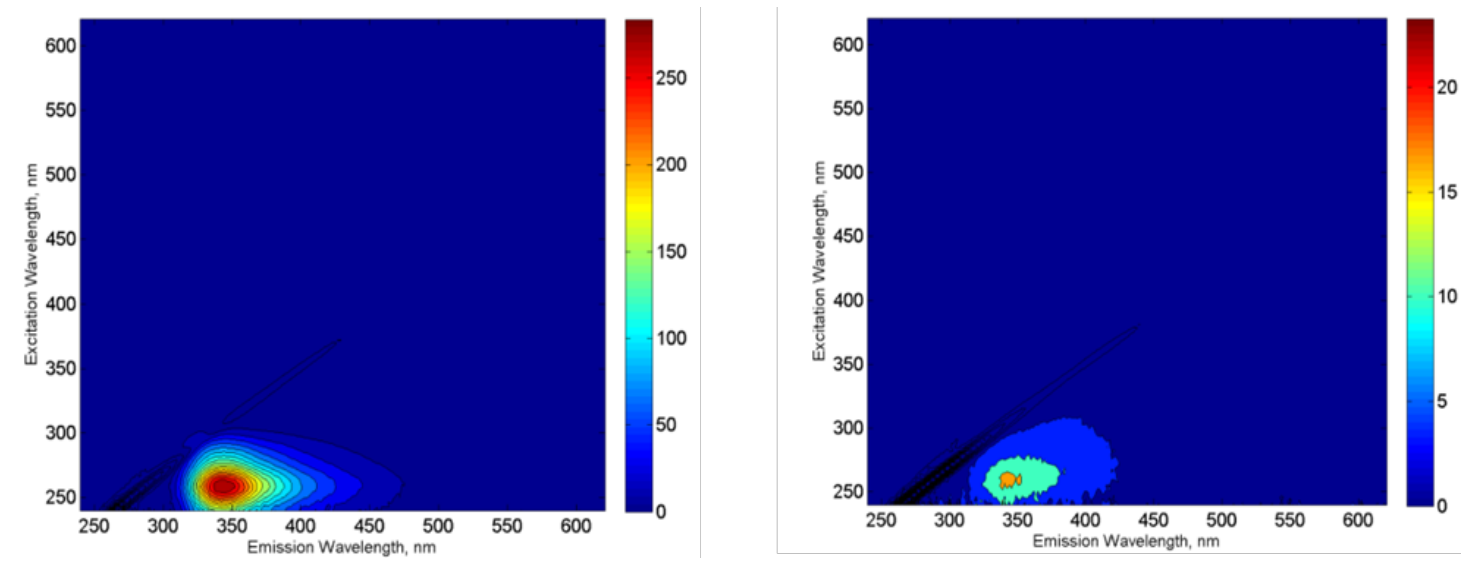

Figure 1-3. Excitation emission matrix fluorescence spectra of Gallic acid (left) and tannin acid (right)

\section{Sampling}

Floc samples, i.e, unconsolidated surface sediments were collected at FCE-LTER (Florida Coastal Everglades Long Term Ecological Research) SRS6 site (Figure 1-4). Hydrology at the site is seasonally driven by freshwater inputs and tidal inputs. The SRS6 site is located close to the mouth of the Shark River with peat soils over $1 \mathrm{~m}$ thick at the site overlaying karstic bedrock. The riparian mangrove forests lining the Shark River are a mixture of white (Laguncularia racemosa), black (Avicennia germinans) and red mangroves (Rhizophora mangle). (see http://fcelter.fiu.edu/research/sites/). Organic matter in floc at SRS6 consists almost entirely of mangrove detritus.

Floc samples were collected according to Pisani et al. (2013). Briefly, loose particles overlaying sediments in a small tidal creek adjacent to SRS6 were collected with a turkey baster. While collecting the floc, excess water was decanted and the floc was placed in pre-rinsed $1 \mathrm{~L}$ Teflon jars (Nalgene). After transport to the lab, samples were 
frozen, and then freeze-dried to remove water. The freeze-dried floc samples were grinded and sieved through a $0.5-\mathrm{mm}$ sieve to remove large particles and then stored frozen in combusted glass jars (Ichem) prior to analysis.

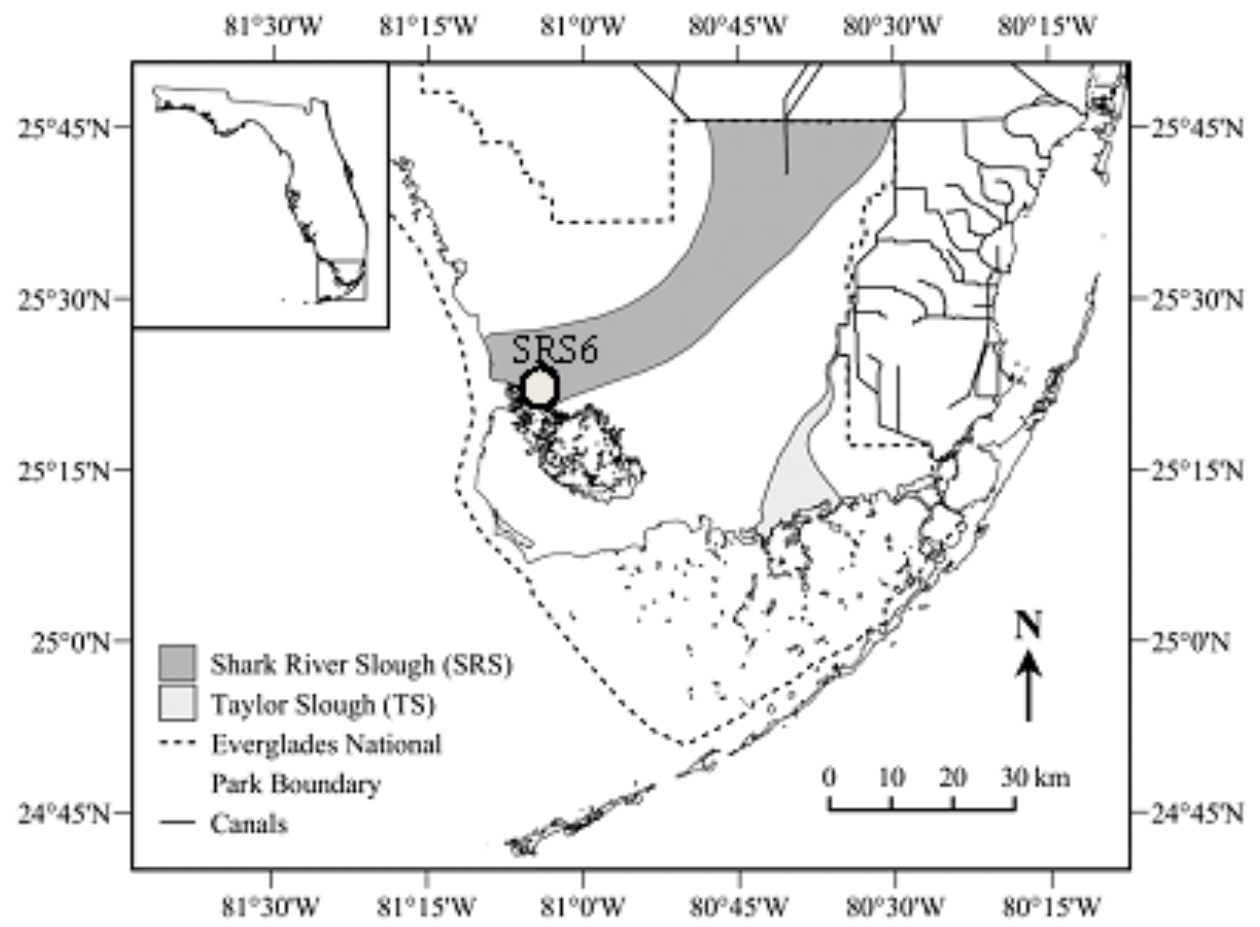

Figure 1-4. Sampling site SRS6 location in the Everglades National Park 
Materials and methods

Materials

Gallic acid monohydrate standard (GA) (ACS reagent, $\geq 98.0 \%$ ), 3,4-Dihydroxy5-methoxybenzaldehyde (DMBA) (96\%) and tannic acid (TA) (PURISS., USP, powder) were purchased from Sigma-Aldrich Co. (St. Louis, MO). Working solutions of gallic acid and DMBA were prepared in ethanol (EtOH) and ethyl acetate solution (EtAc) $(\mathrm{v}: \mathrm{v}=95: 5)$ and stored at $4^{0} \mathrm{C}$. Ethanol (EtOH) (99.5\%, ACS reagent, absolute, 200 proof) was purchased from ACROS Organics. Ethyl acetate was purchased from Fisher Scientific Inc. The derivatization agent N, O-Bis(trimethylsilyl) trifluoroacetamide (BSTFA) (98 to 100\% N, O-bis-trimethylsilyl-trifluoroacetamide) and pyridine (ACS reagent, $\geq 99.0 \%$ ), was purchased from Fisher Scientific Inc. Varian Bond Elut PPL cartridges were purchased from Agilent Technologies.

Stock solution was prepared as follows: $5.258 \mathrm{mg}$ GA standard, 4.877mg DMBA standard and $5.257 \mathrm{mg}$ TA standard were dissolved in 25ml EtOH + EtAc (v:v=95:5) solution respectively. The stock solutions were stored in ambient glass vials and kept in the freezer at $-18^{\circ} \mathrm{C}$. 
Methods

\section{Derivatization}

Derivatization of $-\mathrm{OH}$ and $-\mathrm{COOH}$ groups present in gallic acid can be accomplished through silylation, acylation, or alkylation to improve its volatility for GC/MS analysis. Silylation is sufficient for compounds containing active hydrogen atoms, e.g. acids, alcohols, thiols, amines, amides, etc. Therefore, silylation was selected as the derivatization method for this experiment to enhance detection.

The most common silyl derivatives are TMS (Trimethylsilyl) derivatives. BSA (N,O-Bis(trimethylsilyl)-acetamide) and BSTFA are widely used reagents to introduce the TMS group. They can be used directly or in the presence of a catalyst, such as, TMCS (Trimethylchlorosilane), TFA (Trifluoroacetamide), hydrochloric acid, potassium acetate, piperidine or pyridine. In the experiment, because of the three - $\mathrm{OH}$ groups and one $\mathrm{COOH}$ group that gallic acid contains, its volatility is limited and it must first be derivatized for better GC/MS detection and resolution. Therefore, BSFTA and pyridine $(\mathrm{v}: \mathrm{v}=10: 3)$ were used to form silyl derivative analytes via the reaction presented below:

Equation 1-1.<smiles>O=C(O)c1cc(O)c(O)c(O)c1</smiles>

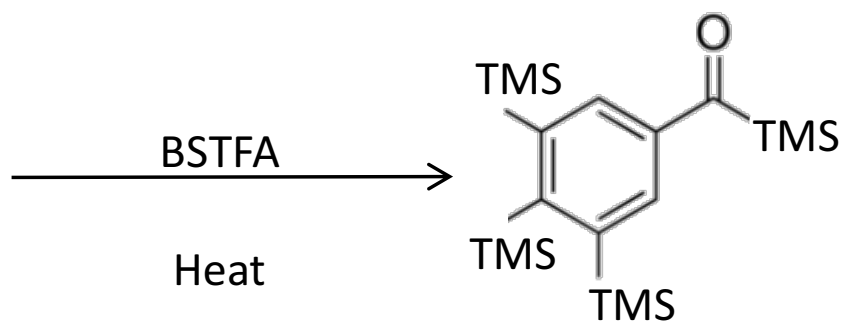


For the gallic acid silyl derivative, the molecular ion is $\mathrm{m} / \mathrm{z} 458$ and the major fragmentation ion is represented by $\mathrm{m} / \mathrm{z} 281$ because of the loss of two TMS groups (Tor et al., 1996).

In the present experiment, BSFTA and pyridine (v:v=10:3) were used as derivatization reagents to convert analytes to silyl derivatives. Different derivatization reagent concentrations and reaction times were performed in the present study. The procedure of derivatization is described as follows: The gallic acid sample was placed in a $4 \mathrm{ml}$ glass vial and subsequently dried with $\mathrm{N}_{2}$. BSTFA and pyridine solution were added to the dried sample and the glass vial was immediately capped. Next, the vial was agitated for 10 seconds and then placed in an oven set at $70^{\circ} \mathrm{C}$ for 30 minutes.

\section{Internal standard}

An internal standard (IS) is a substance added to a sample in a known quantity as a reference to correct for certain factors such as analyte loss during sample preparation, volume differences in injection, chromatographic analysis differences and response factor change. For GC/MS, a good internal standard should contain the following characteristics:

-Not present in the original sample

- Stable and non-reactive with any compounds in the sample (or the stationary or mobile phases)

-Easily identifiable either by time in the chromatogram or by mass in the mass spectra -Contain similar chemical properties to the target analyte to minimize the bias throughout the sample preparation steps including extraction and derivatization 
Therefore, 3,4-Dihydroxy-5-methoxybenzaldehyde (DMBA) was selected as the internal standard for the analysis of gallic acid as it matches these criteria. Its silylation reaction formula is presented as follows:

Equation 1-2.

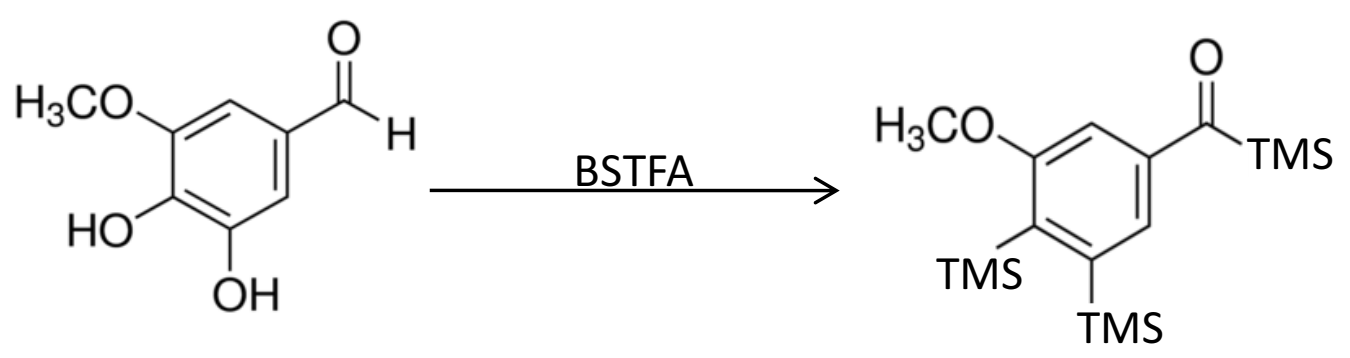

For the internal standard DMBA-TMS, the molecular ion is $\mathrm{m} / \mathrm{z} 400$ and the major fragmentation ion is represented by $\mathrm{m} / \mathrm{z} 223$ because of the loss of two TMS groups (Experiment data).

A standard curve was prepared by the analysis of known amounts of gallic acid and internal standard (IS). Concentration of the target compound can be calculated through this equation:

Equation 1-3.

Concentration of compound $=($ Concentration of IS $\times$ area of compound peak $) /$ Area of IS peak 


\section{Hydrolysis}

Hydrolysis of tannin to gallic acids could be achieved by acid hydrolysis (Tor et al., 1996) and enzyme hydrolysis (Seth and Subhash, 2000). However, enzyme hydrolysis has been rarely reported in the literature and is precluded to avoid complex background of GC/MS measurement. The hydrolysis method used in this study is on the basis of the research of Tor et al. (1996), using $3 \% \mathrm{HCl}$ reacting with hydrolyzable tannin at $110^{\circ} \mathrm{C}$ for 4 hours. The reaction was carried out in a $15 \mathrm{~mL}$ screw cap hydrolysis tube, which was filled with $\mathrm{N}_{2}$ to replace air and limit the oxidation process while reacting in the oven. The chemical reaction of tannic acid hydrolysis is provided in Figure 1-5. (tannic acid structure was downloaded from Wikipedia): 


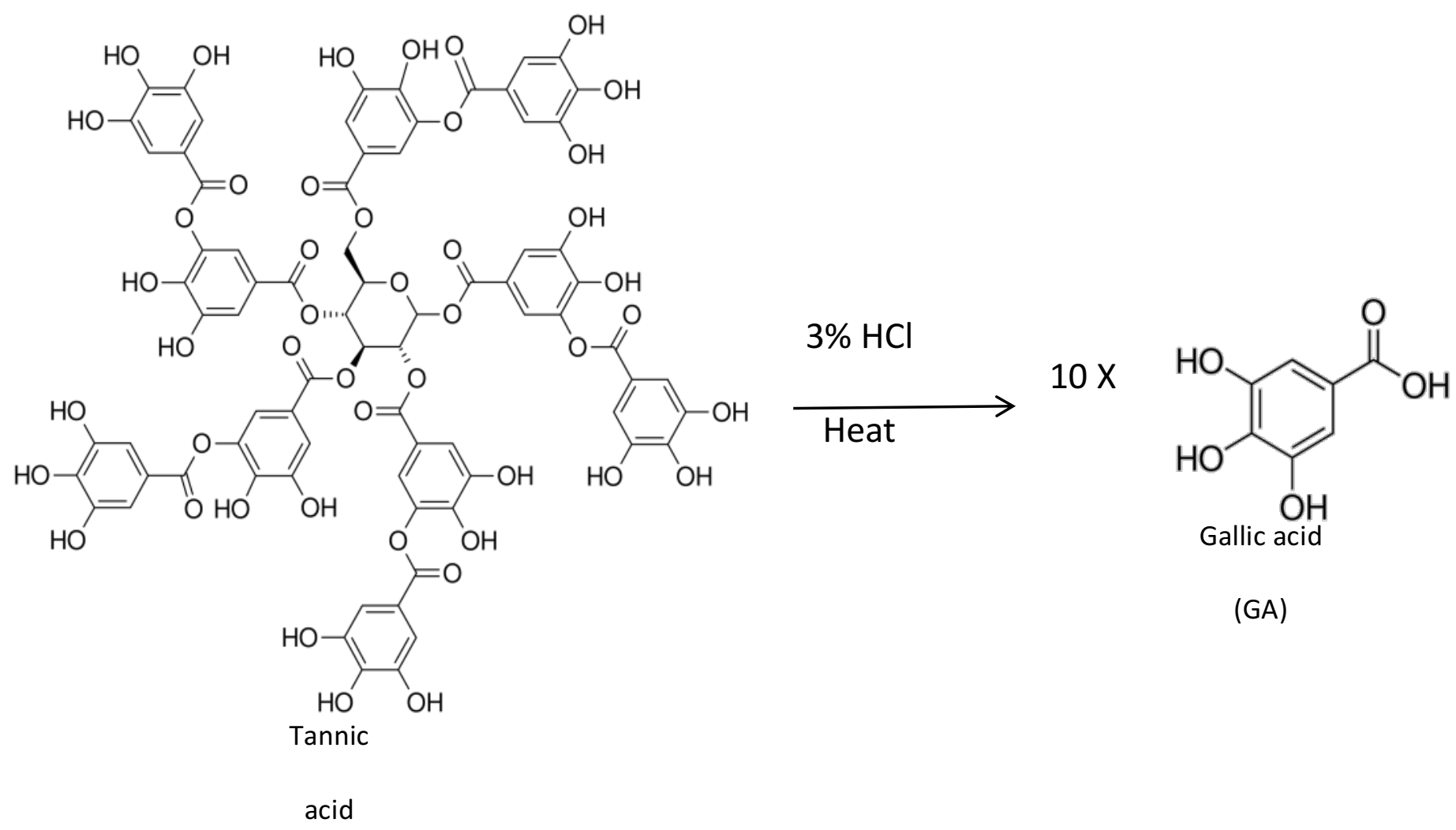

Figure 1-5. The chemical reaction of tannic acid hydrolysis 


\section{Extraction}

Liquid-liquid extraction using ethanol $(\mathrm{EtOH})$ and ethyl acetate solution (EtAc) $(\mathrm{v}: \mathrm{v}=95: 5)$ (Tor et al., 1996) was performed in a glass separatory funnel. The upper solution was collected into a round bottom flask after passing through a funnel loaded with sodium sulfate to remove any remaining water. Funnels were rinsed three times with $5 \% \mathrm{EtOH}+$ EtAc solution and the rinse solution was collected into the same round bottom flask. After extraction, excess solvents were removed using a rotary evaporator and the concentrated extract was transferred to clean $4 \mathrm{ml}$ vials for derivatization.

\section{GC/MS}

Chromatography is a process used for separating compounds in a complex mixture (Golay et al., 1958; Simmons et al., 1961). In order to quantify the polyphenol concentration in NOM, chromatography was chosen for the selective analysis of gallic acid. The appropriate and sensitive detector for this study is mass spectrometry. Thus, the analyses described in this chapter were performed by GC/MS, which is an analytical method that combines the features of gas-chromatography and mass spectrometry to identify different substances within a test sample.

The GC/MS analysis was performed using a Hewlett-Packard 6890 GC with a Restek Rtx-5MS column (30 m, 0.25 mm inner diameter), linked to a HP 5973 MS system. The GC oven temperature was programmed as follows: $60^{\circ} \mathrm{C}$ (hold $1 \mathrm{~min}$ ), ramp to $300{ }^{\circ} \mathrm{C}$ at a rate of $10^{\circ} \mathrm{C} / \mathrm{min}$, then held at $300{ }^{\circ} \mathrm{C}$ for $5 \mathrm{~min}$. Identification of gallic 
acid was confirmed by comparing spectra from the NIST (National Institute of Standards and Technology) library with the gallic acid standard mass spectra and retention time.

Analytical measurements of UV-vis, EEMs (Emission Excitation Matrix), DOC

In order to quantify the real protein induced 'protein-like' fluorescence, the gallic acid induced 'protein-like' fluorescence needs to be substracted from the mass 'proteinlike' fluorescence. The proposed approach is that the gallic acid concentration would be measured through GC/MS and then knowing the fluorescence quantum yield of gallic acid, the fluorescence intensity of the gallic acid induced 'protein-like' fluorescence could be deduced. The fluorescence quantum yield of gallic acid was calculated as follows (Birks, 1970 and Valeur, 2012).

Equation 1-4.

$$
\frac{\Phi_{G A}}{\phi_{T y r}}=\frac{\int_{0}^{\infty} I_{G A}\left(\lambda_{e x}\right) d \lambda_{e m}}{A_{G A}\left(\lambda_{e x}\right)} \times \frac{A_{T y r}\left(\lambda_{e x=276 n m}\right)}{\int_{0}^{\infty} I_{T y r}\left(\lambda_{e x=276 n m}\right) d \lambda_{e m}}
$$

Where $I$ represents the integrated fluorescence intensity at a single excitation wavelength $\lambda_{\text {ex }}$ across a range of emission wavelengths $\lambda_{\text {em }} \cdot \phi_{\text {Tyr }}=0.14\left(\lambda_{\text {ex }}=276 \mathrm{~nm}\right)$ (Chen, 1967).

Therefore, fluorescence and UV absorbance measurements of gallic acid and tyrosine were performed on Aqualog (Horiba) spectrofluorometer. The UV spectra were measured from $240 \mathrm{~nm}$ to $621 \mathrm{~nm}$ at an increment of $3 \mathrm{~nm}$. The fluorescence was 
measured from excitation $240 \mathrm{~nm}$ to $621 \mathrm{~nm}$ at an increment of $3 \mathrm{~nm}$ along with emission from $241 \mathrm{~nm}$ to $622 \mathrm{~nm}$ at an increment of $1.5 \mathrm{~nm}$.

The DOC concentration was used to calculate solid phase extraction (SPE) recovery rate. It was measured by high-temperature catalytic combustion using a Shimadzu TOC-5000A analyzer. Briefly, samples were acidified with $3 \mathrm{M} \mathrm{HCl}$ and purged with $\mathrm{CO}_{2}$ free air in order to remove inorganic carbon prior to analysis. Then samples were purged to a reactor where the temperature is $680^{\circ} \mathrm{C}$ or higher in order to convert the carbonates to $\mathrm{CO}_{2}$ gas for detection.

Solid phase extraction

Solid phase extraction using Varian Bond Elut PPL cartridges (PPLs) was proved to be one of the most efficient methods to isolate DOM and the DOC recovery rate on average reaches $62 \%$ (Dittmar et al., 2008). Prior to extraction, floc extracts were acidified to $\mathrm{pH}=2$ using $\mathrm{HCl}$ and then passed through Varian Bond Elut PPL cartridge (1g). After $\mathrm{N}_{2}$ air drying the cartridge, the DOM was eluted with methanol.

\section{Freeze drying}

Freeze-drying is an alternative method for DOC concentration other than SPE. This method could preserve the high polarity and / or low molecular weight compounds that may be missed out through extractions with PPLs. In the present study, the DOC with 'protein-like' fluorescence was not retained by PPLs and the explanations are present in the following (results and discussion) section. In order to better preserve all the 
$\mathrm{DOM}$, floc extract was freeze dried at $-50^{\circ} \mathrm{C}$ to remove water. Unlike PPL cartridges, which used sorption to retain DOM, freeze-drying sublimated water and left behind all the DOM, as such they should be more representative and quantitative.

\section{Overview}

The experimental process in the present study is concluded in Figure 1-6. This experiment was first carried out using a gallic acid standard to establish the calibration curve (Figure 1-6 Step 1). Then internal standard was introduced to determine the precision of detection (Figure 1-6 Step 2). Later, recovery of polyphenol hydrolysis was calculated using gallic acid and tannic acid standard (Figure 1-6 Step 3). After method development, environmental samples were tested (Figure 1-6 Step 4; 5; 6). 


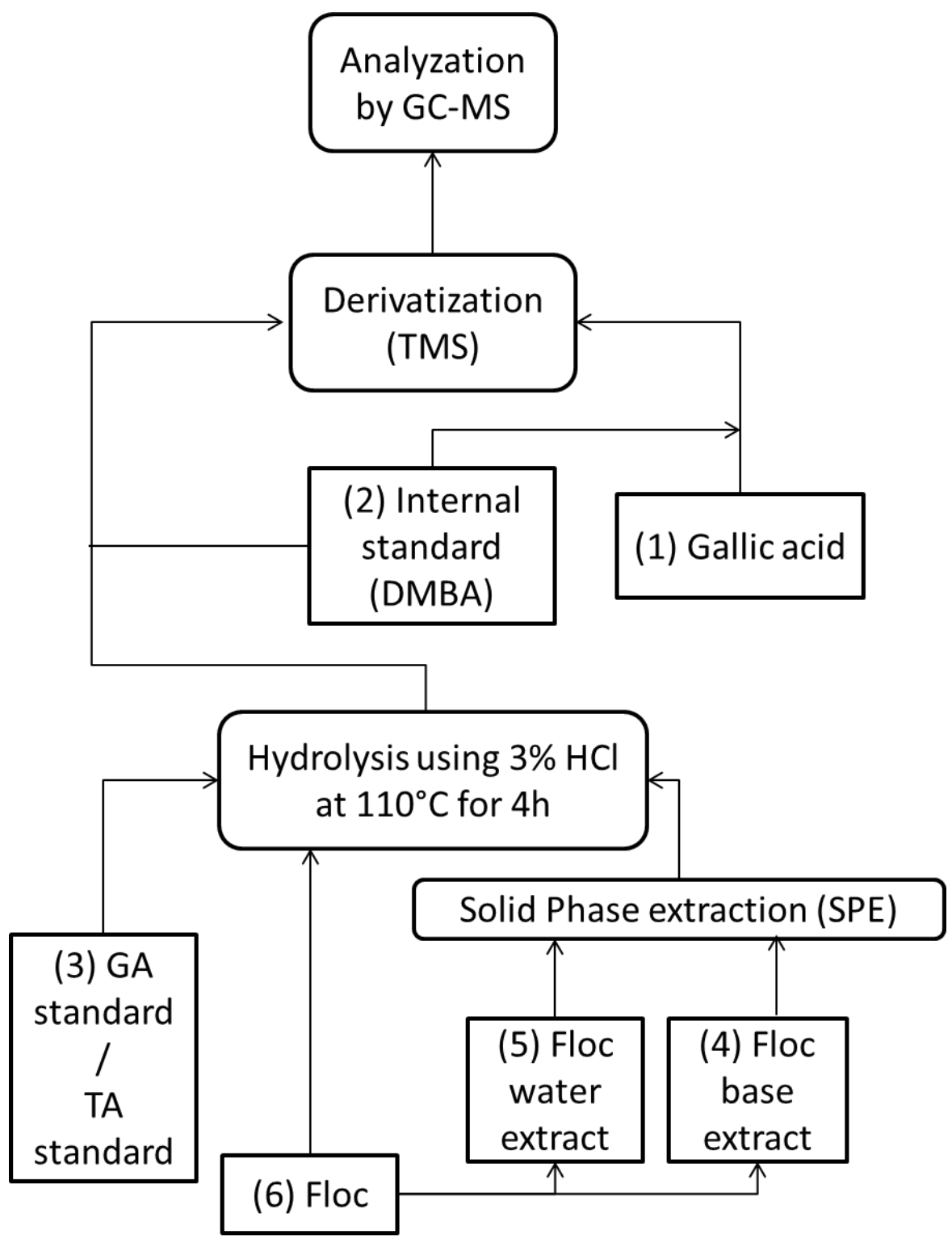

Figure 1-6. Flow diagram of the overall analytical procedure. Numbers in the scheme indicated the beginning of an independent experiential procedure. 
Results and discussion

Quantification of gallic acid standard

In order to quantify the gallic acid in GC/MS, a set of gallic acid standard was prepared. One $\mathrm{ml}$ gallic acid stock solution was diluted to $25 \mathrm{ml}$ and stored in a glass vial as gallic acid solution. 100, 200, 400 and $600 \mu \mathrm{L}$ of gallic acid solution was spiked into the sample and blow dried under $\mathrm{N}_{2}$. The experiment was first performed using $200 \mu \mathrm{l}$ derivatization reagent (BSTFA and pyridine solution) with a reaction time of $60 \mathrm{~min}$. The total ion chromatogram (TIC) of gallic acid major fragment ion $\mathrm{m} / \mathrm{z}=281$ showed two separate peaks which were formed by incomplete derivatization of gallic acid on the basis of the MS information obtained (Figure 1-7). A fully derivatized gallic acid MS spectrum from the literature is shown in Figure 1-8. On the basis of the fragmentation information from the MS, the 16.86 min peak in Figure 1-7 is an incomplete gallic acid derivative where the $-\mathrm{COOH}$ group was not fully derivatized (Figure 1-9). The $16.97 \mathrm{~min}$ peak in Figure 1-7 represented fully derivatized gallic acid (Figure 1-10). 


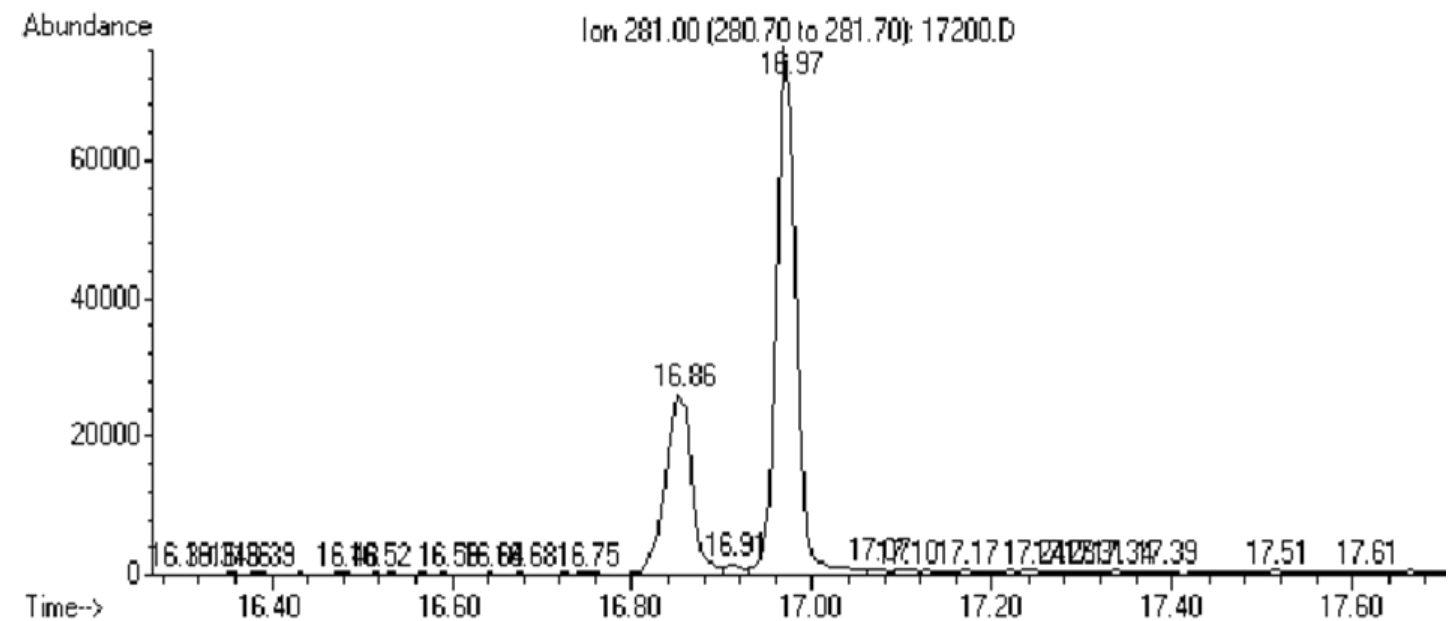

Figure 1-7. Total ion chromatogram spectrum of gallic acid using fragment ion $\mathrm{m} / \mathrm{z}=281$

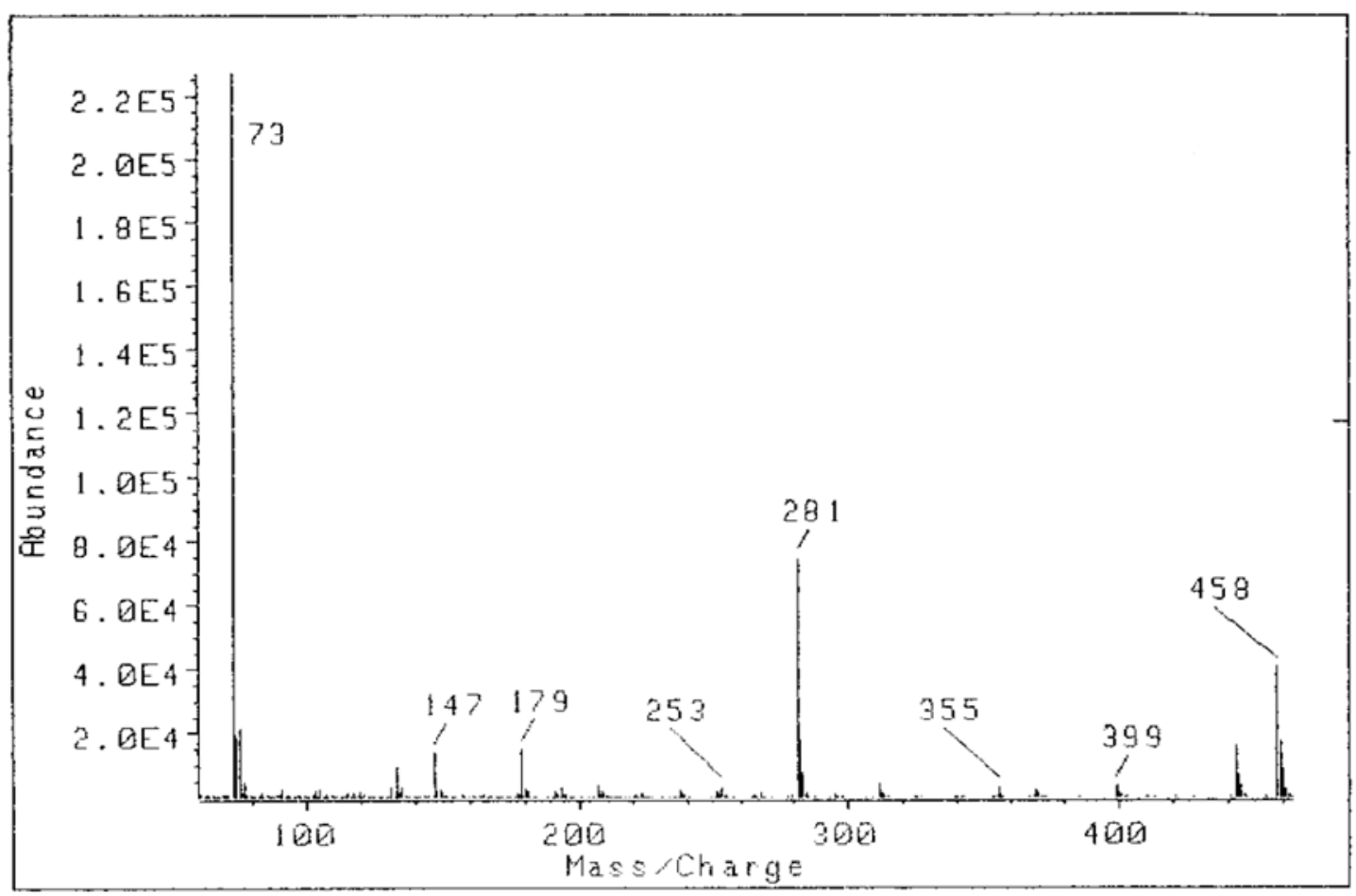

Figure 1-8. Standard MS spectrum of gallic acid from literature (Tor et al.,1996) 


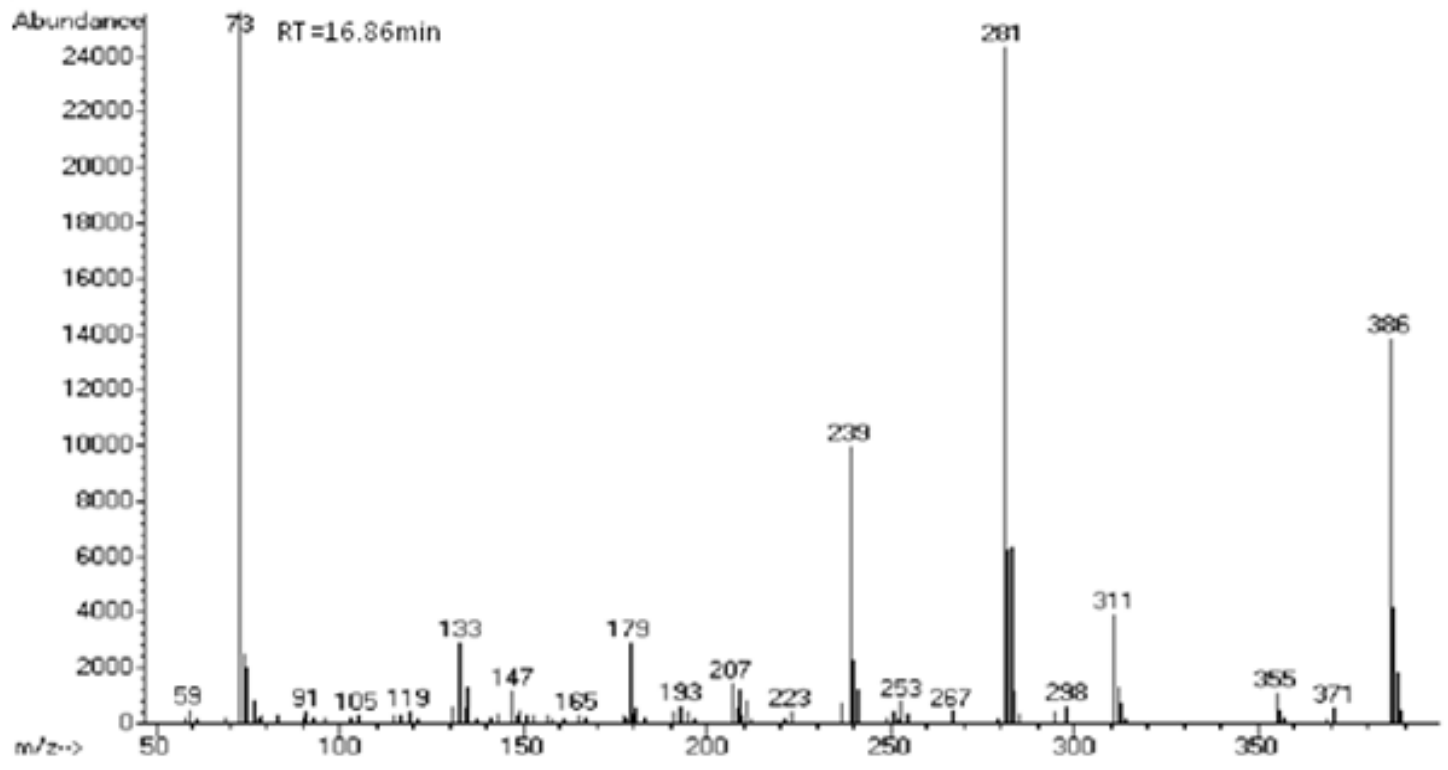

Figure 1-9. MS spectrum of peak 16.86 min in Figure 1-7 (MS spectrum of incomplete derivatized GA)

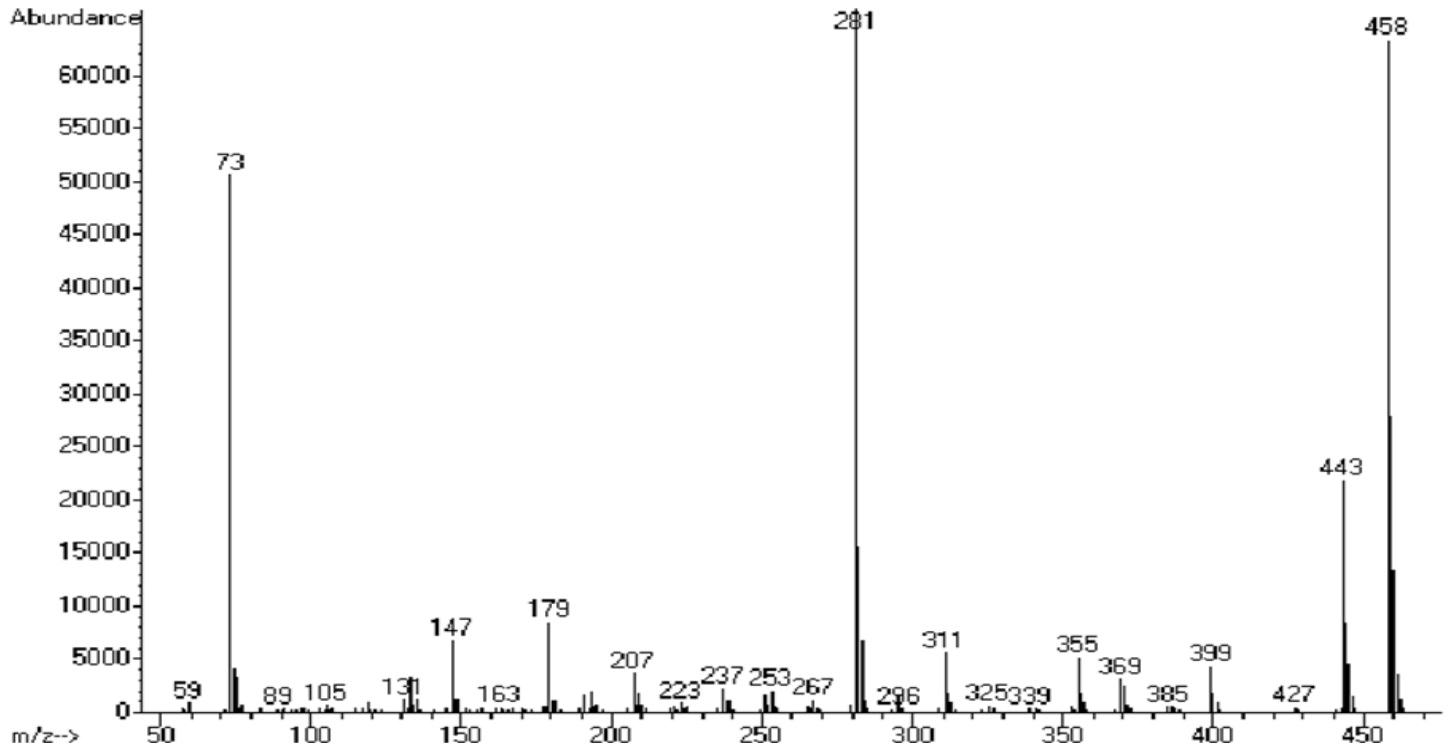

Figure 1-10. MS spectrum of peak 16.97 min in Figure 1-7 (MS spectrum of complete derivatized GA) 
The 'BSTFA Product Specification' from Supelco suggested that if derivatization is not complete a higher reagent concentration and/or longer time should be evaluated. In order to reduce the incomplete derivatization, the experiment was first repeated by increasing the amount of derivatization reagent to $300 \mu 1$. A paired t-test of incomplete and complete derivatized gallic acid peak area ratio was performed to determine if the derivatization agent amount change would affect the derivatization efficiency. The pvalue $=0.26>0.05$, providing evidence that no significant difference is caused due to the change of derivatization reagent. Therefore, a longer reaction time (120 min) was applied for a final reaction method of $200 \mu \mathrm{l}$ of BSFTA and pyridine $(\mathrm{v}: \mathrm{v}=10: 3)$ at $70^{\circ} \mathrm{C}$ for 120 min. Significant improvement of derivatization was achieved and all the gallic acid was fully derivatized (Figure 1-11).

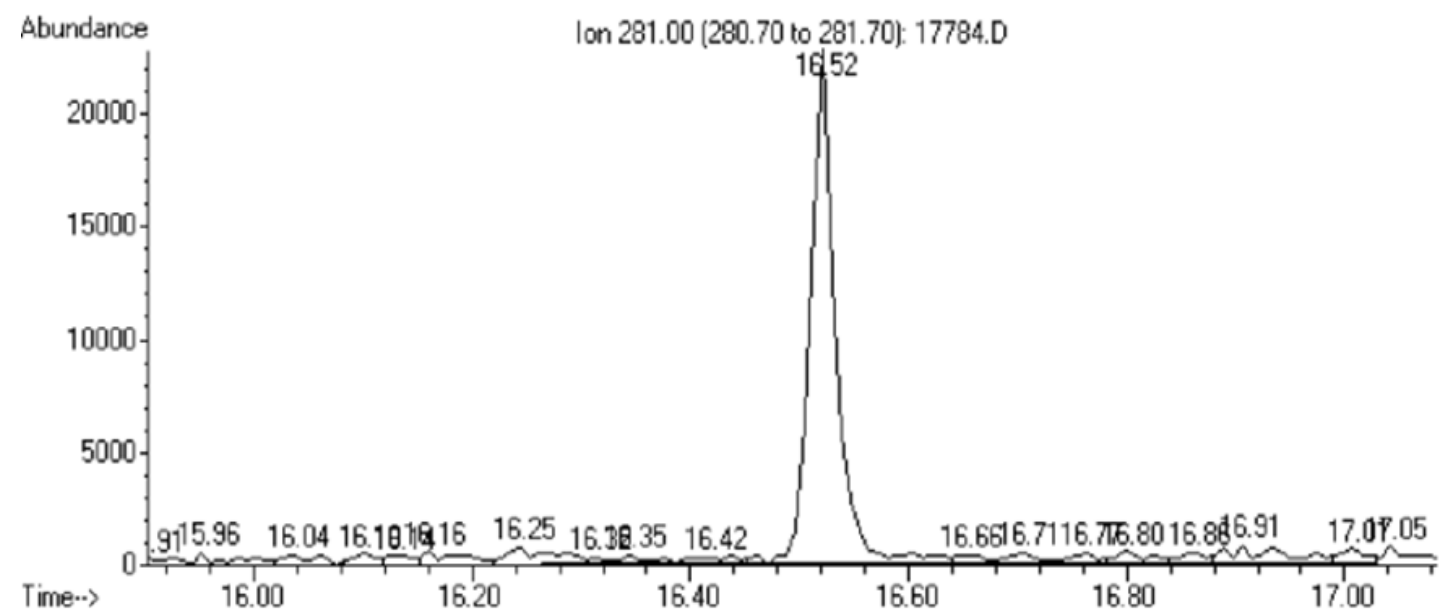

Figure 1-11. Total ion chromatogram spectrum of gallic acid using fragment ion $\mathrm{m} / \mathrm{z}=281$ 
Table 1-1. Peak area of complete and incomplete derivatized gallic acid TIC

\begin{tabular}{ccccccc}
\hline & & & & & \multicolumn{2}{c}{ Peak imcomplete / Peak } \\
Gallic acid & Compelete derivatized & Incomplete derivatized & \multicolumn{2}{c}{ complete } \\
concentration & $200 \mu 1$ & $300 \mu 1$ & $200 \mu 1$ & $300 \mu 1$ & $200 \mu 1$ & $300 \mu 1$ \\
$(\mathrm{ppm})$ & BSTFA & BSTFA & BSTFA & BSTFA & BSTFA & BSTFA \\
\hline 10 & $9.71 \mathrm{E}+05$ & $1.34 \mathrm{E}+06$ & $1.48 \mathrm{E}+05$ & $7.17 \mathrm{E}+05$ & $1.52 \mathrm{E}-01$ & $5.37 \mathrm{E}-01$ \\
20 & $5.16 \mathrm{E}+06$ & $1.49 \mathrm{E}+07$ & $1.64 \mathrm{E}+06$ & $3.72 \mathrm{E}+06$ & $3.18 \mathrm{E}-01$ & $2.50 \mathrm{E}-01$ \\
40 & $5.72 \mathrm{E}+07$ & $1.32 \mathrm{E}+08$ & $3.71 \mathrm{E}+06$ & $6.57 \mathrm{E}+06$ & $6.49 \mathrm{E}-02$ & $4.96 \mathrm{E}-02$ \\
60 & $3.75 \mathrm{E}+08$ & $3.78 \mathrm{E}+08$ & $2.26 \mathrm{E}+06$ & $4.64 \mathrm{E}+06$ & $6.05 \mathrm{E}-03$ & $1.23 \mathrm{E}-02$ \\
\hline
\end{tabular}


Quantification of gallic acid standard using internal standard

Although the gallic acid standard was successfully derivatized and detected by GC/MS, the precision of this method decreased as gallic acid concentration increased (Figure 1-12). To improve the precision and accuracy of the results, the internal standard was spiked into the sample before derivatization. One ml DMBA stock solution was diluted to $25 \mathrm{ml}$ and was stored in a glass vial in the freezer. A set of gallic acid standards were prepared again with $100 \mu 1 \mathrm{DMBA}$ solution spiked in them. The TIC of gallic acid and DMBA is showed in Figure 1-13. On the basis of the fragmentation information from MS, the 16.25min peak in Figure 1-13 represents DMBA (Figure 1-14) and the $16.52 \mathrm{~min}$ peak in Figure 1-13 represents gallic acid (Figure 1-15).

A new calibration curve was formed using the internal standard (Figure 1-16). $50 \mu \mathrm{l}, 100 \mu \mathrm{l}, 200 \mu \mathrm{l}$ and $400 \mu \mathrm{l}$ GA solution was spiked with $100 \mu \mathrm{l}$ DMBA solution in a $4 \mathrm{ml}$ screw cap vial followed by $\mathrm{N}_{2}$ dry and then silyl derivatized by BSTFA. The new calibration curve with internal standard (DMBA) showed $\mathrm{R}^{2}=0.981$ and a significant increase of sample reproducibility compared to the calibration curve with internal standard $\left(\mathrm{R}^{2}=0.954\right)$. 


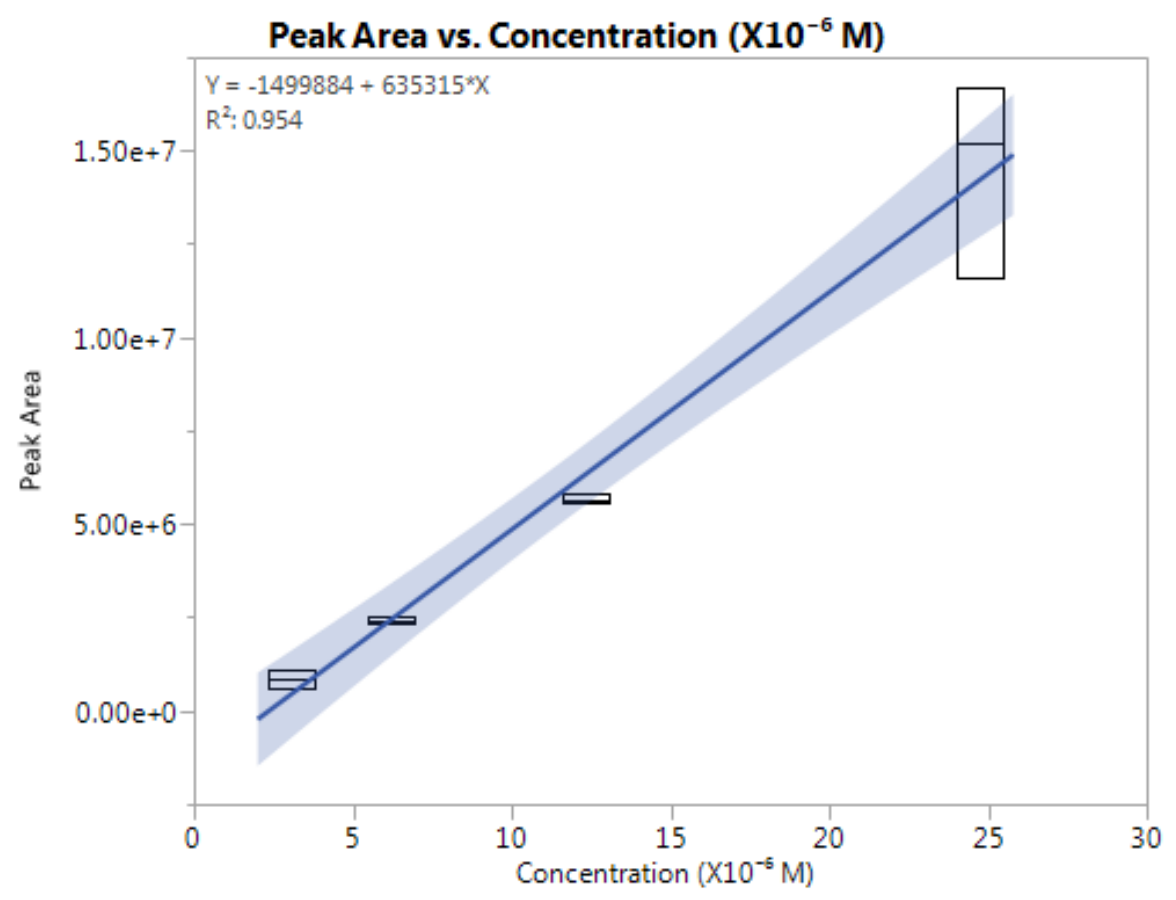

Figure 1-12. The calibration curve of gallic acid using external standard. The blue line is a linear prediction and the blue shade is its $95 \%$ confidence zone.

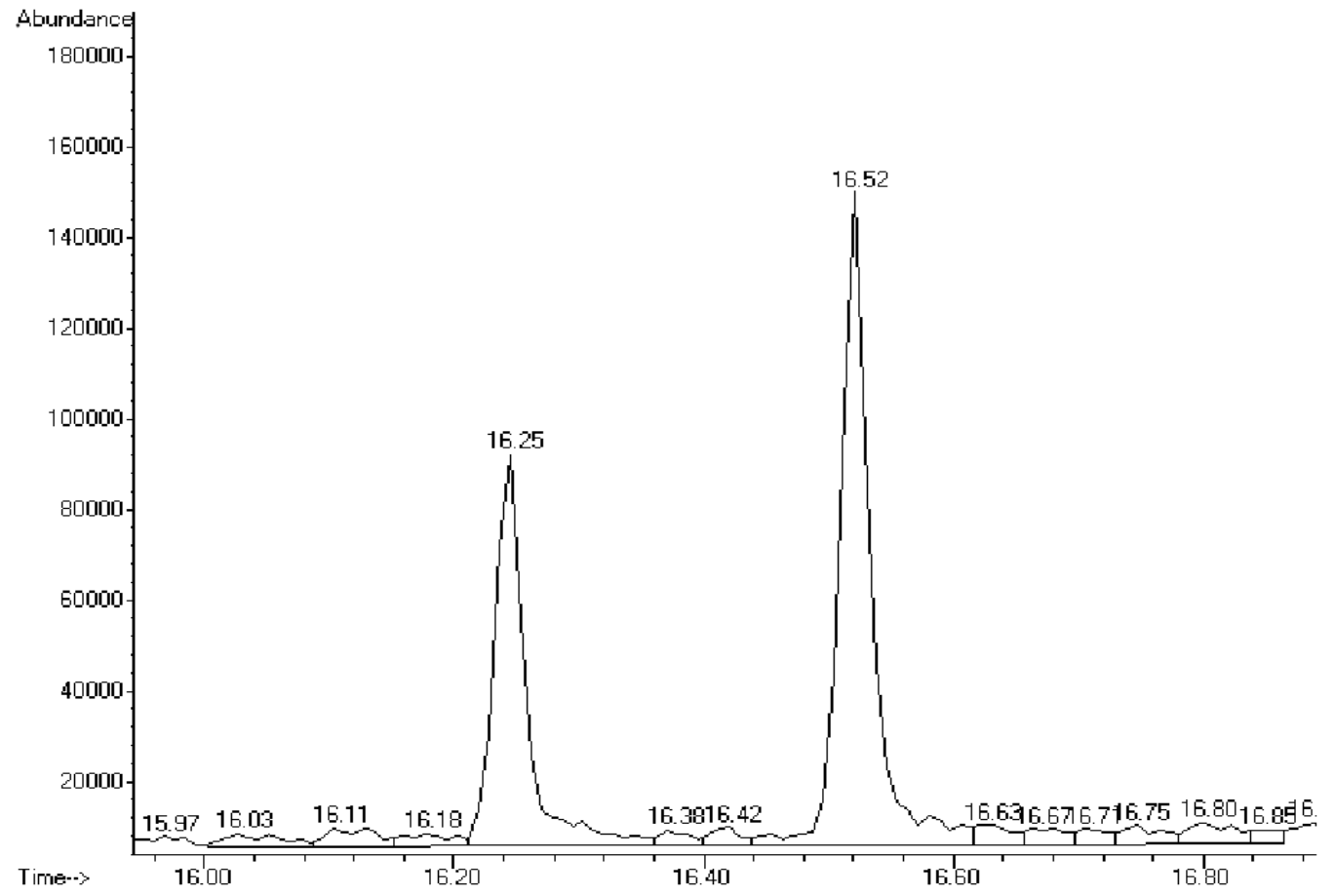

Figure 1-13. Total ion chromatogram spectrum of DMBA and gallic acid 


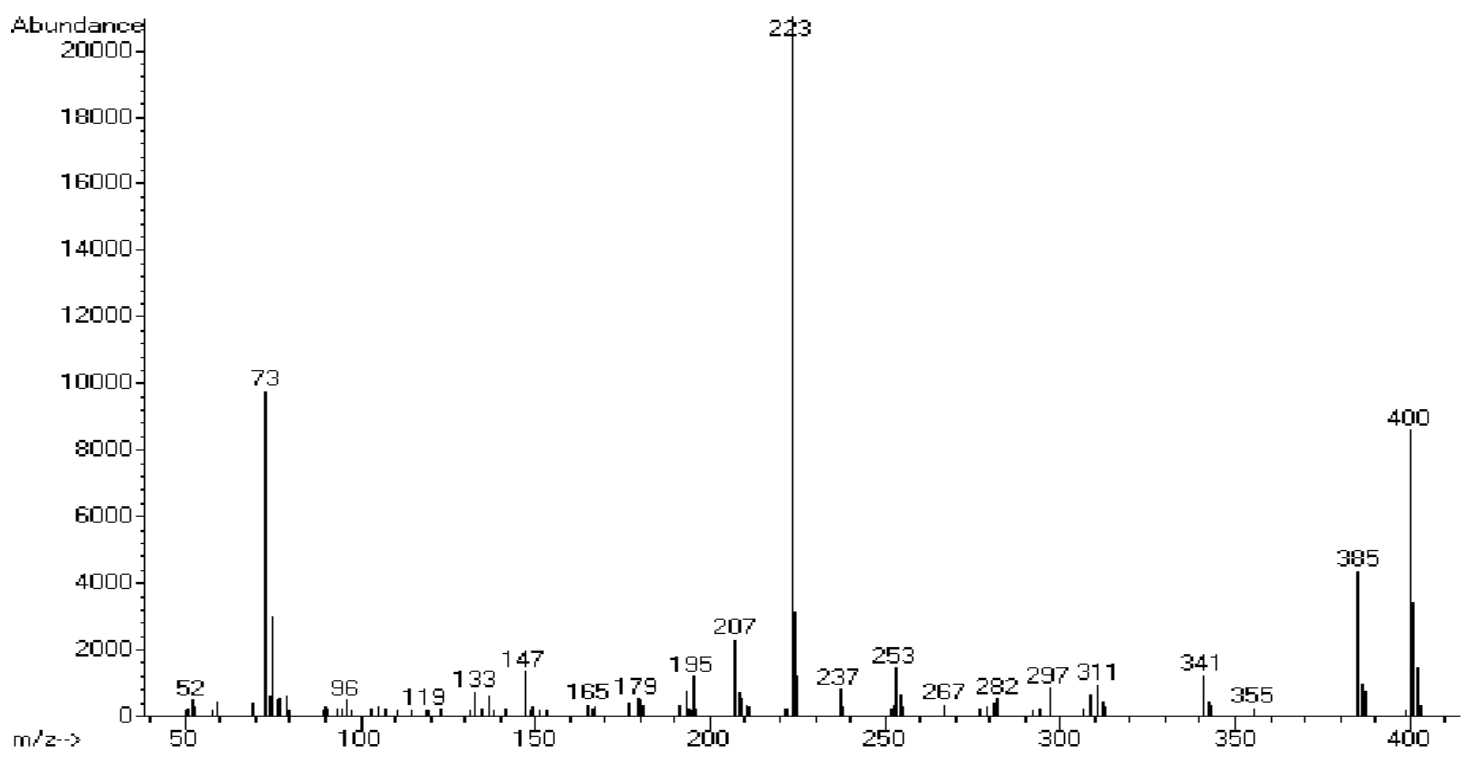

Figure 1-14. MS spectrum of the peak at 16.25 min in Figure 1-13 (MS spectrum of DMBA)

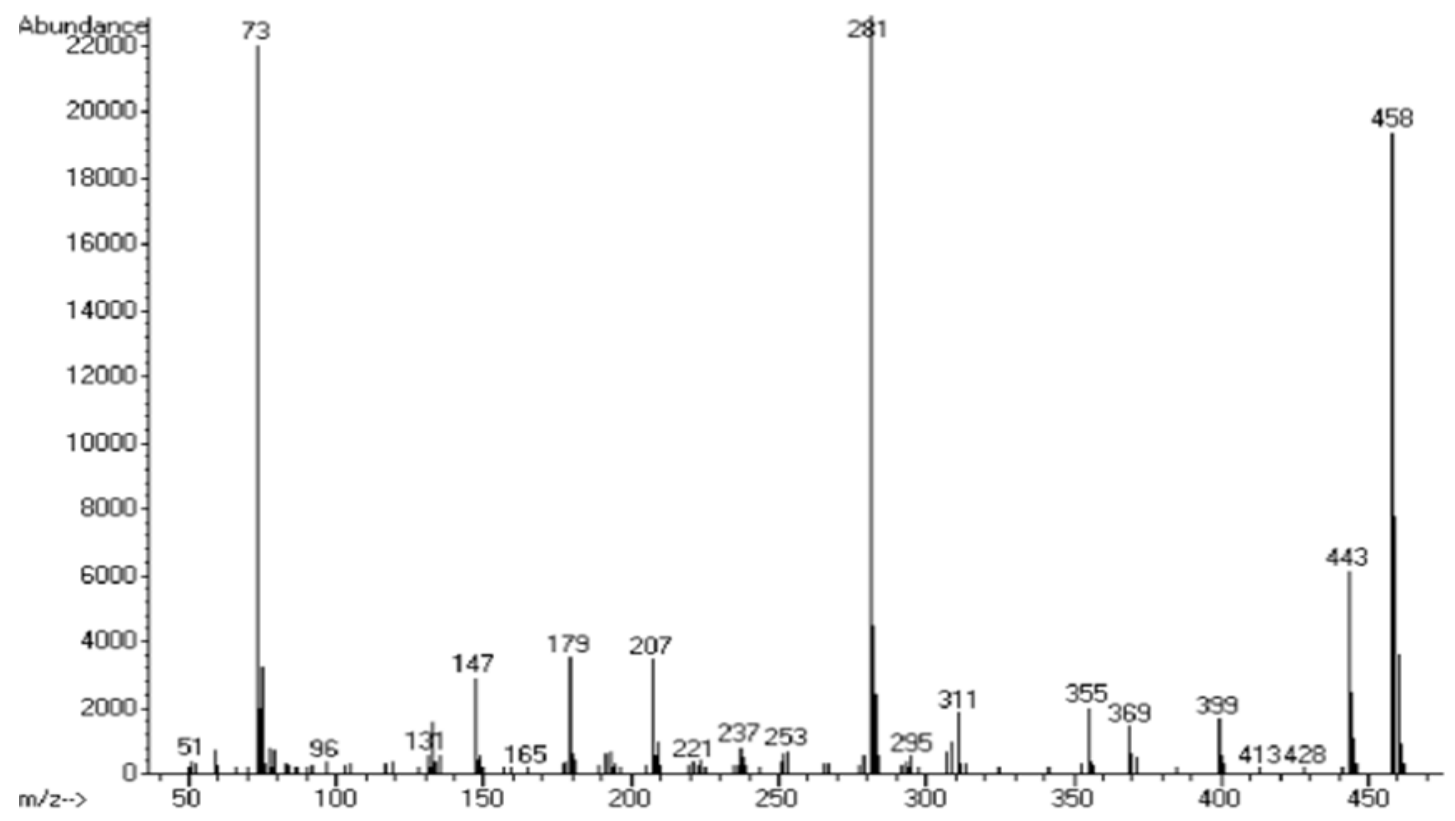

Figure 1-15. MS spectrum of the peak at $16.52 \mathrm{~min}$ in Figure 1-13 (MS spectrum of GA) 


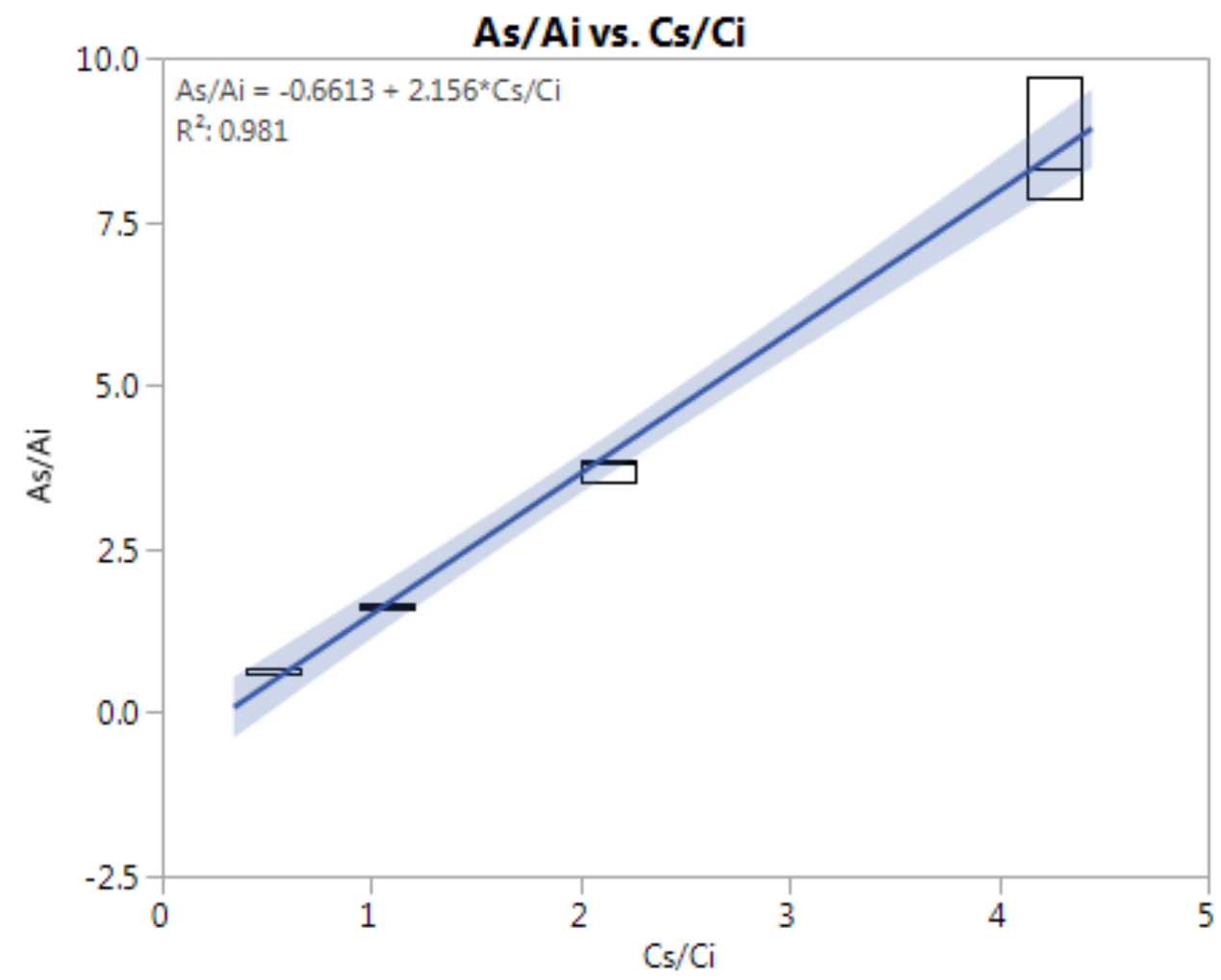

Figure 1-16. The calibration curve of gallic acid using internal standard. $A_{s}$ and $A_{i}$ stand for peak area of gallic acid and DMBA respectively. $C_{s}$ and $C_{i}$ stand for concentrations of gallic acid and DMBA respectively. The blue line is a linear prediction and the blue shade is its $95 \%$ confidence zone. 


\section{Sample loss quantification}

Sample loss during hydrolysis was back calculated using the gallic acid standard. Briefly, $200 \mu$ l gallic acid solution was placed in a $15 \mathrm{ml}$ screw cap hydrolysis tube, blown dry with $\mathrm{N}_{2}$ and then hydrolyzed by $3 \% \mathrm{HCl}$ in the oven for 4 hours. The solution was transferred to a separatory funnel and was extracted using an EtOH and EtAc solution $(\mathrm{v}: \mathrm{v}=5: 95)$. The extract passed through sodium sulfate to eliminate water and was collected in a round bottom flask for concentration via rotary evaporation. The sample was then transferred to a $4 \mathrm{ml}$ screw cap vial and spiked with $200 \mu \mathrm{l}$ of the DMBA standard solution. After being dried with $\mathrm{N}_{2}, 200 \mu 1$ BSTFA solution was added to the vials which were then sealed and derivatized. The average percent recovery of gallic acid after hydrolysis was $78 \%$, which indicated a $22 \%$ sample loss during the hydrolysis process.

Tannic acid (hydrolyzable tannin) standard

After quantifing the sample loss of the hydrolysis step, a hydrolyzable tannin standard, tannic acid was used to evaluate the recovery rate, assuming that tannic acid is a representative proxy for NOM polyphenols. One mole of tannic acid can be hydrolyzed to ten moles of gallic acid. One $\mathrm{ml}$ tannic acid stock solution was diluted to $25 \mathrm{ml}$ and $200 \mu \mathrm{L}$ aliquot was treated using the same protocol as the sample loss quantification experiment. Tannic acid showed an average present recovery of 57\%. 
Floc sample (Environmental sample)

Fluorescence quantum yield and DOC

Fluorescence quantum yield is usually calculated as absolute fluorescence quantum yield or relative fluorescence quantum yield (Würth et al., 2013). In the present research, the relative fluorescence quantum yield of gallic acid is calculated using tyrosine as a reference standard. The tyrosine quantum yield $\phi_{\mathrm{Tyr}}=0.14\left(\lambda_{\mathrm{ex}}=276 \mathrm{~nm}\right)$ (Chen, 1967). The gallic acid quantum yield is 0.033 and was calculated as follows:

Equation 1-5.

$$
\Phi_{G A}=\frac{\int_{0}^{\infty} I_{G A}\left(\lambda_{e x}\right) d \lambda_{e m}}{A_{G A}\left(\lambda_{e x}\right)} \times \frac{A_{T y r}\left(\lambda_{e x=276 n m}\right)}{\int_{0}^{\infty} I_{T y r}\left(\lambda_{e x=276 n m}\right) d \lambda_{e m}} \times \phi_{T y r}
$$

The DOC concentration of the floc extract is $68.02 \pm 6.73 \mathrm{ppm}$. The DOC concentration of the floc extract after SPE is $37.98 \pm 12.11 \mathrm{ppm}$. Therefore, DOC recovery rate of the PPL could be calculated by using the difference between DOC concentration of floc extract and DOC concentration of floc extract after SPE over the original DOC concentration and the average recovery rate is $44.17 \%$. Compared with the reported PPL DOC recovery rate (Dittmar et al., 2008), the DOC recovery rate in the present study is lower than average. A possible explanation is that PPL is not very efficient while retaining the type of DOC from site SRS6. 


\section{GC/MS}

After the gallic acid and tannic acid standards were successfully quantified by GC/MS, the next step was to quantify gallic acid in an environmental floc sample. Base extract is a common method for particulate organic matter (POM) extraction (Kuwatsuka et al., 1992; Santin et al., 2009; Osburn et al., 2012). Therefore, 0.1 M NaOH solution was used to extract organic matter from sedimentary organic matter pools.

Briefly, $2.583 \mathrm{~g}$ floc were weighted and placed in a $500 \mathrm{~mL}$ polycarbonate bottle with $500 \mathrm{~mL}$ 0.1 M NaOH solution. The extract was filtered through GF/F filters and neutralized to $\mathrm{pH}=7$ with concentrated hydrochloric acid $(\mathrm{HCl})$. A small portion was saved for DOC measurements and the rest was acidified to $\mathrm{pH}=2$ for SPE. After SPE, the samples were treated the same way as tannic acid standard. Surprisingly, no gallic acid signal was detected. Possible explanations were that gallic acid was absent in the floc sample or the gallic acid was lost during sample preparation. Therefore, the experiment was repeated using $750.2 \mathrm{mg}$ gallic acid standard to check the recovery. However, the gallic acid peak was still not detected. A color change of gallic acid solution was observed in the process of dissolving gallic acid in the alkali solution, which indicated a possible chemical reaction. The literature reports sugguest that gallic acid is not stable at a high $\mathrm{pH}$ condition $(0.1 \mathrm{M} \mathrm{NaOH}$ has $\mathrm{pH}=13)$ (Friedman and Hella, 1993). Therefore, in place of a base extraction, the gallic acid standard and the floc samples were re-extracted in Milli-Q water. 

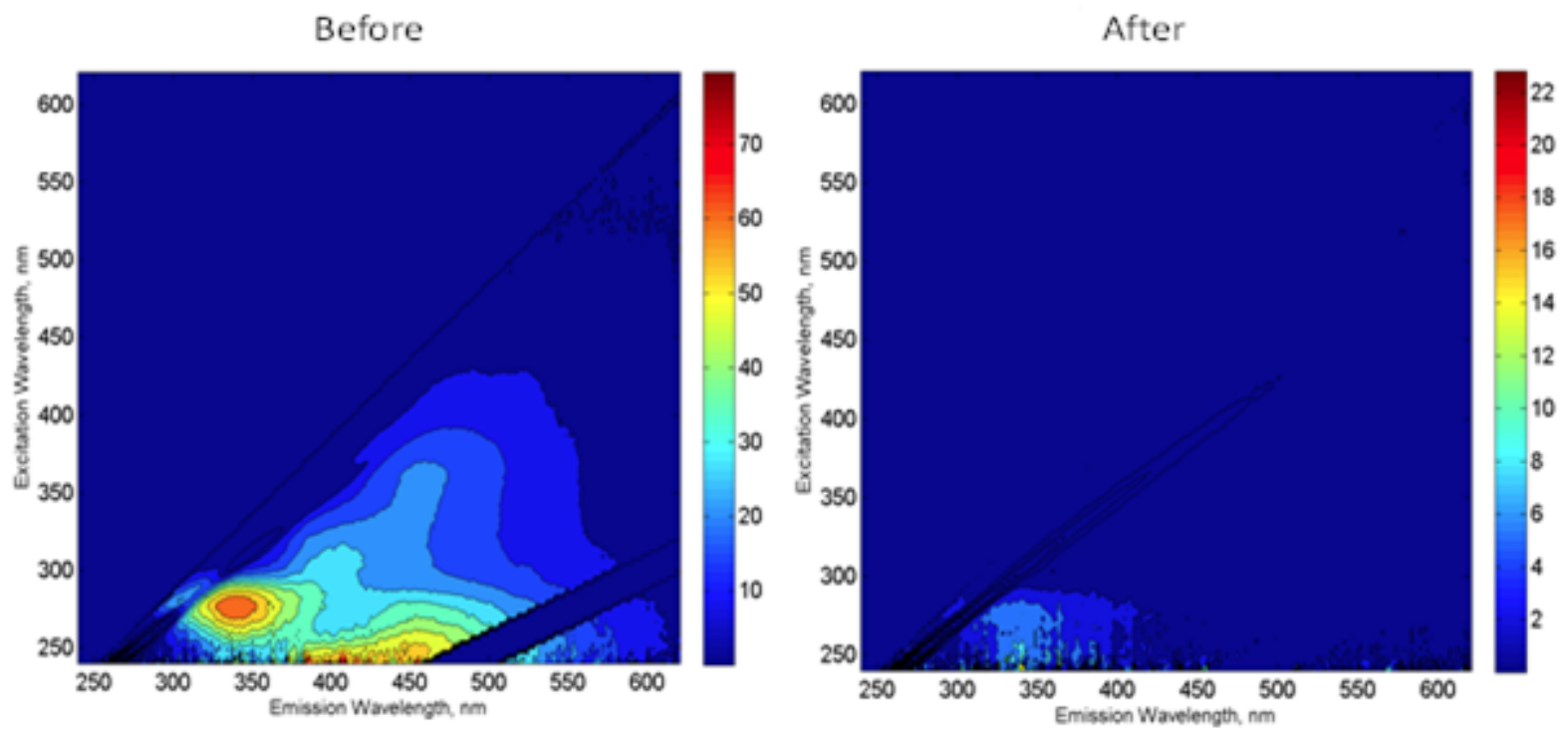

Figure 1-17. Fluorescence EEMs of floc extract before (left) and after (right) Varian Bond Elut PPL cartridges
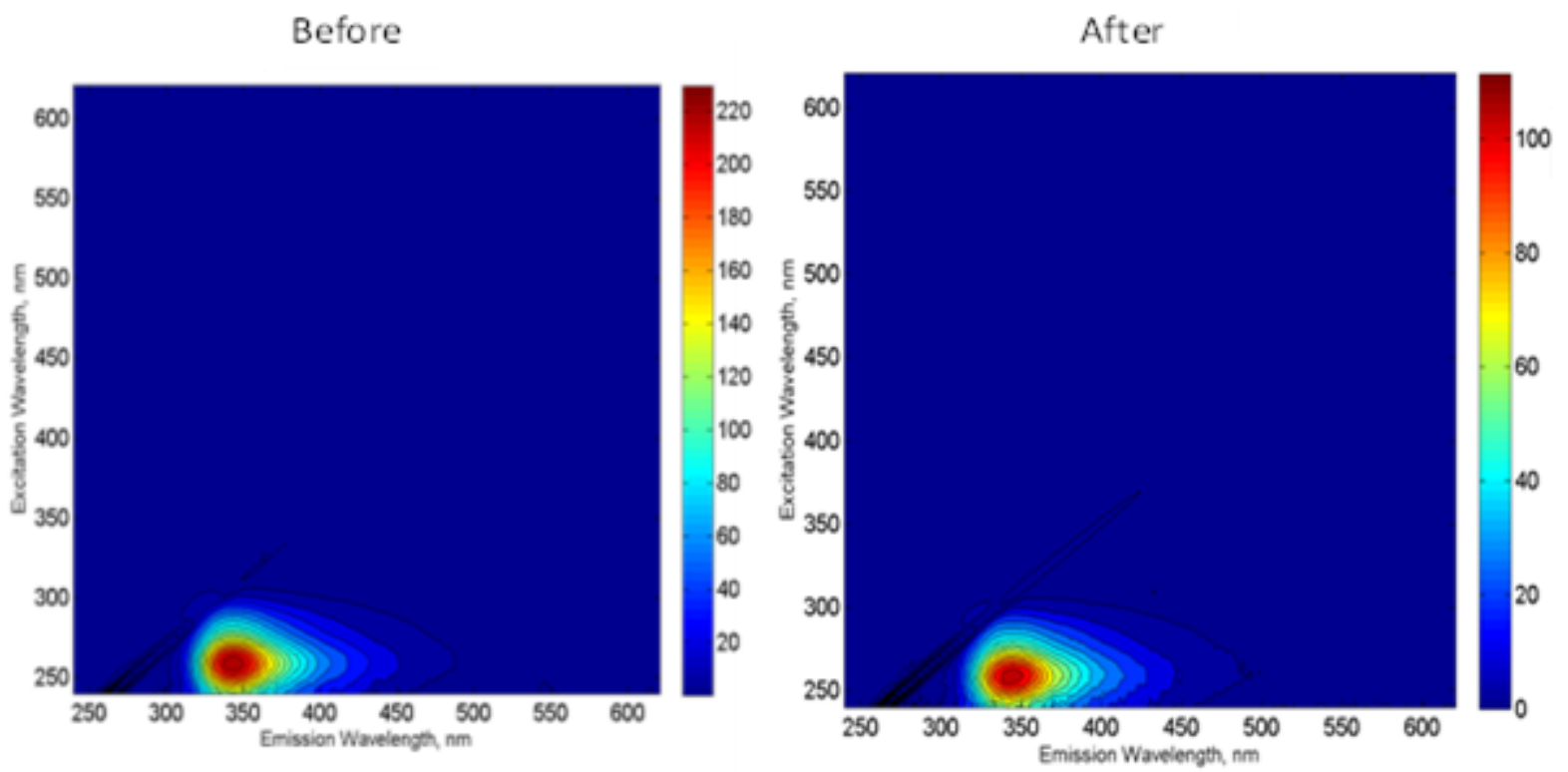

Figure 1-18. Fluorescence EEMs of gallic acid before (left) and after (right) Varian Bond Elut PPL cartridges 
Gallic acid was detected in the water extracted gallic acid standard (one of the triplicate samples) using this method, but the recovery rate of the gallic acid standard was only $0.74 \%$. The gallic acid peak was not detected in floc samples. The fluorescence of the floc extract and gallic acid before and after SPE were measured on the Aqualog to investigate what portion of DOM was not retained by the Varian Bond Elut PPL cartridges respectively. The fluorescence EEMs are presented in Figure 1-17 and Figure 1-18. By comparing the 3D fluorescence EEMs of the floc extract and gallic acid before and after SPE, the DOC with 'protein-like' fluorescence was left out by PPL which indicated that the PPL cartridge does not appear to be efficient at retaining 'protein-like' fluorescence compounds.

Therefore, freeze-drying of floc water extract was used for maximum retention of DOM.A 2.5794g floc sample was extracted with 500mL Milli-Q water and then filtered through combusted GF/F filters. All filtered extracts were transferred to a $500 \mathrm{~mL}$ glass vial and freeze-dried at $-50^{\circ} \mathrm{C}$. Solid brown powder $(0.386 \mathrm{~g})$ was collected from the vial after freeze-drying. Freeze-dried floc extract was preserved in a glass amber vial at $-18^{\circ} \mathrm{C}$ freezer prior to analysis. However, the gallic acid signal was not detected in the freezedried samples.

On the basis of these environmental experiment results, gallic acid is difficult to detect in water samples. Therefore, in order to eliminate the uncertainty that happened in the extraction process, direct hydrolysis was also attempted on the floc sample. Briefly, $0.007 \mathrm{~g}$ floc sample was placed with $3 \% \mathrm{HCl}$ in the hydrolysis tube and reacted at $110{ }^{\circ} \mathrm{C}$ for 4 hours and then processed through liquid-liquid extraction using EtOH + EtAc 
solution followed by rotary evaporation and derivatization. Gallic acid was detected in the floc sample (Figure 1-19 and 1-20). However, the detected gallic acid recovery was low and highly variable $(0.15 \%-0.19 \%)$ in the repeated trials.

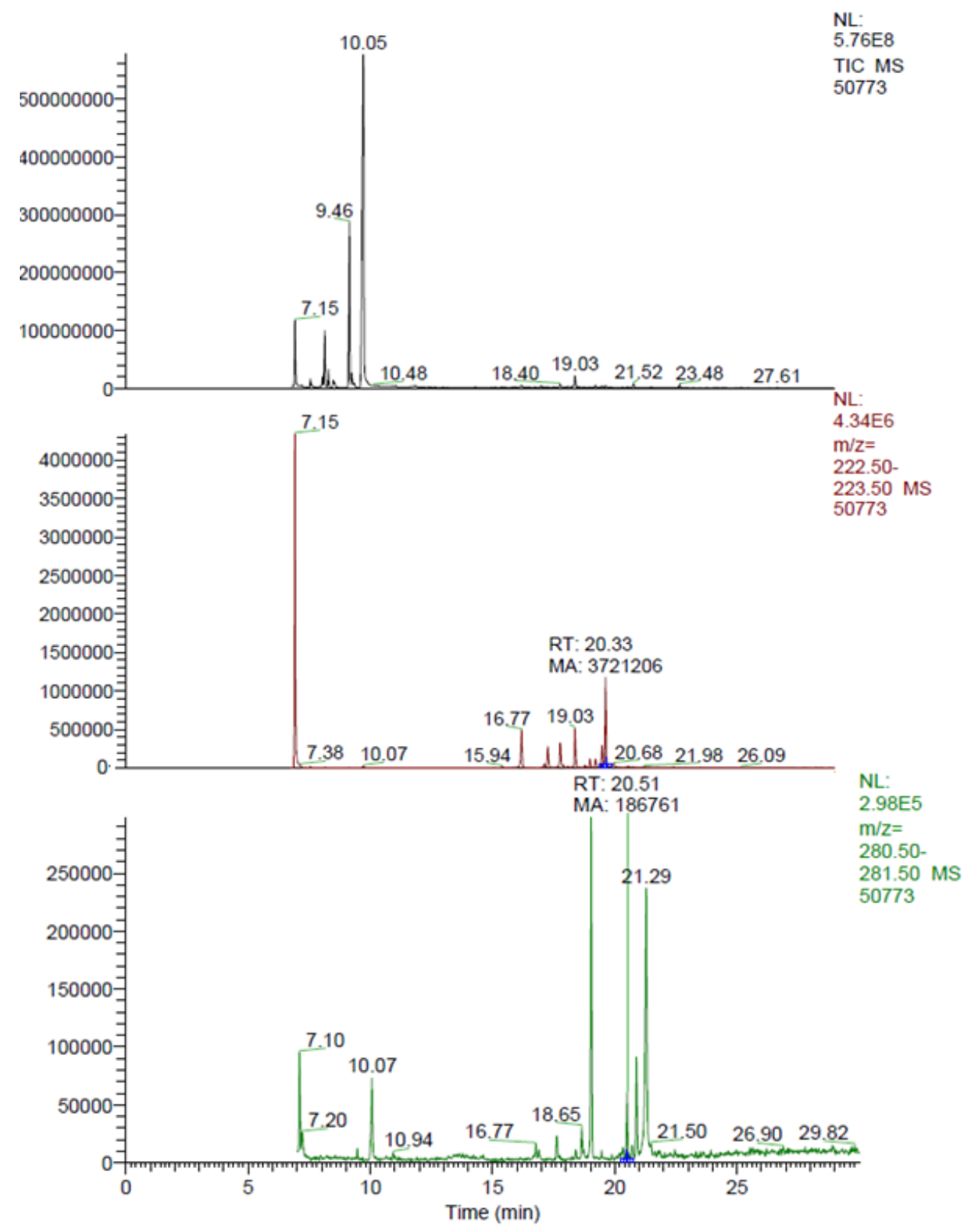

Figure 1-19. GC/MS of hydrolyzed floc sample (TIC) 

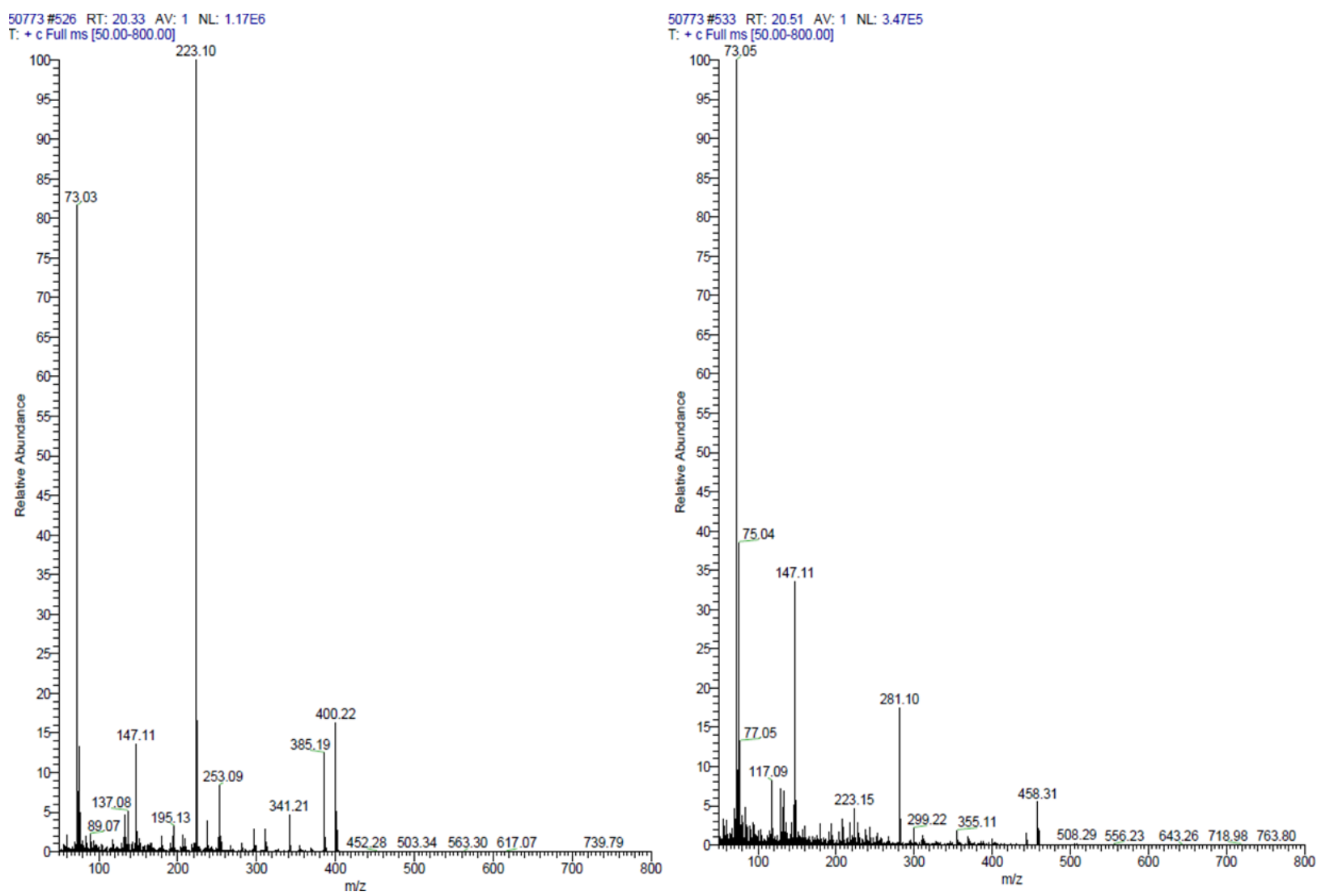

Figure 1-20. GC/MS of hydrolyzed floc sample (MS) 


\section{Conclusion}

In this study, GC/MS was used to quantify gallic acid in an attempt to quantify the polyphenol contribution to 'protein-like' fluorescence. The method is sensitive for measuring the gallic acid standard directly and the one-step derivatization is convenient and efficient. Hydrolysis followed by liquid-liquid extraction has an average percent recovery of $78 \%$. However, when applied to environmental samples, some difficulties were encountered.

Overall, several possibilities could lead to the absence of gallic acid in the field sample. Solid phase extraction (SPE) through Varian Bond Elut PPL cartridges was less efficient for extracting 'protein-like' fluorescence compounds than other DOM. The alternative concentration method, freeze-drying, is time consuming and actually took about a week per sample in the present study. Tannins are photo-reactive in water and can change significantly in chemical structure over a short period of time (Maie et al., 2008). Small polyphenols from mangrove-derived DOM have a half-life of less than one day (Scully et al., 2004). In the present experiment, amber glassware was used to minimize photoreaction and samples were stored in a freezer for better preservation. However, the sample preparation for environmental water samples is time consuming and shade limited. Therefore, tannins may degrade before detection can occur. For future research, other analytical methods, such as LC/MS that has been applied for several polyphenols analysis, could be an alternative option. The LC/MS could simplify the sample pre-treatment process, therefore shorten the storage time, and minimize the sample degradation (Kiehne et al., 1996; Weingerl et al., 2009). 
Another possible explanation is that gallic acid is a limited proxy and GC/MS is a conditional method for tannins quantification. At SRS6, a mean annual litterfall rate of $3.12 \pm 0.26 \mathrm{~g} \mathrm{~m}^{2} \mathrm{~d}^{-1}$ were estimatedusing monthly collections of litter fall material in litter baskets ( Jaffe et al., 2007). The average monthly Rhizophora mangle leaves litterfall collected in SRS6 is 4.5g in average (Data set available atLTER website). The gallic acid could only be produced by hydrolyzable tannin which is less abundant than condensed tannin in plants (Hernes et al., 2001). In addition, hydrolyzable tannin other than tannic acid might produce less counts of gallic acid after hydrolysis. Many questions remain with regards to the potential contribution of polyphenols like gallic acid to "protein-like" fluorescence in NOM. Unfortunately, as a result of analytical difficulties combined with the high reactivity of tannins, the present study was inconclusive. Further research efforts are needed to advance the field.

\section{References}

Aiken, George R., Cynthia C. Gilmour, David P. Krabbenhoft, and William Orem. 'Dissolved Organic Matter in the Florida Everglades: Implications for Ecosystem Restoration.' Critical Reviews in Environmental Science and Technology 41, no. sup1 (February 17, 2011): 217-48.

Benner, Ronald, Patrick G. Hatcher, and John I. Hedges. 'Early Diagenesis of Mangrove Leaves in a Tropical Estuary: Bulk Chemical Characterization Using Solid-State 13C NMR and Elemental Analyses.' Geochimica et Cosmochimica Acta 54, no. 7 (July 1, 1990): 2003-13.

Benner, Ronald, Bopaiah Biddanda, Brenda Black, and Matthew McCarthy. 'Abundance, Size Distribution, and Stable Carbon and Nitrogen Isotopic Compositions of Marine Organic Matter Isolated by Tangential-Flow Ultrafiltration.' Marine Chemistry 57, no. 34 (July 1997): 243-63.

Benoit, J. M., R. P. Mason, C. C. Gilmour, and G. R. Aiken. 'Constants for Mercury Binding by Dissolved Organic Matter Isolates from the Florida Everglades.' Geochimica Et Cosmochimica Acta 65, no. 24 (December 2001): 4445-51. 
Birks, JB; Photophysics of Aromatic Molecules. Wiley-Interscience (1970)

Brand-Williams, W_, M. E. Cuvelier, and C. L. W. T. Berset. 'Use of a free radical method to evaluate antioxidant activity.' LWT-Food Science and Technology 28.1 (1995): $25-30$.

Bray, George A. 'A simple efficient liquid scintillator for counting aqueous solutions in a liquid scintillation counter.' Analytical biochemistry 1.4 (1960): 279-285.

Brouillard, R., O. Dangles, and J. B. Harborne. 'The flavonoids: advances in research since 1986.' by Harborne JB, Chapman \& Hall, London (1994): 565-588.

Brym, Adeline, et al. 'Optical and chemical characterization of base-extracted particulate organic matter in coastal marine environments.' Marine Chemistry 162 (2014): 96-113.

Chen, Meilian, et al. 'Spatial and temporal variability of dissolved organic matter quantity and composition in an oligotrophic subtropical coastal wetland.'

Biogeochemistry 115.1-3 (2013): 167-183.

Chen, Meilian, and Rudolf Jaffé. 'Photo- and Bio-Reactivity Patterns of Dissolved Organic Matter from Biomass and Soil Leachates and Surface Waters in a Subtropical Wetland.' Water Research 61 (September 15, 2014): 181-90.

Chen, Raymond F. 'Fluorescence Quantum Yields of Tryptophan and Tyrosine.' Analytical Letters 1, no. 1 (January 1, 1967): 35-42.

Chen, Ronghua, and Robert R. Twilley. 'Patterns of Mangrove Forest Structure and Soil Nutrient Dynamics along the Shark River Estuary, Florida.' Estuaries 22, no. 4 (December 1999): 955-70.

Childers, Daniel L., Joseph N. Boyer, Stephen E. Davis, Christopher J. Madden, David T. Rudnick, and Fred H. Sklar. 'Relating Precipitation and Water Management to Nutrient Concentrations in the Oligotrophic 'upside-Down' Estuaries of the Florida Everglades.' Limnology and Oceanography 51, no. 1part2 (January 1, 2006): 602-16.

Coble, P. G., S. A. Green, N. V. Blough, and R. B. Gagosian. 'Characterization of Dissolved Organic Matter in the Black Sea by Fluorescence Spectroscopy.' Nature 348, no. 6300 (1990): 432-35.

Coble, Paula G. 'Characterization of Marine and Terrestrial DOM in Seawater Using Excitation-Emission Matrix Spectroscopy.' Marine Chemistry 51, no. 4 (January 1996): $325-46$.

Cooper, William J., Rod G. Zika, Robert G. Petasne, and Anne M. Fischer. 'Sunlightinduced photochemistry of humic substances in natural waters: major reactive species.' 
Aquatic Humic Substances: Influence on Fate and Treatment of Pollutants. American Chemical Society, Washington DC. (1989): 333-362

Davis, Steve, and John C. Ogden. Everglades: The Ecosystem and Its Restoration. CRC Press, 1994.

Davis, Steven M., Daniel L. Childers, Jerome J. Lorenz, Harold R. Wanless, and Todd E. Hopkins. 'A Conceptual Model of Ecological Interactions in the Mangrove Estuaries of the Florida Everglades.' Wetlands 25, no. 4 (December 2005): 832-42.

Dittmar, Thorsten, Boris Koch, Norbert Hertkorn, and Gerhard Kattner. 'A Simple and Efficient Method for the Solid-Phase Extraction of Dissolved Organic Matter (SPE-DOM) from Seawater.' Limnology and Oceanography: Methods 6, no. 6 (June 1, 2008): 230-35.

Fellman, Jason B., Eran Hood, David V. D'Amore, Richard T. Edwards, and Dan White. 'Seasonal Changes in the Chemical Quality and Biodegradability of Dissolved Organic Matter Exported from Soils to Streams in Coastal Temperate Rainforest Watersheds.' Biogeochemistry 95, no. 2-3 (June 20, 2009): 277-93.

Fellman, Jason B., Kevin C. Petrone, and Pauline F. Grierson. 'Source, Biogeochemical Cycling, and Fluorescence Characteristics of Dissolved Organic Matter in an Agro-Urban Estuary.' Limnology and Oceanography 56, no. 1 (January 1, 2011): 243-56.

Fourqurean, James W., Ronald D. Jones, and Joseph C. Zieman. 'Process Influencing Water Column Nutrient Characteristics and Phosphorus Limitation of Phytoplankton Biomass in Florida Bay, FL, USA:Inferences from Spatial Distributions.' Estuarine, Coastal and Shelf Science 36, no. 3 (March 1993): 295-314.

Friedman, Mendel, and Hella S. Jürgens. 'Effect of $\mathrm{pH}$ on the Stability of Plant Phenolic Compounds.' Journal of Agricultural and Food Chemistry 48, no. 6 (June 1, 2000): 2101-10.

Gélinas, Yves, Jeff A. Baldock, and John I. Hedges. 'Demineralization of Marine and Freshwater Sediments for CP/MAS 13C NMR Analysis.' Organic Geochemistry 32, no. 5 (May 2001): 677-93.

Godshalk, Gordon L., and Robert G. Wetzel. 'Decomposition of Aquatic Angiosperms. I. Dissolved Components.’ Aquatic Botany 5 (January 1, 1978): 281-300.

Golay, Marcel JE, and D. H. Desty. 'Gas chromatography.' Academic, New York (1958): 36.

Gosselink, J. G., and R. E. Turner. 'role of hydrology in freshwater wetland ecosystems.' Freshwater wetlands (1978). 
Gross, Georg G., Richard W. Hemingway, and Takashi Yoshida, eds. Plant polyphenols 2: chemistry, biology, pharmacology, ecology. Vol. 66. Springer Science \& Business Media, (2012): 883-884

Halliwell, Barry. 'How to Characterize a Biological Antioxidant.' Free Radical Research Communications 9, no. 1 (January 1, 1990): 1-32.

Helms, John R., Aron Stubbins, Jason D. Ritchie, Elizabeth C. Minor, David J. Kieber, and Kenneth Mopper. 'Absorption Spectral Slopes and Slope Ratios as Indicators of Molecular Weight, Source, and Photobleaching of Chromophoric Dissolved Organic Matter.' Limnology and Oceanography 53, no. 3 (May 1, 2008): 955-69.

Hernes, Peter J, Ronald Benner, Gregory L Cowie, Miguel A Goñi, Brian A Bergamaschi, and John I Hedges. 'Tannin Diagenesis in Mangrove Leaves from a Tropical Estuary: A Novel Molecular Approach.' Geochimica et Cosmochimica Acta 65, no. 18 (September 15, 2001): 3109-22.

Hertkorn, N., M. Harir, K. M. Cawley, P. Schmitt-Kopplin, and R. Jaffé. 'Molecular Characterization of Dissolved Organic Matter from Subtropical Wetlands: A Comparative Study through the Analysis of Optical Properties, NMR and FTICR/MS.' Biogeosciences Discussions 12 (August 1, 2015): 13711-65.

Hood, Eran, Jason Fellman, Robert G. M. Spencer, Peter J. Hernes, Rick Edwards, David D'Amore, and Durelle Scott. 'Glaciers as a Source of Ancient and Labile Organic Matter to the Marine Environment.' Nature 462, no. 7276 (December 24, 2009): 1044-47.

Huang, Dejian, Boxin Ou, and Ronald L. Prior. 'The Chemistry behind Radical scavenging ability Assays.' Journal of Agricultural and Food Chemistry 53, no. 6 (March 1, 2005): 1841-56.

Inthorn, Maik, Thomas Wagner, Georg Scheeder, and Matthias Zabel. 'Lateral Transport Controls Distribution, Quality, and Burial of Organic Matter along Continental Slopes in High-Productivity Areas.' Geology 34, no. 3 (March 1, 2006): 205-8.

Jaffé, R., J. N. Boyer, X. Lu, N. Maie, C. Yang, N. M. Scully, and S. Mock. 'Source Characterization of Dissolved Organic Matter in a Subtropical Mangrove-Dominated Estuary by Fluorescence Analysis.' Marine Chemistry 84, no. 3-4 (January 2004): 195210.

Jaffé, Rudolf, Ralph Mead, Maria E Hernandez, Maria C Peralba, and Olga A DiGuida. 'Origin and Transport of Sedimentary Organic Matter in Two Subtropical Estuaries: A Comparative, Biomarker-Based Study.' Organic Geochemistry 32, no. 4 (April 2001): 507-26. 
Jaffe, Rudolf, Childers, Daniel, Boyer, Joseph, Fourqurean, James, and Trexler, Joel. 'Final Report for NSF Award \#9910514 (2000-2006).' Florida Coastal Everglades Long Term Ecological Research Florida International University, August 2007.

Jaffé, R., D. McKnight, N. Maie, R. Cory, W. H. McDowell, and J. L. Campbell. 'Spatial and Temporal Variations in DOM Composition in Ecosystems: The Importance of LongTerm Monitoring of Optical Properties.' Journal of Geophysical Research:

Biogeosciences 113, no. G4 (December 1, 2008): G04032.

Kalle, Kurt. 'Fluoreszenz und Gelbstoff im Bottnischen und Finnischen Meerbusen.' Deutsche Hydrografische Zeitschrift 2, no. 4 (July 1949): 117-24.

Karl, David M., George A. Knauer, and John H. Martin. 'Downward Flux of Particulate Organic Matter in the Ocean: A Particle Decomposition Paradox.' Nature 332 (March 1, 1988): 438-41.

Kieber, Robert J., Robert F. Whitehead, and Stephen A. Skrabal. 'Photochemical Production of Dissolved Organic Carbon from Resuspended Sediments.' Limnology and Oceanography 51, no. 5 (September 1, 2006): 2187-95.

Kördel, W., Manos Dassenakis, J. Lintelmann, and S. Padberg. 'The Importance of Natural Organic Material for Environmental Processes in Waters and Soils (Technical Report).' Pure and Applied Chemistry 69, no. 7 (1997): 1571-1600.

Kujawinski, Elizabeth B, Michael A Freitas, Xu Zang, Patrick G Hatcher, Kari B GreenChurch, and R. Benjamin Jones. 'The Application of Electrospray Ionization Mass Spectrometry (ESI MS) to the Structural Characterization of Natural Organic Matter.' Organic Geochemistry 33, no. 3 (March 2002): 171-80.

Kuwatsuka, Shozo, Akira Watanabe, Kazuhito Itoh, and Shigemitsu Arai. 'Comparison of Two Methods of Preparation of Humic and Fulvic Acids, IHSS Method and NAGOYA Method.' Soil Science and Plant Nutrition 38, no. 1 (March 1, 1992): 23-30.

Lapierre, Jean-François, François Guillemette, Martin Berggren, and Paul A. del Giorgio. 'Increases in Terrestrially Derived Carbon Stimulate Organic Carbon Processing and CO2 Emissions in Boreal Aquatic Ecosystems.' Nature Communications 4 (December 13, 2013): 2972.

Larsen, Laurel G., George R. Aiken, Judson W. Harvey, Gregory B. Noe, and John P. Crimaldi. 'Using Fluorescence Spectroscopy to Trace Seasonal DOM Dynamics, Disturbance Effects, and Hydrologic Transport in the Florida Everglades.' Journal of Geophysical Research: Biogeosciences 115, no. G3 (September 1, 2010): G03001.

Lead, J. R., and Wilkinson, K. J. Environmental colloids and particles: Present knowledge and future developments. In K. J. Wilkinson and J. R. Lead (Eds.), 
Environmental colloids and particles: Behaviour, separation and characterisation. IUPAC series on analytical and physical chemistry of environmental system John Wiley \& Sons, Ltd., Chichester, West Sussey, England. (2007): Vol. 10, pp. 1-17

LTER website:

http://fcelter.fiu.edu/data/core/metadata/?datasetid=LT PP Castaneda 001

Kiehne, A., and U. H. Engelhardt. 'Thermospray-LC-MS Analysis of Various Groups of Polyphenols in Tea. I. Catechins, Flavonol O-Glycosides and Flavone C-Glycosides.' Zeitschrift Für Lebensmittel-Untersuchung Und -Forschung 202, no. 1 (January 1996): 48-54.

Loveless, Charles M. 'A Study of the Vegetation in the Florida Everglades.' Ecology 40, no. 1 (1959): 2-9.

Maie, Nagamitsu, Norman M. Scully, Oliva Pisani, and Rudolf Jaffé. 'Composition of a 'protein-like' Fluorophore of Dissolved Organic Matter in Coastal Wetland and Estuarine Ecosystems.' Water Research 41, no. 3 (February 2007): 563-70.

Maie, Nagamitsu, Oliva Pisani, and Rudolf JaffÉ. 'Mangrove Tannins in Aquatic Ecosystems: Their Fate and Possible Influence on Dissolved Organic Carbon and Nitrogen Cycling.' Limnology and Oceanography 53, no. 1 (January 1, 2008): 160-71.

Moran, David T., J. Carter Rowley, and George Aiken. 'Trout Olfactory Receptors Degenerate in Response to Water-Borne Ions.' Annals of the New York Academy of Sciences 510, no. 1 (November 1, 1987): 509-11.

Osburn, Christopher L., Lauren T. Handsel, Molly P. Mikan, Hans W. Paerl, and Michael T. Montgomery. 'Fluorescence Tracking of Dissolved and Particulate Organic Matter Quality in a River-Dominated Estuary.' Environmental Science \& Technology 46, no. 16 (August 21, 2012): 8628-36.

Pisani, Oliva, Youhei Yamashita, and Rudolf Jaffé. 'Photo-Dissolution of Flocculent, Detrital Material in Aquatic Environments: Contributions to the Dissolved Organic Matter Pool.' Water Research 45, no. 13 (July 2011): 3836-44.

Parlanti, E., K. Wörz, L. Geoffroy, and M. Lamotte. 'Dissolved Organic Matter Fluorescence Spectroscopy as a Tool to Estimate Biological Activity in a Coastal Zone Submitted to Anthropogenic Inputs.' Organic Geochemistry 31, no. 12 (December 2000): $1765-81$.

Qualls, Robert G., and Curtis J. Richardson. 'Factors Controlling Concentration, Export, and Decomposition of Dissolved Organic Nutrients in the Everglades of Florida.' Biogeochemistry 62, no. 2 (February 2003): 197-229. 
Rice-Evans, Catherine A., Nicholas J. Miller, and George Paganga. 'Structureantioxidant activity relationships of flavonoids and phenolic acids.' Free radical biology and medicine 20.7 (1996): 933-956.

Riley, John Price, and Roy Chester. 'Introduction to marine chemistry.' (1971).

Roux, David G., Daneel Ferreira, Hans K. L. Hundt, and Elfranco Malan. "Structure, stereochemistry, and reactivity of natural condensed tannins as a basis for their extended industrial application." ResearchGate, no. 28 (January 1, 1975): 335-53.

Herz, Werner. 'The Organic Constituents of Higher Plants, Their Chemistry and Interrelationships.' Journal of the American Chemical Society 85, no. 18 (September 1, 1963): 2876-2876.

Salonen, K., and A. Vähätalo. 'Photochemical Mineralisation of Dissolved Organic Matter in Lake Skjervatjern.' Environment International, Special Issue on the Humex Project and Humic Substances, 20, no. 3 (1994): 307-12.

Seth, Malini, and Subhash Chand. 'Biosynthesis of Tannase and Hydrolysis of Tannins to Gallic Acid by Aspergillus Awamori - Optimisation of Process Parameters.' Process Biochemistry 36, no. 1-2 (September 2000): 39-44.

Santín, C., Y. Yamashita, X. L. Otero, M. Á Álvarez, and R. Jaffé. 'Characterizing Humic Substances from Estuarine Soils and Sediments by Excitation-Emission Matrix Spectroscopy and Parallel Factor Analysis.' Biogeochemistry 96, no. 1-3 (July 31, 2009): $131-47$.

Schwede-Thomas, S. B., Y. P. Chin, K. J. Dria, P. Hatcher, E. Kaiser, and B. Sulzberger. 'Characterizing the Properties of Dissolved Organic Matter Isolated by XAD and C-18 Solid Phase Extraction and Ultrafiltration.' Aquatic Sciences 67, no. 1 (March 2005): 6171. doi:10.1007/s00027-004-0735-4.

Scully, Norman M., William J. Cooper, and Lars J. Tranvik. 'Photochemical Effects on Microbial Activity in Natural Waters: The Interaction of Reactive Oxygen Species and Dissolved Organic Matter.' FEMS Microbiology Ecology 46, no. 3 (December 1, 2003): $353-57$.

Scully, Norman M., Nagamitsu Maie, Susan K. Dailey, Joseph N. Boyer, Ronald D. Jones, and Rudolf Jaffe. 'Early Diagenesis of Plant-Derived Dissolved Organic Matter along a Wetland, Mangrove, Estuary Ecotone.' Limnology and Oceanography 49, no. 5 (2004): 1667-78.

Sheldon, R. W., T. P. T. Evelyn, and T. R. Parsons. 'On the Occurrence and Formation of Small Particles in Seawater.' Limnology and Oceanography 12, no. 3 (April 1, 1967): $367-75$. 
Sigma-Aldrich Co. 'BSTFA Product Specification.' Supelco, 1997.

Simmons, M. C., and T. R. Kelley. Quantitative Analysis of Complex Samples by GasLiquid Chromatography and Mass Spectrometry. Barber-Colman Co., Houston, Texas, 1961.Stedmon, Colin A, Stiig Markager, and Rasmus Bro. 'Tracing Dissolved Organic Matter in Aquatic Environments Using a New Approach to Fluorescence Spectroscopy.' Marine Chemistry 82, no. 3-4 (August 2003): 239-54.

Stephens, John C. 'Subsidence of Organic Soils in the Florida Everglades1.' Soil Science Society of America Journal 20, no. 1 (1956): 77-80.

Takeda, Kazuhiko, Hiroshi Takedoi, Shuhei Yamaji, Keiichi Ohta, and Hiroshi Sakugawa. 'Determination of Hydroxyl Radical Photoproduction Rates in Natural Waters.' Analytical Sciences 20, no. 1 (2004): 153-58.

Tor, Elizabeth R., Traci M. Francis, Dirk M. Holstege, and Francis D. Galey. 'GC/MS Determination of Pyrogallol and Gallic Acid in Biological Matrices as Diagnostic Indicators of Oak Exposure.' Journal of Agricultural and Food Chemistry 44, no. 5 (January 1, 1996): 1275-79.

Troxler, Tiffany, Evelyn Gaiser, Jordan Barr, Joseph Fuentes, Rudolf Jaffe', Daniel Childers, Ligia Collado-Vides, et al. 'Integrated Carbon Budget Models for the Everglades Terrestrial-Coastal-Oceanic Gradient: Current Status and Needs for Inter-Site Comparisons.' FCE LTER Journal Articles, September 1, 2013.

Valeur, Bernard, and Mário Nuno Berberan-Santos. Molecular fluorescence: principles and applications. John Wiley \& Sons, 2012.

Weingerl, Vesna, Matija Strlic, and Drago Kocar. 'Comparison of Methods for Determination of Polyphenols in Wine by HPLC-UV/VIS, LC/MS/MS and Spectrophotometry.' Acta Chimica Slovenica 56, no. 3 (January 1, 2009): 698-703.

Würth, Christian, Markus Grabolle, Jutta Pauli, Monika Spieles, and Ute Resch-Genger. 'Relative and Absolute Determination of Fluorescence Quantum Yields of Transparent Samples.' Nature Protocols 8, no. 8 (August 2013): 1535-50.

Ya, Chao. 'Sources, Fate and Transformation of Organic Matter in Wetlands and Estuaries.' FIU Electronic Theses and Dissertations, (September 30, 2014).

Yamashita, Youhei, and Eiichiro Tanoue. 'Chemical Characterization of 'protein-like' Fluorophores in DOM in Relation to Aromatic Amino Acids.' Marine Chemistry 82, no. 3-4 (August 2003): 255-71. 
Zsolnay, Ádám. 'Dissolved Organic Matter: Artefacts, Definitions, and Functions.' Geoderma, Ecological aspects of dissolved organic matter in soils, 113, no. 3-4 (May 2003): 187-209. 


\title{
CHAPTER II
}

\begin{abstract}
Dissolved organic matter (DOM) optical properties (using on the basis of UV absorbance and fluorescence measurements), reactive species (RS) generation (including singlet oxygen, hydroxyl radical, and excited triplet states of dissolved organic matter) and radical scavenging ability (DOM redox potential) were studied for a broad range of Everglades water samples with distinctly different DOM compositions in order to better understand DOM photo-reactivity. The samples ranged from fresh-water marsh to mangrove estuary and seagrass-dominated marine waters. Samples were subdivided into three categories through hierarchical cluster analysis: ocean, estuary and terrestrial which match with different vegetation characteristics. Halides or ionic strength influence on RS generation upon solar irradiation was estimated to be minor for Everglades DOM, while DOM aromaticity was found to be the critical factor in determining the photoproduction of RS from DOM. The higher DOM aromaticity (SUVA), the lower RS quantum yields, but the higher the photoproduction rate of these species. The redox potential of DOM can also alter the photoproduction rates by quenching the formation of RS. The RS quantum yield decreased with the increase of DOM redox potential, indicating a quenching of the singlet oxygen RS. The RS formation rates were controlled by the DOC and CDOM concentration. Normalized RS formation rates appeared to be influenced by the degree of humification (HIX) of the DOM and by molecular weight characteristics $\left(\mathrm{S}_{\mathrm{R}}\right)$, both related to the DOM composition. In general, DOM photoreactivity as defined by RS production correlated well with a combination of DOM compositional features including aromaticity, molecular weight and redox potential.
\end{abstract}


Introduction

Natural organic matter (NOM) in aquatic systems plays an important biochemical role in the ecosystem. Natural organic matter is defined as detrital material derived from plants and animals, and their degradation products occurring in aquatic systems (Riley and Chester, 1971). It is classed as dissolved organic matter (DOM) and particulate organic matter (POM) on the basis of filtration using $0.7 \mu \mathrm{m}$ glass fiber filters (Aiken et al., 2011; Morel and Gschwend, 1987; Lead and Wilkinson, 2007). Dissolved organic matter is a heterogeneous mixture of aliphatic and aromatic organic compound (Cooper et al., 1989).

Dissolved organic matter is known as a photosensitizer and its photosensitizing properties are a consequence of production of reactive species (RS) including hydroxyl radical $(\bullet \mathrm{OH})$, singlet oxygen $\left({ }^{1} \mathrm{O}_{2}\right)$ and excited triplet states of dissolved organic matter ( ${ }^{3} \mathrm{DOM}^{*}$ ) (Balakrishnan et al., 1970; Warneck et al., 1988; Vione et al., 2006). Nitrate, nitrite (Mack et al., 1999; Ji et al., 2012; Dong et al., 2012) and photo-Fenton reaction (Voelker et al., 1997; Fukushima et al., 2001) are well-known •OH radical sources. However, in natural water environments with limited nitrate, nitrite and hydrogen peroxide concentration, chromophoric dissolved organic matter (CDOM) becomes a significant hydroxyl radical source (Takeda et al., 2004). Moreover, ${ }^{3} \mathrm{DOM} *$ is known to be an important precursor for singlet oxygen (Zepp et al., 1977; Haag et al., 1984). Therefore, CDOM may be an important proxy for RS formation. Moreover, studies in fresh-water and estuarine water showed that estuarine samples are more photo-reactive and have higher RS formation rates along with higher organic carbon content than fresh- 
water samples (Takeda et al., 2004; Housari et al., 2010). Another finding demonstrated that increasing humic concentration could also enhance $\bullet \mathrm{OH}$ photoproduction rates (Mopper et al., 1990) and the main source of ${ }^{1} \mathrm{O}_{2}$ are the moieties that are present in the terrestrial humic substances (Timko et al., 2014). Alternatively, halide radicals such as bromide or chloride could contribute to the photoproduction of RS from DOM as well (Glover et al., 2013).

While many studies have examined the RS produced from DOM using humic standards (Parker et al., 2013; Cawley et al., 2015) or organic contaminants (Canonica et al., 2008; Wenk et al., 2012; Mostafa et al., 2013), limited information is available on the effect of NOM character on RS formation. As the largest subtropical wetland in the United States, the Everglades not only maintains a diversity of vegetation, but is also unique in its low iron, phosphate and nitrate / nitrite concentration (Chambers et al., 2006). Because of the high variation in DOM character (i.e., composition) in the Everglades (e.g. Maie et al., 2005), it would be of interest to understand how RS production is coupled to such DOM diversity. Timko et al (2014) studied the formation rates and steady-state concentrations of singlet oxygen, hydroxyl radical and triplet excited-state DOM and how these species corresponded to the optical properties of DOM during the late dry season of the Everglades. Their study suggested that DOM quality and quantity is coupled to the production of RS.

Moreover, DOM not only plays a role as a photosensitizer but can also act as a radical scavenger in the natural aquatic environment. Its radical scavenging ability, which are mainly attributed to hydroquinone and phenol moieties (Wenk et al., 2012; Page et al., 
2014). Some DOM components such as polyphenols are known for their radical scavenging ability (Halliwell et al., 1990; Rice-Evans et al., 1996). Free radical scavengers can interrupt radical chain reactions, or even prevent the reactive oxidants from being formed in the first place (Huang et al., 2005). Radical scavenging ability of DOM was studied in the Everglades and showed a strong relation with mangrove DOM (Romera-Castillo et al., 2015), which is known to produce a significant amount of tanninlike polyphenols (Maie et al., 2006).

The current study took place at two major drainages, Shark River Slough (SRS) and the Taylor Slough (TS) together with a marine site -- Florida Bay (FB) in the Everglades National Park (ENP). Surface waters in the ENP drain into Florida Bay and Florida Shelf naturally and create a salinity gradient along SRS and TS (Gooselink and Turner, 1978). The seasonal climate variations in the Everglades represent clear wet (between June and November) and dry seasons (December to May) with about $80 \%$ of total annual precipitation occurring in the wet season. In the dry season, freshwater inflows are reduced and estuarine residence time increases. These altering processes are responsible for nutrient availability and water quality (Childers, et al., 2006) which including changes in DOM residence times, with potential effects on its reactivity. The Shark River Slough estuary is strongly connected to the Gulf of Mexico and receives significant tidal influence (Fourqurean et al. 1993). Therefore, in the present study, a broad range of DOM samples were compared in equal basis using RS parameters and redox potential along with optical properties to understand the DOM photo-activity in the Everglades. 
The compositional features of DOM also vary on spatial scales in the Everglades, in part as a result of source changes (Maie et al., 2005; Chen et al., 2013). In the upstream SRS and TS, the freshwater marsh is dominated by sawgrass (Cladium) and periphyton. The TS sites dry more frequently and for a longer duration compared to SRS sites, therefore, containing marl soils rather than peat. Further downstream, in TS and SRS, the primary producer biomass is dominated by mangroves. Compared to mangrovedominated sites located in TS and SRS, TS sites have significantly shorter trees, lower rates of litterfall and root production than SRS sites. In FB, biomass is dominated by seagrass. These vegetation and hydrological patterns result in a highly variable DOM character imprint in this ecosystem.

This study is the first study where a broad range of DOM samples, with significant compositional differences were compared on the basis of DOM organic matter optical properties, RS generation, and radical scavenging ability in order to better understand the DOM photo-reactivity. We hypothesize that RS productivity would be directly related to the aromaticity of DOM samples. At the same time, we assume that redox potential would have a significant impact on the generation of RS and thus the overall photo-reactivity.

Experimental methods

Chemicals

The FFA was purchased from TCI America. Phenol was purchased from Sigma Aldrich. The TMP and Benzene were purchased from Alfa Aesar. Methanol (HPLC 
grade) was purchased from BWD (VWR Analytical) or Honeywell. Phosphoric acid was purchased from J.T. Baker. Varian Bond Elut PPL cartridges were purchased from Agilent Technologies.

\section{Sampling}

Water samples were obtained from the Everglades National Park, Florida, USA (Figure 2-1). Samples were collected from long-term monitored FCE-LTER sites located in Shark River Slough (SR2, SR4, and SR6), Taylor Slough (TS2, TS3, and TS7) and Florida Bay (FB21). Samples were collected as surface water in pre-rinsed polyethylene bottles and transported back to the lab on ice. Samples were then filtered through $0.7 \mu \mathrm{m}$ filters (Gelman GF/F) and stored in polyethylene bottles at $4{ }^{\circ} \mathrm{C}$. 


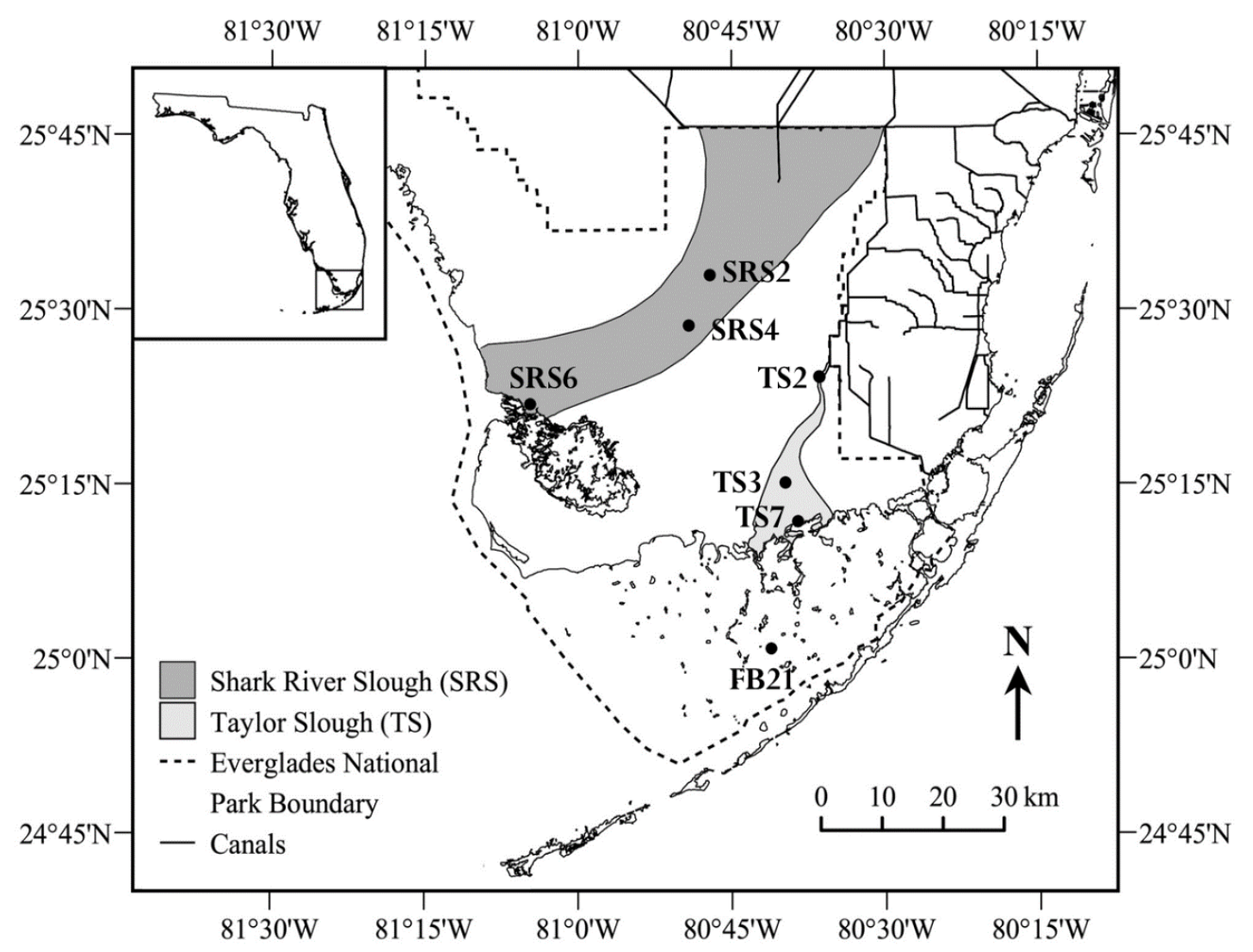

Figure 2-1. Sampling sites along Shark River Slough (SRS-2/4/6), Taylor Slough (TS-2/3/7) and Florida Bay (FB21). Sub-environments: freshwater marsh (peat; SRS-2/3), freshwater marsh (marl; TS-2), mangrove estuarine (peat; SRS-4/6), mangrove estuarine (marl; TS-7), and Florida Bay (FB) estuary (FB-21). 


\section{Methods}

\section{Reactive species measurement}

Reactive species (RS) measured in the present study include: hydroxyl radicals $(\bullet \mathrm{OH})$, singlet oxygen $\left({ }^{1} \mathrm{O}_{2}\right)$ and excited triplet states of dissolved organic matter $\left({ }^{3} \mathrm{DOM} \mathrm{M}^{*}\right)$ using the following probe: benzene (Balakrishnan et al., 1970; Warneck et al., 1988), Furfuryl alcohol (FFA) (Haag et al.,1984a; 1984b) and 2,4,6-trimethylphenol (TMP) (Cawley et al., 2009; Rosado-Lausell et al., 2013), respectively.

Benzene serves as a common probe for hydroxyl radicals $(\bullet \mathrm{OH})$ measurements and is converted to phenol (Warneck et al., 1988).

Equation 2-1.

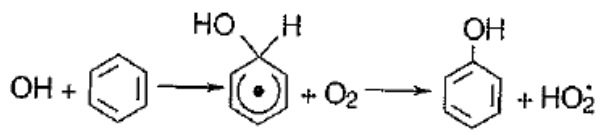

The formation of singlet oxygen $\left({ }^{1} \mathrm{O}_{2}\right)$ is via energy transfer from excited triplet states of dissolved organic matter $\left({ }^{3} \mathrm{DOM}^{*}\right)$ to ground state $\mathrm{O}_{2}$ (Zepp et al., 1977; Zepp et al., 1981). Detection of singlet oxygen $\left({ }^{1} \mathrm{O}_{2}\right)$ is usually performed by using the probe furfuryl alcohol (FFA), which is easy to employ because of its high water solubility and low volatility (Haag et al., 1984a; 1984b). 
Equation 2-2.

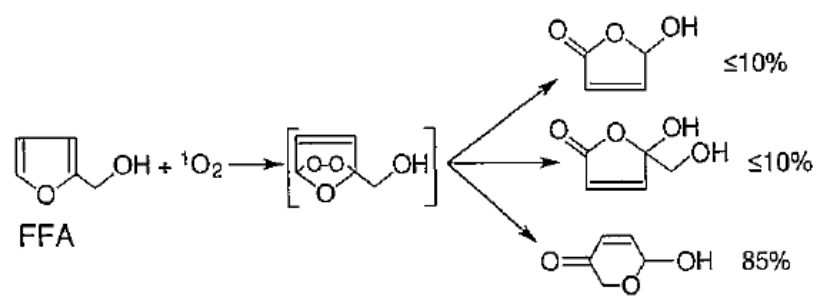

Excited triplet state dissolved organic matter ( $\left.{ }^{3} \mathrm{DOM}^{*}\right)$ was measured using probe 2,4,6-trimethylphenol (TMP), which is selectively reactive toward this photo-transient species. The methyl groups on TMP act as electron donors to the conjugated ring, which stabilizes the TMP cation after oxidation by ${ }^{3}$ DOM (Cawley et al., 2009).

The RS quantum yields determined in this experiment were well documented elsewhere (Mostafa et al., 2013, Dong et al., 2012).A Cary 100 UV/Vis spectrophotometer was used to measure absorbance scans. Samples were measured in triplicate using deionized water as a $100 \%$ transmittance blank. Samples for irradiation were placed in clear borosilicate glass HPLC vials positioned on their side to chill in $20{ }^{\circ} \mathrm{C}$ water bath under the Oriel Solar Simulator (Model 1429A). The specific rate of light absorbance $\left(\mathrm{K}_{\mathrm{DOM}}\right)$ was calculated using the following equation for summing $\lambda=290-400 \mathrm{~nm}$.

Equation 2-3.

$$
k_{D O M-a}=\sum_{i=290}^{400 n m} \frac{E_{\lambda, i}^{0} \varepsilon_{\lambda, i}\left(1-10^{-\varepsilon_{\lambda, i}[D O M] Z}\right)}{\varepsilon_{\lambda, i}[D O M] Z} \Delta \lambda_{i}
$$


And $\Delta \lambda$ is set at $1 \mathrm{~nm}$. The variable $E_{\lambda, i}^{0}$ represent the near surface photon irradiance, $\varepsilon_{\lambda, i}$ is the apparent molar absorptivity, The quantum yield could then be calculated using the following equation:

Equation 2-4.

$$
\Phi=\frac{R_{R O S}}{I_{D O M}}=\frac{R_{R O S}}{k_{D O M-a}[D O M]}
$$

The term $\mathrm{R}_{\mathrm{ROS}}$ stands for the rate of ROS formation $\left[\mathrm{M} \mathrm{s}^{-1}\right]$ and $\mathrm{I}_{\mathrm{DOM}}$ represents the rate of light absorption by DOM [Ein s ${ }^{-1}$. The $\mathrm{R}_{\mathrm{ROS}}$ was measured through the loss of ROS probe 2-furan methanol (FFA), benzene and 2,4,6-trimethylphenol (TMP) which were detected by HPLC.

Take ${ }^{1} \mathrm{O}_{2}$ as an example:

Equation 2-5.

$$
R^{{ }^{o_{2}}}=R_{F F A} \frac{k_{F F A,{ }^{1} O_{2}} F F A^{0}+k_{d}}{k_{F F A,{ }^{1} O_{2}} F F A^{0}}
$$

Where $\mathrm{FFA}_{0}$ is the FFA concentration at time zero and $k_{F F A,{ }^{1} O_{2}}$ stands for the reaction rate between FFA and ${ }^{1} \mathrm{O}_{2}$.

All RS measurements repeated here were determined by colleagues at the University of Colorado through a collaborative effort. 
Antioxidant activity measurement

An efficient method of DOM radical scavenging ability evaluation is using 2,2diphenyl-1-picrylhydrazyl (DPPH•) to react with DOM in a methanol solution (BrandWilliams et al., 1995; Wei et al., 2010; Romera-Castillo et al., 2015). The DPPH• has a characteristic wavelength absorbance at $515 \mathrm{~nm}$ which would be reduced or eliminated by a radical scavenger $(\mathrm{AH})$ or a radical species $(\mathrm{R} \bullet)($ Brand-Williams et al., 1995).

Equation 2-6.

\section{$\mathrm{DPPH}^{\bullet}+\mathrm{AH} \rightarrow \mathrm{DPPH}-\mathrm{H}+\mathrm{A} \bullet$ $\mathrm{DPPH}^{\bullet}+\mathrm{R} \bullet \rightarrow \mathrm{DPPH}-\mathrm{R}$}

Therefore, a sample's radical scavenging ability could be quantified by measuring its UV absorbance reduction after DPPH• reaction at wavelength $515 \mathrm{~nm}$.

The radical scavenging ability measurements in the experiment have been described in detail previously (Brand-Williams et al., 1995; Wei et al., 2010) and recently adapted specifically to DOM (Romera-Castillo et al., 2015). Briefly, Varian Bond Elut PPL cartridges were used to isolate DOM extracts. Then methanol was used to elute the DOM. The methanol extracts were then mixed with DPPH• reagent, shaken and left to react in the dark at room temperature for 15 minutes. The UV absorbance at $515 \mathrm{~nm}$ decreased after reaction and was measured in a Varian Cary 50 biospectrophotometer. The radical scavenging ability $\left(\mathrm{A}_{\mathrm{x}} \mathrm{A}\right)$ is expressed as: 
Equation 2-7.

$$
\mathrm{A}_{\mathrm{x}} \mathrm{A}=\left[1-\left(\mathrm{A}_{\mathrm{A}}-\mathrm{A}_{\mathrm{C}}\right) / \mathrm{A}_{\mathrm{B}}\right] \times 100
$$

Where $A_{A}$ is the absorbance of the antioxidant sample at the end of the reaction time; $A_{C}$ is the absorbance of the sample blank at the beginning of the reaction time (t=0); and $A_{B}$ is the absorbance of the methanol blank at the beginning of the reaction time $(\mathrm{t}=0)$.

The radical scavenging ability of samples in the present study is determined as IP100 value, which is the antioxidant activity for $100 \mathrm{mg} / \mathrm{L}$ methanol extracted DOC using the calibration curve. The larger IP100 value stands for higher DOM radical scavenging ability.

Dissolved organic carbon and optical properties measurements

The DOC concentrations were measured with a Shimadzu TOC-5000 analyzer through high temperature combustion. The DOC concentration of water samples was measured directly from the filtered water samples. An aliquot $(200 \mu 1)$ of each methanol DOM extract was dried with $\mathrm{N}_{2}$ gas and was also subject to vacuum in a freeze dryer for $2 \mathrm{~h}$ to ensure the complete dryness of the samples. Once dried, all the samples were redissolved with 10ml Milli-Q water for DOC measurement.

The UV absorbance spectra and fluorescence spectra were obtained for each natural water sample using the Aqualog (Horiba) spectrofluorometer with a $1 \mathrm{~cm}$ quartz cuvette. The excitation wavelength was scanned from $240 \mathrm{~nm}$ to $621 \mathrm{~nm}$ with an increment of $3 \mathrm{~nm}$. The emission wavelength was scanned from $241 \mathrm{~nm}$ to $622 \mathrm{~nm}$ in 1.5 
$\mathrm{nm}$ steps. The UV-Vis spectra were collected from $240 \mathrm{~nm}$ to $621 \mathrm{~nm}$ with an increment of $3 \mathrm{~nm}$ simultaneously. The optical parameters used in the present study include HIX (humification index) (Senesi et al., 1991; Zsolnay et al., 1999; Huguet et al., 2009); $a_{254}$ $\left(\mathrm{m}^{-1}\right), \mathrm{SUVA}_{254}(\mathrm{~L} / \mathrm{mgC} \mathrm{m})$ (Weishaar et al., 2003); Slope Ratio $\left(\mathrm{S}_{\mathrm{R}}\right)$ (Helms et al., 2008) and E3:E3 (Peuravuori et al., 1997).

The humification index is a fluorescence index that assessed the relative degree of humification and was calculated as the ratio of the peak area under the emissions 434$480 \mathrm{~nm}$ and 300-346 nm from excitation $255 \mathrm{~nm}$ (Zsolnay et al., 1999). High HIX values correspond to the presence of complex molecules like high molecular weight aromatics (Senesi et al., 1991). The $\mathrm{a}_{254}$ value is the absorption coefficient at wavelength $254 \mathrm{~nm}$ and the more aromatic OM correspond to a higher absorbance at wavelength $254 \mathrm{~nm}$ (Weishaar et al., 2003). Because of the instrument limitation, the UV absorbance in this study was performed at wavelength $255 \mathrm{~nm}$ instead. $\mathrm{a}_{255}=2.303^{*} \mathrm{~A}_{255} / \mathrm{d}$, where $\mathrm{d}$ is the length of the cuvette which is $1 \mathrm{~cm} ; \mathrm{A}_{255}$ is the UV absorbance value at wavelength 255 ; $\mathrm{a}_{255}$ is the absorption coefficient at wavelength $255 \mathrm{~nm} ; 2.303$ is a conversion factor from a decimal to natural $\log$. $\operatorname{SUVA}_{255}(\mathrm{~L} / \mathrm{mgC} \mathrm{m})=\mathrm{a}_{255}\left(\mathrm{~cm}^{-1}\right) / \mathrm{DOC}(\mathrm{mg} / \mathrm{L}) \times 100(\mathrm{~cm} / \mathrm{m})$. Slope Ratio in this study was calculated out of slopes of two narrow wavelength intervals, 275-295 nm and 350-400 nm. E2:E3 is the ratio of a sample's absorbance at $254 \mathrm{~nm}$ to that at $365 \mathrm{~nm}$ and in the present study is the ratio of a sample's absorbance at $255 \mathrm{~nm}$ to that at $366 \mathrm{~nm}$ due to equipment limitation. Slope Ratio (Helms et al., 2008) and E3:E3 (Peuravuori et al., 1997) are both inversely related with the molecular weight of DOM. 
Results and discussion

General observations

In this study, multiple descriptors were investigated in an attempt to find correlations between RS and DOM optical or chemical parameters. This would benefit the RS prediction from readily measured parameters. All the detailed data are listed in the appendix (Table S1).

Spatially, samples in this study can be divided into three groups on the basis of their environmental characteristics. The first group is comprised of marine water samples, corresponding to the seagrass dominated Florida Bay location (FB21), characterized by low absorption coefficient values $\left(\mathrm{a}_{255}=0.12-0.16 \mathrm{~cm}^{-1}\right)$ and low DOC concentration (5.5-7.5ppm). The second group contained all of the fresh-water marsh samples (SRS2, TS2, TS3), with high DOC concentration (8.5-22.7ppm) and UV absorbance $\left(\mathrm{a}_{255}=\right.$ 0.34-1.17 $\mathrm{cm}^{-1}$ ). The third group contained estuarine samples (SRS6, TS7) which are associated with mangrove forests and had intermediate absorption coefficient values $\left(\mathrm{a}_{255}\right.$ $\left.=0.44-1.43 \mathrm{~cm}^{-1}\right)$ and DOC concentrations (9.0-19.0 ppm). Moreover, on the basis of soil type, the Shark River Slough, characterized by peat soil, is much more organic matter enriched compared to Taylor Slough, which features marl soil. Therefore, the DOC concentration in SRS fresh-water marsh site (SRS2) is the highest. Besides, the fringe mangrove environment has been reported to have significant contributions of highly aromatized CDOM (Jaffe et al., 2004; Chen et al., 2013). Therefore, the higher absorption coefficient value and DOC concentration of site TS7 compared to TS2 and 
TS3 is not unexpected. Combined with salinity value, the TS7 November sample was strongly influenced by saltwater intrusion from Florida Bay and shared more similarity to FB21 samples than the other TS7 samples.

\section{Cluster analysis}

To identify specific relationships between the DOM samples studied here, hierarchical cluster analysis was used as a common multivariate statistical method. Cluster analysis was performed on the basis of RS quantum yields $\left(\cdot \mathrm{OH} \_\mathrm{QY},{ }^{1} \mathrm{O}_{2} \mathrm{QY}\right.$, $\left.{ }^{3} \mathrm{DOM}^{*}{ }_{-} \mathrm{QY}\right)$, antioxidant activity (IP100) and optical properties (E2:E3, $\left.\mathrm{a}_{255}, \mathrm{HIX}\right)$ information. As previously observed (Maie et al., 2005; Chen et al., 2013), a clear spatial cluster was perceived, likely driven by soil type and plant cover characteristics (Figure 22). The cluster clearly separated the dataset (data reorganized into monthly averages) into sub-environment types as follows: Taylor River mangrove estuary site (TS7), Shark River mangrove estuary sites (SRS6), Shark River mangrove ecotone (SRS4), Taylor River fresh-water (FW) marsh sites (TS2,TS3), Shark River FW marsh site (SRS2) and estuary-FB site (FB21). In order to get more details, cluster analysis using monthly data was also performed (Figure 2-3). The samples generally grouped into similar subenvironments as bay DOM, fresh-water marsh DOM and mangrove DOM. The November samples from site TS7 fell out from the general mangrove group. The salinity value of that sample is 25.3 PSU which is about three times higher than the other two month $($ Avg. $=9.6)$ indicating that TS7 site was strongly influenced by Florida bay water intrusions at that time. November is the beginning of the dry season in the Everglades. Reduced freshwater discharge at this site was previously shown to lead to a shift from 
estuary DOM to marine DOM (Chen et al., 2013). Thus, TS7 November sample showed a low $\mathrm{a}_{255}$ and DOC value which is similar to FB samples.

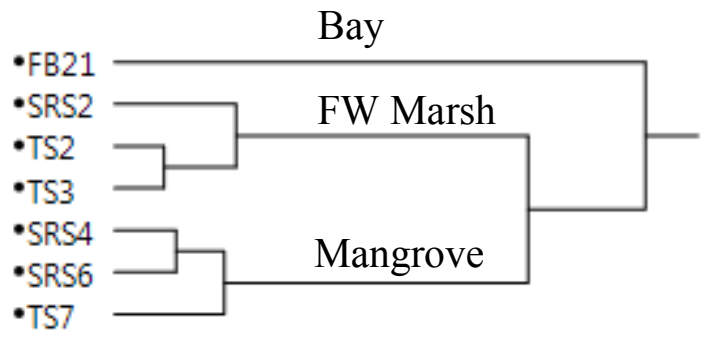

Figure 2-2. Cluster analysis with RS quantum yields, antioxidant activity and optical properties data reorganized into monthly averages of each site. 


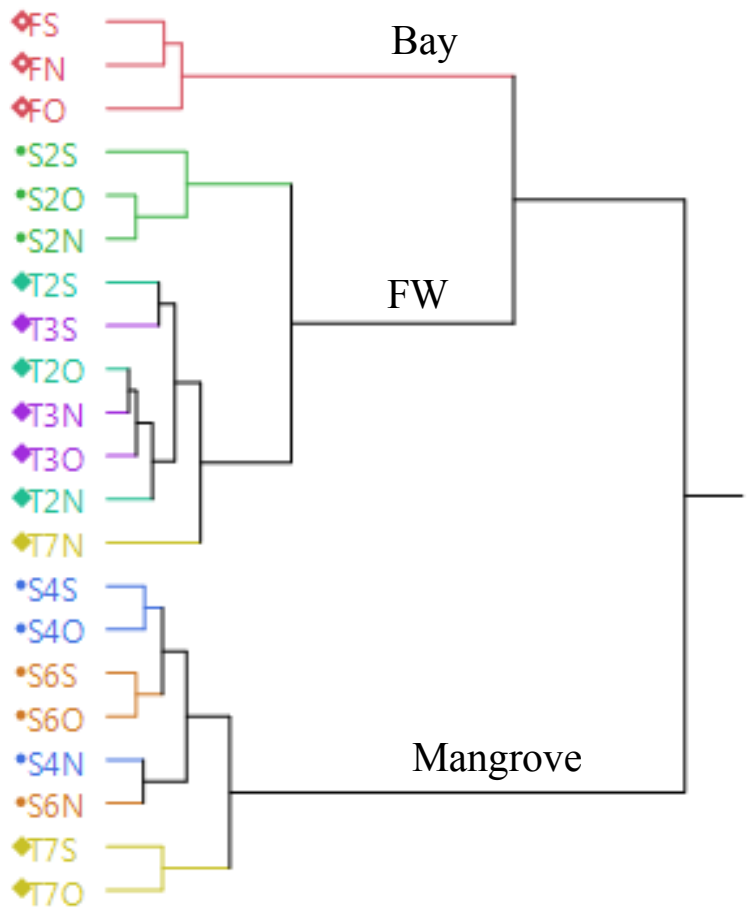

Figure 2-3. Cluster analysis with monthly data. Sample name is a combination of sampling site and month. e.g. FS stands for Florida Bay September sample and T7N stands for TS7 November sample. 


\section{Reactive species}

\section{RS and DOC}

On the basis of previous reports, the DOC concentration in the SRS decreased from the upstream to downstream while the TS showed an opposite trend (Chen et al., 2013; Timko et al., 2014; Romera-Castillo et al., 2015). Peat based fresh-water marsh sub-environment (SRS2) showed a significantly higher concentration of DOC (Avg. = $18.9 \mathrm{ppm})$ compared to the marl-based freshwater sub-environment $(\mathrm{TS} 2-3)($ Avg. $=9.3$ ppm). SRS and TS have similar vegetation but TS sites are subject to frequent dry-down duration during the peak of the dry season, resulting in reduced OM preservation.

DOC concentrations were found to inversely related with RS quantum yields in the present study (Figure 2-4). ${ }^{3} \mathrm{DOM}^{*}$ and ${ }^{1} \mathrm{O}_{2}$ quantum showed very similar trends and are both linearly related with DOC as expected. However, the Shark River freshwater marsh site SRS2 samples appear to be outliers. Although DOC concentration for the SR2 site sample is significantly higher than TS2 and TS3, the fresh-water marsh sites all have similar RS quantum yield value and are higher than mangrove sites in general. Therefore, instead of DOC being the controlling variable here, DOC may be acting as a surrogate for a reactive component. Alternatively, a possible explanation for SRS2 photoproductivity is that soil derived DOC which has not previously been exposed to light is more photoreactive (De Laurentiis et al., 2013; Cory et al., 2015). Moreover, DOC from SRS2 site has a lot of phenolic DOC from periphyton because periphyton was characterized to be abundant in phenolic compounds through TMAH (Tetramethylammonium hydroxide) 
thermochemolysis (Maie et al., 2006) which indicates that DOM composition may be a stronger influence for RS photoproductivity. Besides RS quantum yields, RS formation rates were also linearly correlated with DOC (Figure 2-5). The linear relationship between the $\bullet \mathrm{OH}$ radical formation rate and the DOC concentration confirmed that DOM instead of nitrite or nitrate is the main source of $\bullet \mathrm{OH}$ production in this system. Besides, these N-species are known to be not concentrated in the Everglades (Davis et al., 2003). Samples from SRS2 showed the highest ${ }^{3} \mathrm{DOM}^{*}$ and ${ }^{1} \mathrm{O}_{2}$ formation rate. This result is expected because of their high DOC concentration and quantum yields. Moreover, ${ }^{1} \mathrm{O}_{2}$ formation rate was found linearly related with ${ }^{3} \mathrm{DOM}^{*}$ formation rate which confirmed that ${ }^{3} \mathrm{DOM}^{*}$ is a precursor of ${ }^{1} \mathrm{O}_{2}$ (Zepp et al., 1977; Zepp et al., 1981; Dong et al., 2012) (Figure 2-6). The mechanism of singlet oxygen formation includes the formation of an excited triplet state DOM from the absorbance of specific chromophores and quenching by molecular oxygen (Zepp et al., 1977; Cooper et al.,1988). 


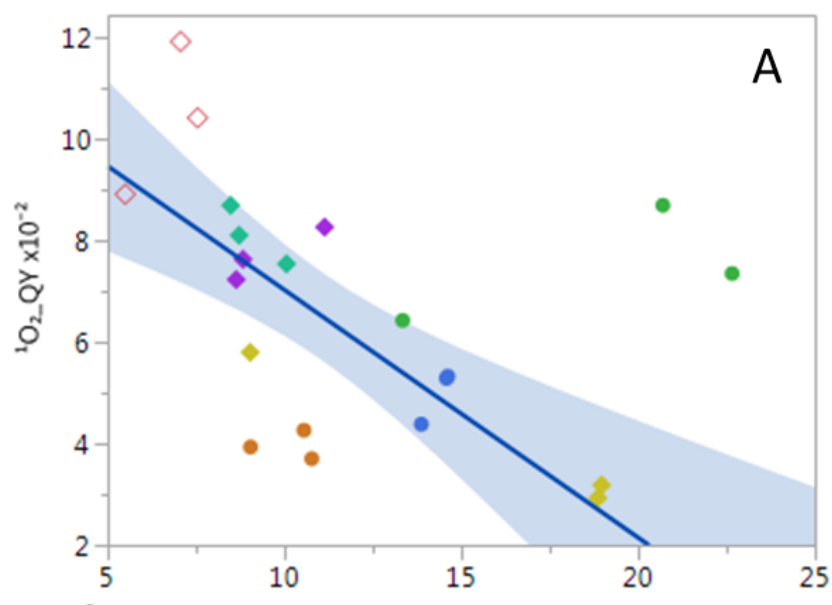

$$
\begin{aligned}
& \text { Site } \\
& \text { FB21 } \\
& \text { SRS2 } \\
& \text { SRS4 } \\
& \text { SRS6 } \\
& \text { TS2 } \\
& \text { TS3 } \\
& \text { TS7 }
\end{aligned}
$$
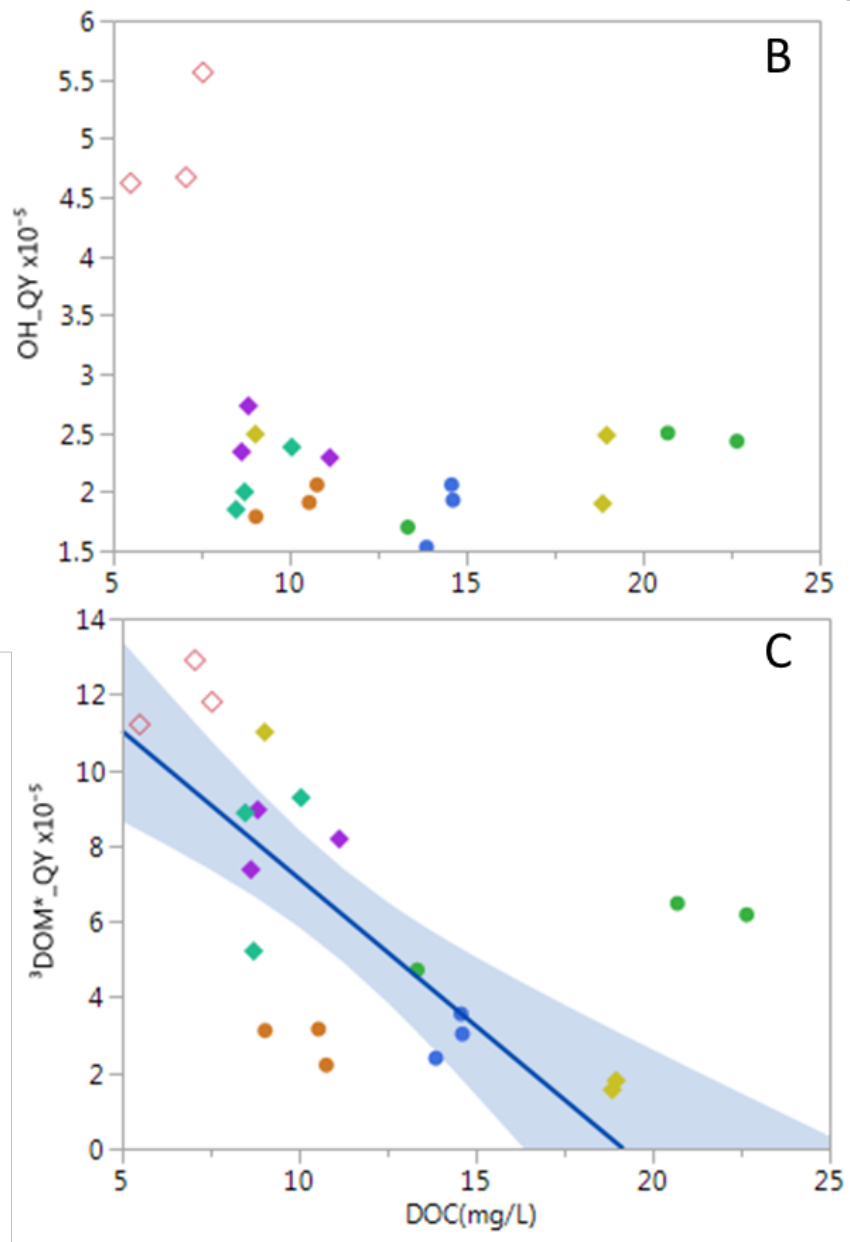

Figure 2-4. Reactive species quantum yields versus DOC concentration. The blue line is a linear prediction excludes SRS2 samples and the blue shade is its $95 \%$ confidence zone. A) Singlet oxygen; B) Hydroxyl radical; C) Excited triplet state DOM. 


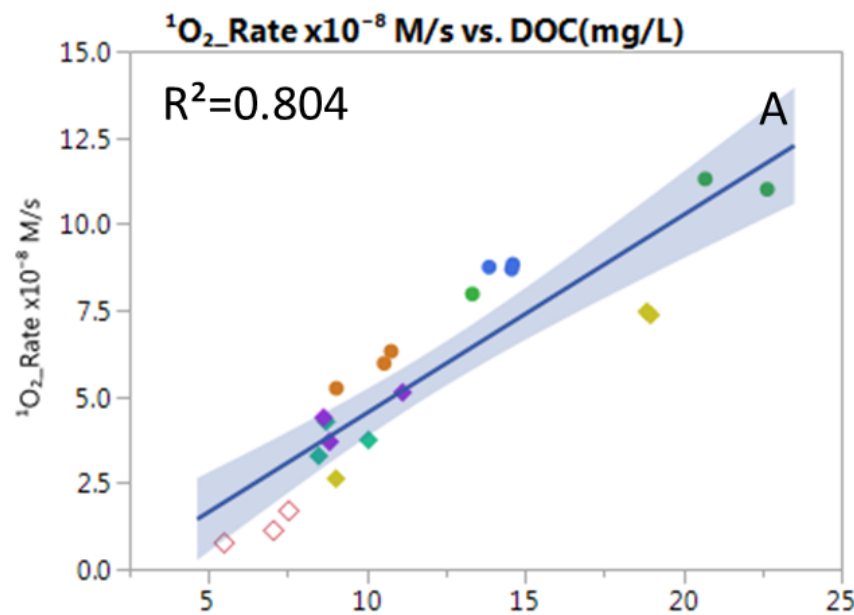

Site

$\checkmark$ FB21

SRS2

SRS4

SRS6

TS2

TS3
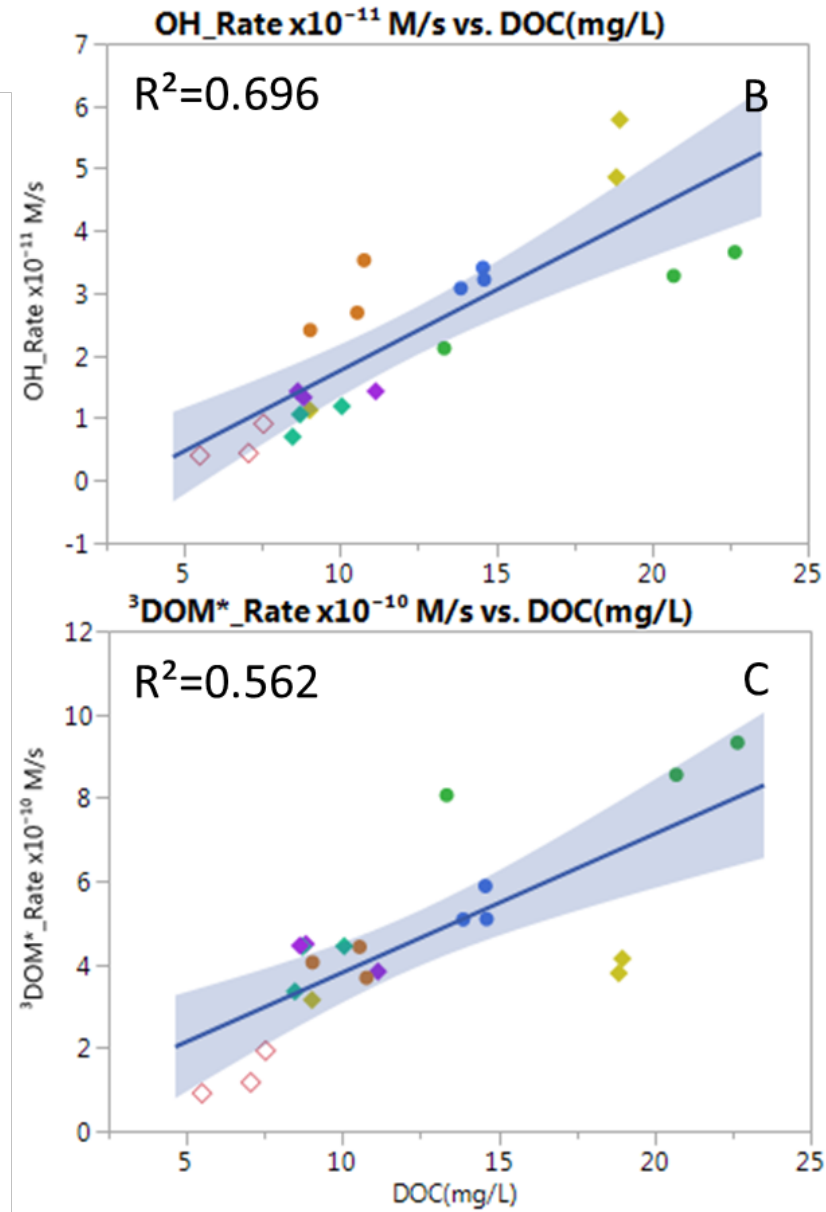

Figure 2-5. Reactive species formation rates versus DOC concentration. Fitting model was linear and the blue region represents the 95\% confidence zone. A) Singlet oxygen; B) Hydroxyl radical; C) Excited triplet state DOM. 


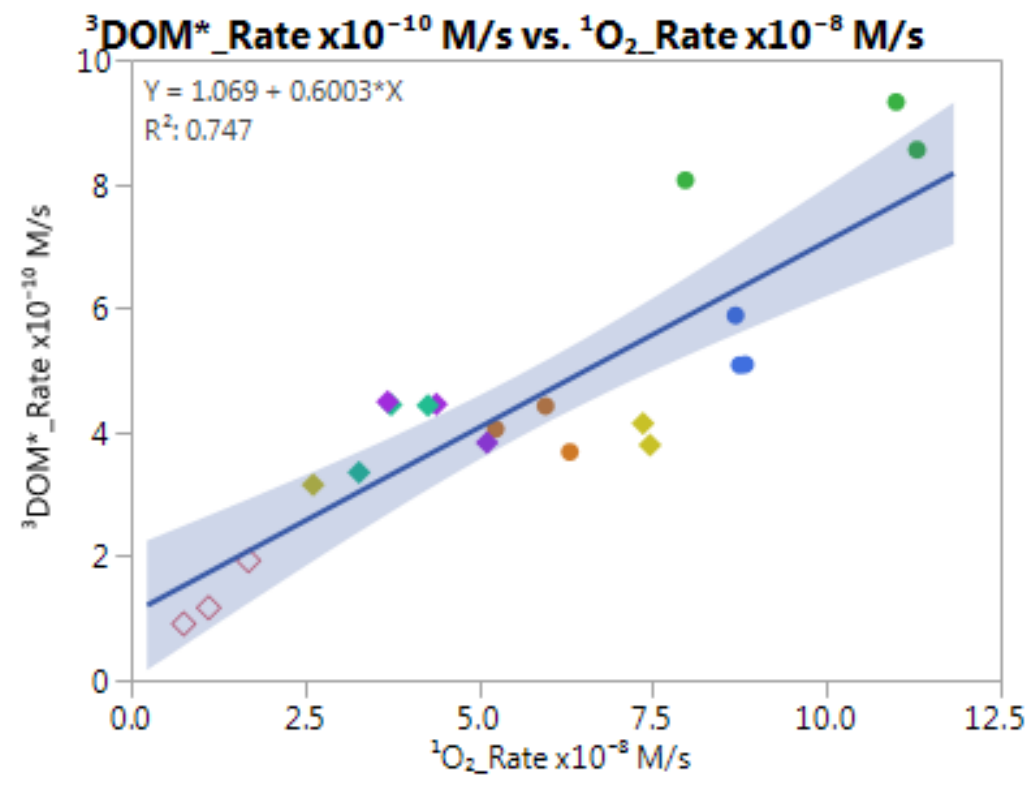

Figure 2-6. Scatter plots showing significant correlation between ${ }^{3} \mathrm{DOM}^{*}$ and ${ }^{1} \mathrm{O}_{2}$ formation rate. $\mathrm{R}^{2}=0.747$. Fitting model was linear and the blue region represents the $95 \%$ confidence zone. 


\section{RS and CDOM (chromophoric dissolved organic matter)}

CDOM is directly related to the light-absorbing fraction of the DOM pool. The more aromatic DOM has a higher absorbance at 254nm (Weishaar et al., 2003). Because of the equipment limitation, the UV absorbance was performed at wavelength $255 \mathrm{~nm}$ instead.

Compared with the RS-DOC correlations shown in the last section (Figure 2-4), use of absorbance coefficient resulted in a better correlation for RS quantum yields with higher $\mathrm{R}^{2}$ values (Figure 2-7) due to the fact that non-light absorbing components from the DOC pool are not considered in CDOM. However, the $\mathrm{a}_{255}$-based correlations still showed a bias for the SRS2 samples. Therefore, SUVA value was calculated to normalize the DOC concentration influence. The SUVA value of SRS2 is similar to the other freshwater marsh sites (TS2 and TS3) which is in agreement with the previous hypothesis that DOM composition is a stronger influence for RS photoproductivity. The SUVA values were observed to be significantly higher for the mangrove sites suggesting highly aromatized DOM contribution from the mangrove environment (Figure 2-8). The correlation between $\mathrm{SUVA}_{255}$ and RS quantum yield showed a better correlation than $\mathrm{a}_{255}$ which indicated that aromaticity of DOM is the dominant variable. In general, mangrove sites had the highest SUVA value and lowest RS quantum yield. The TS7 outlier is from the November sample. 
For RS formation rate, for both $\mathrm{a}_{255}$ and $\mathrm{SUVA}_{255}$ values were compared (Figure 2-9). The $a_{255}$ showed the best correlation which indicated that for RS formation rate, DOM aromaticity by itself is a statistically less significant variable. Combined with the data depicted in Figure 2-5, DOC and CDOM concentration both play important roles in the RS formation. 

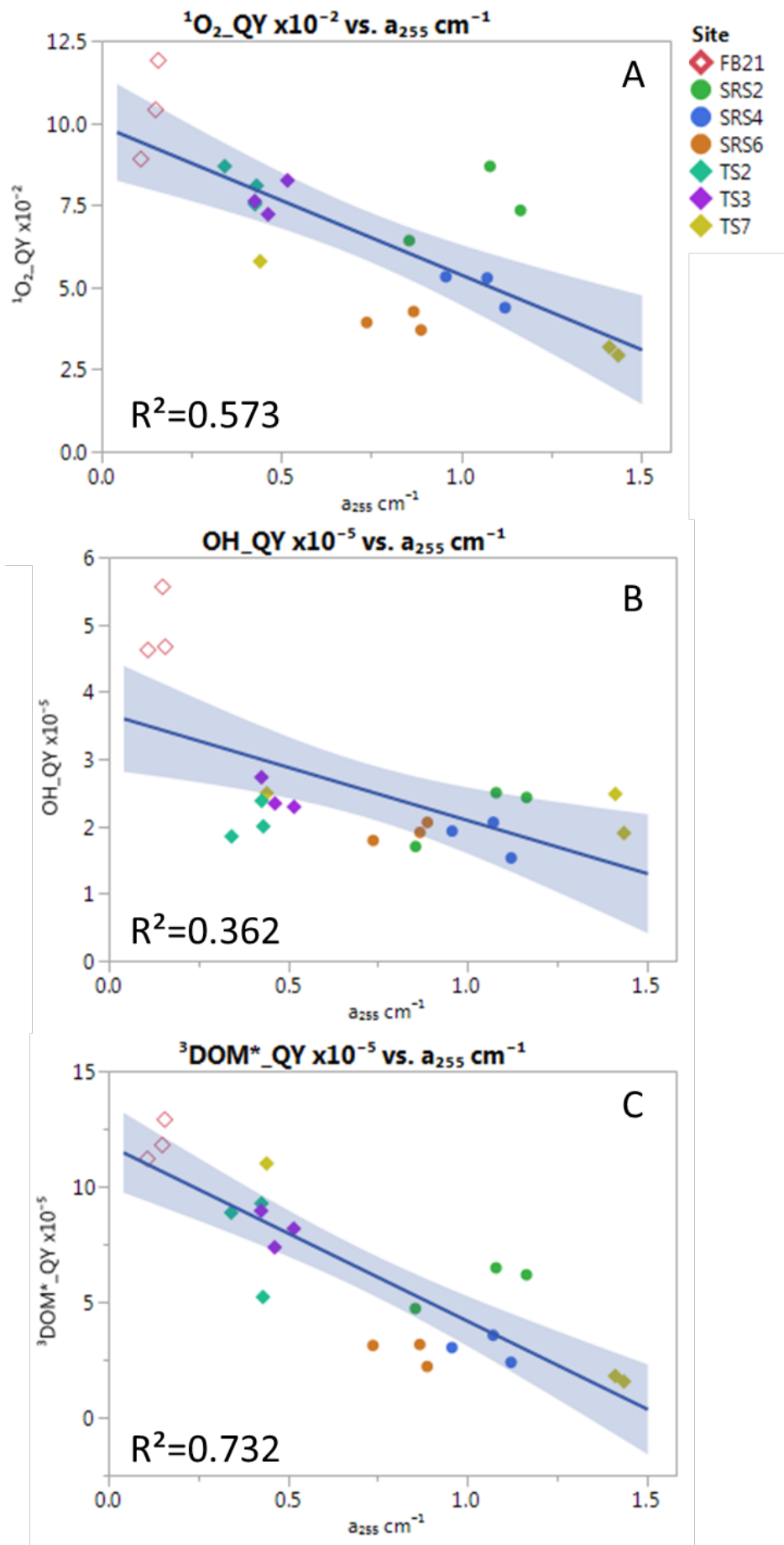

Figure 2-7. Reactive species quantum yields versus absorbance coefficient. Fitting model was linear and the blue region represents the 95\% confidence zone. A) Singlet oxygen; B) Hydroxyl radical; C) Excited triplet state DOM. 

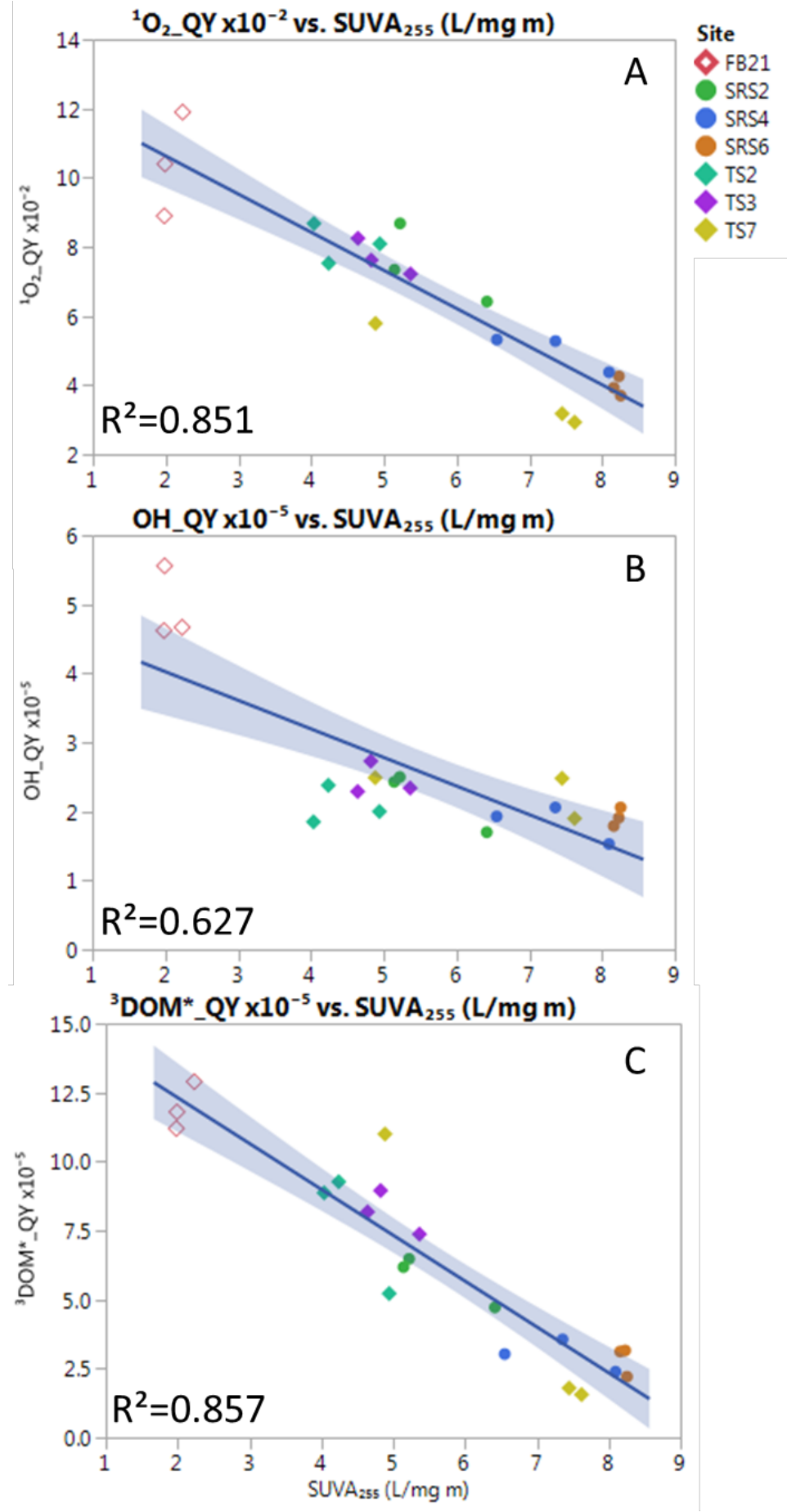

Figure 2-8. Reactive species quantum yields versus SUVA value. Fitting model was linear and the blue region represents the $95 \%$ confidence zone. A) Singlet oxygen; B) Hydroxyl radical; C) Excited triplet state DOM. 

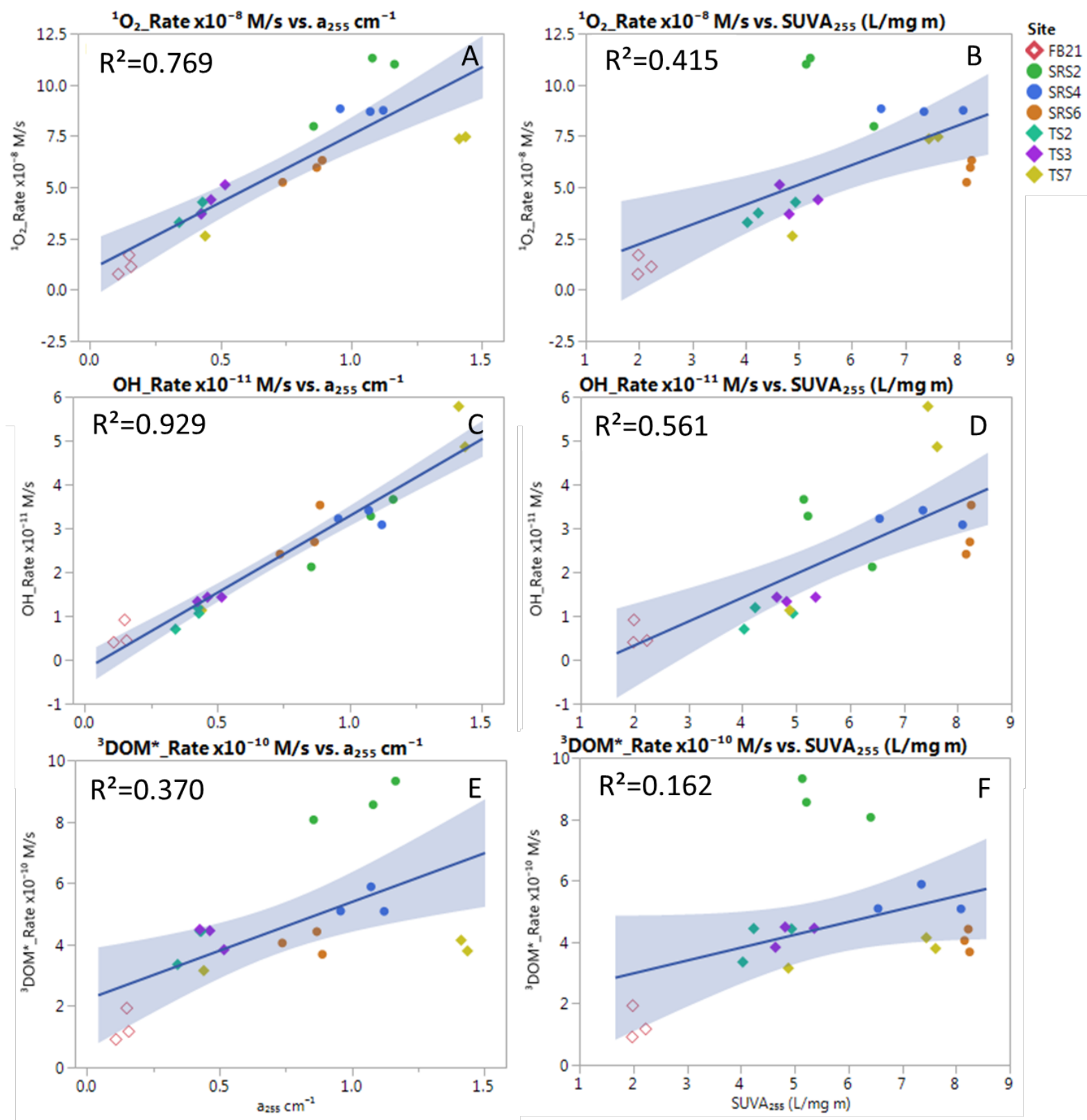

Figure 2-9. Reactive species formation rate versus $\mathrm{a}_{25}$ and SUVA value. Fitting model was linear and the blue region represents the $95 \%$ confidence zone. A) Singlet oxygen formation rate versus $\mathrm{a}_{255}$; B) Singlet oxygen formation rate versus SUVA value; C) Hydroxyl radical formation rate versus $\mathrm{a}_{255}$; D) Hydroxyl radical formation rate versus SUVA value; E) Excited triplet state DOM formation rate versus $\mathrm{a}_{255}$; F) Excited triplet state DOM formation rate versus SUVA value. 


\section{RS and HIX}

In the present study, the relationship between HIX (humification index) value and RS quantum yield was observed (Figure 2-10). Compared with SUVA $_{255}$ which is limited to single wavelength UV absorption, the CDOM was better characterized using fluorescence measurement. HIX is a fluorescence index which assessed the relative degree of humification (Senesi et al., 1991; Zsolnay et al., 1999; Huguet et al., 2009). Higher HIX values corresponded to higher DOM aromaticity (Senesi et al., 1991). ROS quantum yields are linearly and inversely related with the HIX value. In general, mangrove sites had the highest HIX value and lowest ROS quantum yield. This result agrees with the findings using SUVA $_{255}$ value. Previous study using another fluorescence method, PARAFAC analysis, was performed in the same ecosystem and showed a positive correlation between RS formation and terrestrial humic-like DOM abundance (Timko st al., 2014). In the present study, the negative correlation between HIX and RS formation rate agrees with the previous study.

The formation rates of RS are expected to be higher in the estuarine sample than freshwater because of the higher intrinsic absorption of radiation (Housari et al., 2010). The irradiated CDOM is known to be the precursor of RS. Therefore, in the present study, both ${ }^{1} \mathrm{O}_{2}$ and $\bullet \mathrm{OH}$ showed a higher RS formation rate in the estuarine samples as predicted (Figure 2-11 A and C). However, for ${ }^{3} \mathrm{DOM}^{*}$ formation rate, mangrove sites showed lower values than prediction (Figure 2-11 E). Applied DOC normalization, the samples with the highest HIX, namely the Shark River freshwater peat samples and the 
mangrove region samples (estuarine samples), also showed the ${ }^{3} \mathrm{DOM}^{*}$ normalized formation rates were lower than expected from the linear correlation formed by other freshwater marsh DOM samples (Figure 2-11 F). A possible explanation is that DOM molecular weight (MW) affects the RS production. Mangrove DOM has higher aromaticity but a smaller average molecular weight compared with fresh-water marsh DOM which has lower aromaticity but larger molecular weight. Bay DOM has the lowest aromaticity and smallest MW (Chen et al., 2013). Another possible explanation is that the mangrove DOM, which is known to have higher radical scavenging ability, may affect its RS reactivates. These two hypotheses are discussed in the following sections. 


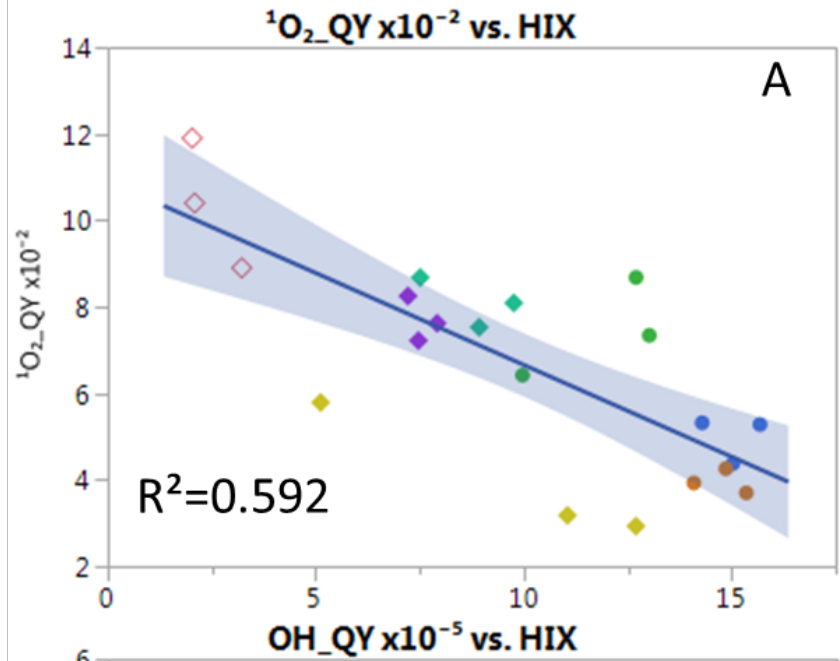

Site

FB21

SRS2

SRSA

SRS6

TS2

TS3

TS7
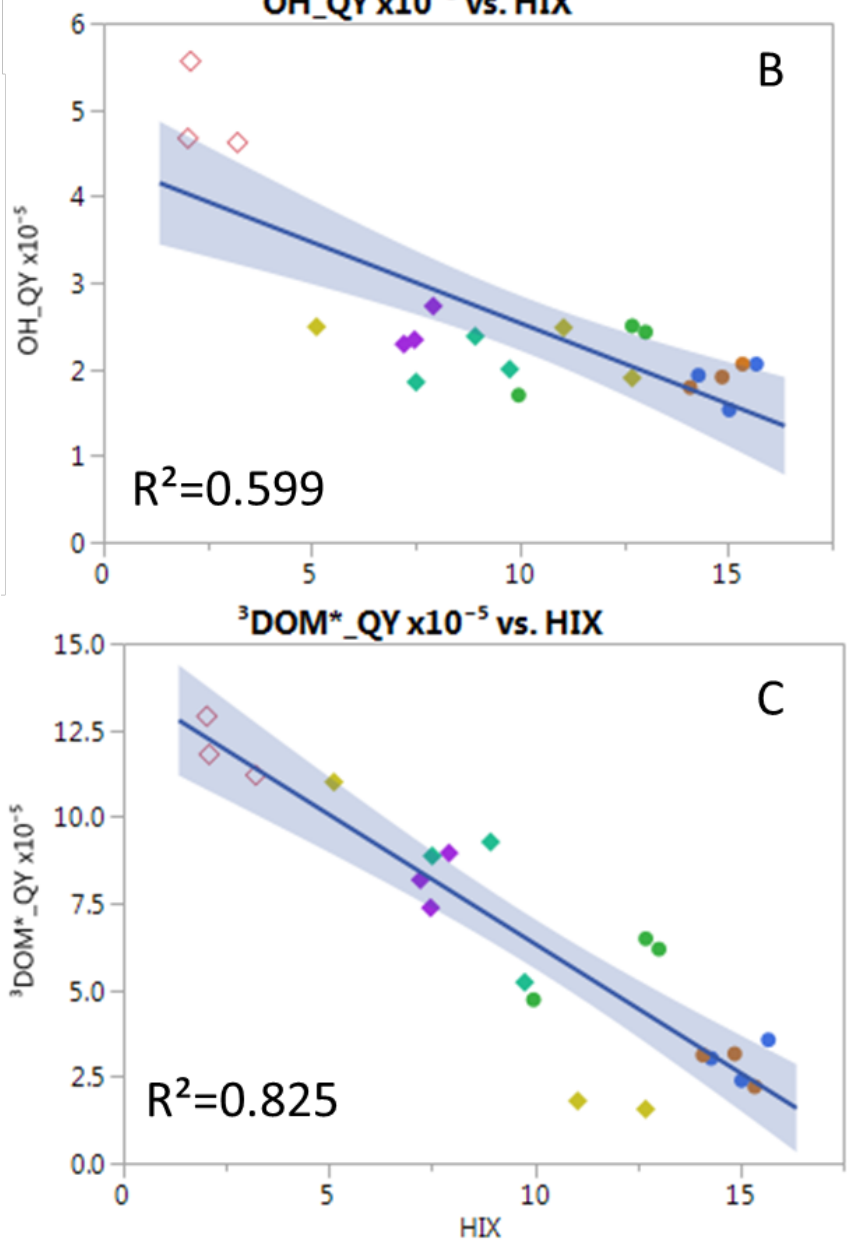

Figure 2-10. Reactive species quantum yields versus HIX value. Fitting model was linear and the blue region represents the 95\% confidence zone. A) Singlet oxygen; B) Hydroxyl radical; C) Excited triplet state DOM. 

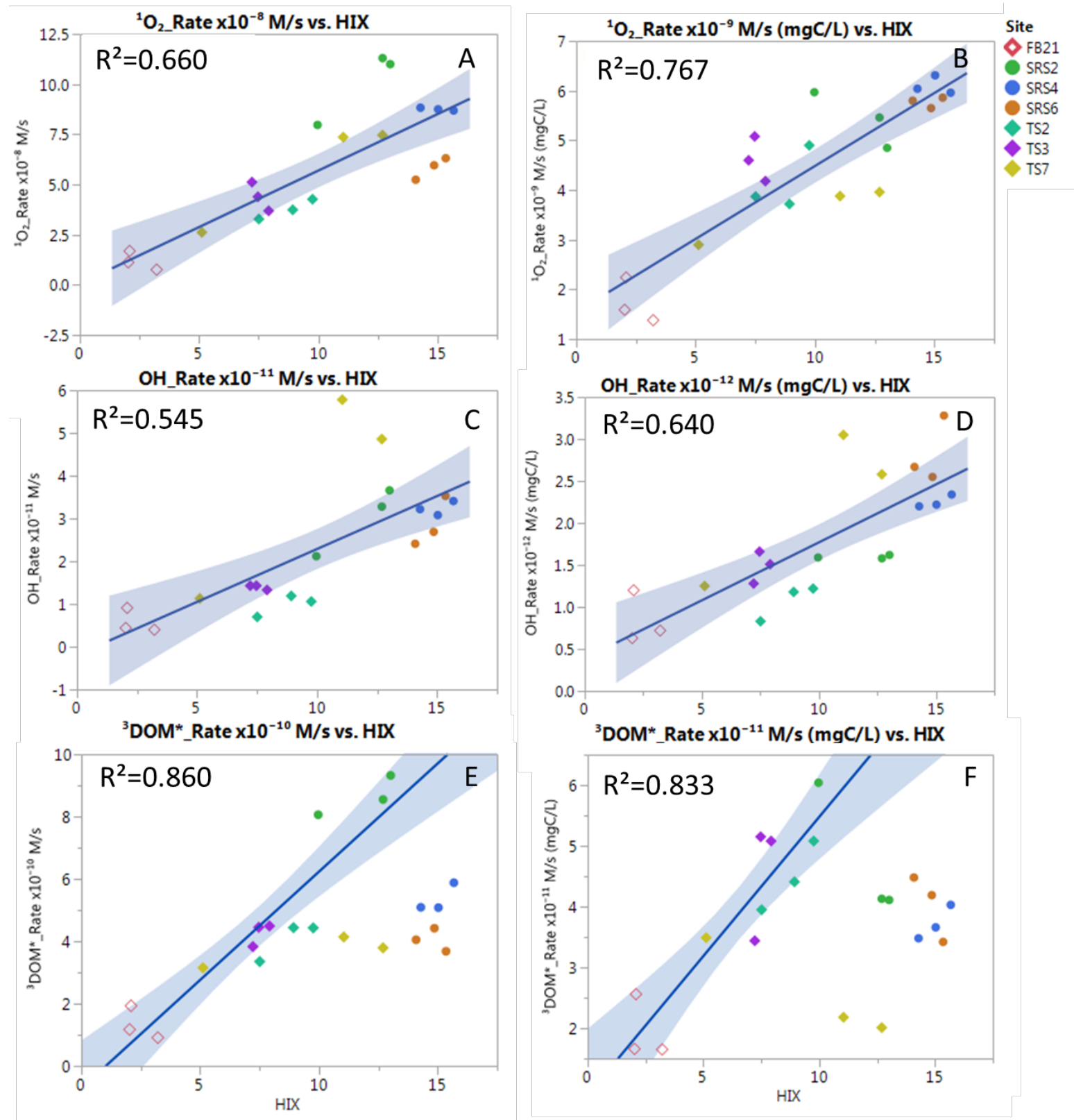

Figure 2-11. Reactive species formation rate and DOC normalized formation rate versus HIX value. Fitting model was linear and the blue region represents the $95 \%$ confidence zone. The linear prediction in $\mathrm{E}$ and $\mathrm{F}$ was formed deprived of mangrove sites samples. Graph A, C, E represented singlet oxygen, hydroxyl radical, and excited triplet state DOM formation rate versus HIX value respectively. B, D, F represented singlet oxygen, hydroxyl radical, excited triplet state DOM normalized formation rate versus HIX value respectively. 


\section{RS and MW (Molecular weight)}

Molecular weight is known to be an important RS predictor. Several studies associated with RS and molecular weights showed that quantum yields are inversely related with MW. (Lee et al., 2013; Mostafa et al., 2014; Cawley et al., 2015). Size fractions of low MW DOM are considered as the best ${ }^{1} \mathrm{O}_{2}$ sensitizers (Cooper et al., 1988).

Both $\mathrm{S}_{\mathrm{R}}$ and E2:E3 were introduced in the methods section and are known as indicators of molecular weight (MW) (Peuravuori et al., 1997; Helms et al., 2008). They are inversely related with the molecular weight of DOM and E2:E3 value also indicates the loss of aromatic groups (Peuravuori et al., 1997). Comparing $\mathrm{S}_{\mathrm{R}}$ and E2:E3 ratio, mangrove DOM has smaller E2:E3 value compared with freshwater marsh DOM but the $\mathrm{S}_{\mathrm{R}}$ value showed an opposite result (Figure 2-12). Slope Ratio in this study was calculated out of slopes of two narrow wavelength intervals, 275-295 nm and 350-400 $\mathrm{nm} . \mathrm{E} 2: \mathrm{E} 3$ is the ratio of a sample's absorbance at $254 \mathrm{~nm}$ to that at $365 \mathrm{~nm}$. Therefore, $\mathrm{S}_{\mathrm{R}}$ contains more optical information and Helms et al. (2008) reported E2:E3 to be a less robust indicator for molecular weight of marine CDOM. The slope ratio pattern in the present study also matches with previous research (Chen et al., 2013). Therefore, a possible explanation is that E2:E3 ratio is not only influenced by molecular weight but also DOM aromaticity. When the quotient E2:E3 increased the aromaticity and molecular size of aquatic humic solutes both decreased (Peuravuori et al., 1997). Therefore, in the present discussion, $S_{R}$ was chosen to be the proxy of molecular weight. Alternatively, E2:E3 ratio was plotted with RS parameters in the appendix (Figure S1 and S2). 
Generally, positive correlations between the slope ratio and the RS quantum yield were observed in the present study (Figure 2-13) from which we conclude that higher MW DOM components are less photoreactive. However, mangrove DOM has lower RS quantum yields than predicted which indicated that MW is not the only control variable for RS photoproduction. Inverse relationships between $\mathrm{S}_{\mathrm{R}}$ and ${ }^{1} \mathrm{O}_{2}$ and ${ }^{3} \mathrm{DOM}{ }^{*}$ formations were observed. The same trend for $\bullet \mathrm{OH}$ appeared after excluded the mangrove sites. However, comparing with Figure 2-5 and Figure 2-9, RS formation rates are more dependent on the DOC and CDOM concentration (Figure 2-14 A, C, E). After DOC normalization, the inverse relationship between the normalized ${ }^{1} \mathrm{O}_{2}$ and ${ }^{3} \mathrm{DOM} *$ formation rate still remains (Figure 2-14 B, F). However, the mangrove DOM has a much higher RS normalized formation rate than other samples. Combined with the information in Figure 2-5 B and Figure 2-9 C and D, DOM composition seems to be a strong influence of $\bullet \mathrm{OH}$ formation. Therefore, the formation of $\bullet \mathrm{OH}$ is more dependent on $\mathrm{DOM}$ composition while the formation of ${ }^{1} \mathrm{O}_{2}$ and ${ }^{3} \mathrm{DOM} *$ are more dependent on DOC concentration or the presence of solution scavengers. 


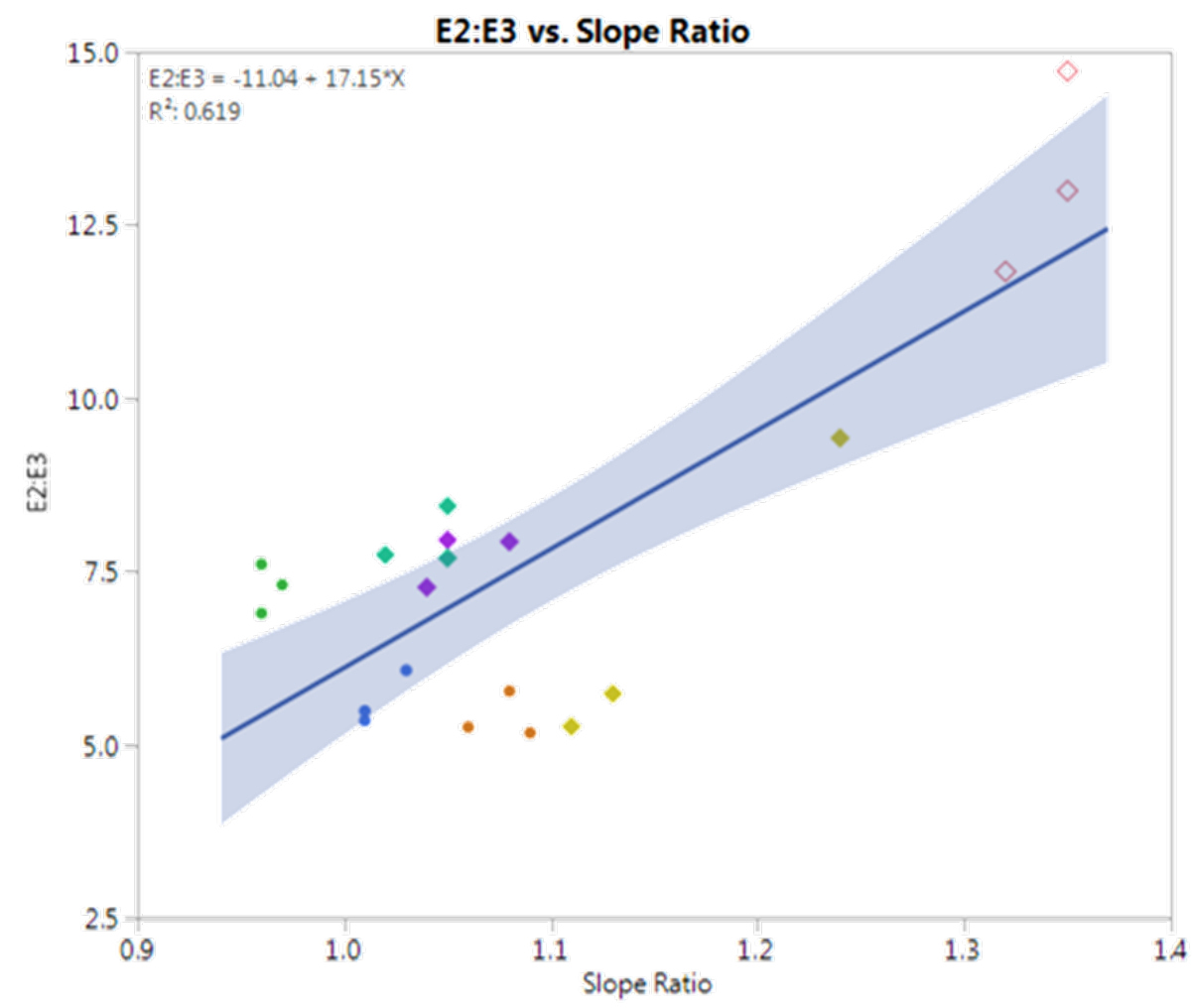

Figure 2-12. Scatter plots showing significant correlation between DOM slope ratio and E2:E3 ratio. $\mathrm{R}^{2}=0.619$. Fitting model was linear and the blue region represents the $95 \%$ confidence zone. 

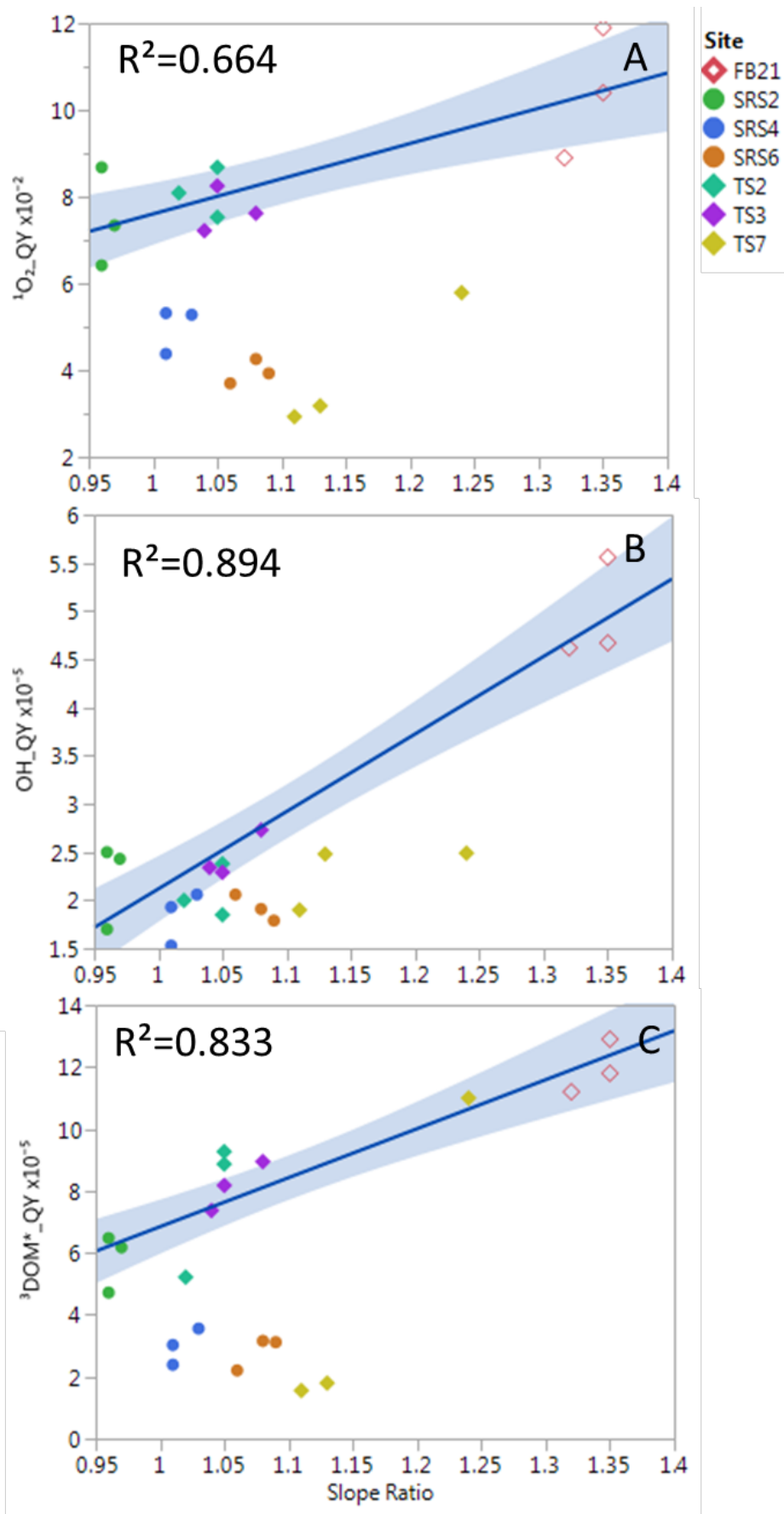

Figure 2-13. Reactive species quantum yields versus slope ratio. The linear predictions were all formed deprived of mangrove sites samples. Fitting model was linear and the blue region represents the 95\% confidence zone. A) Singlet oxygen; B) Hydroxyl radical; C) Excited triplet state DOM. 

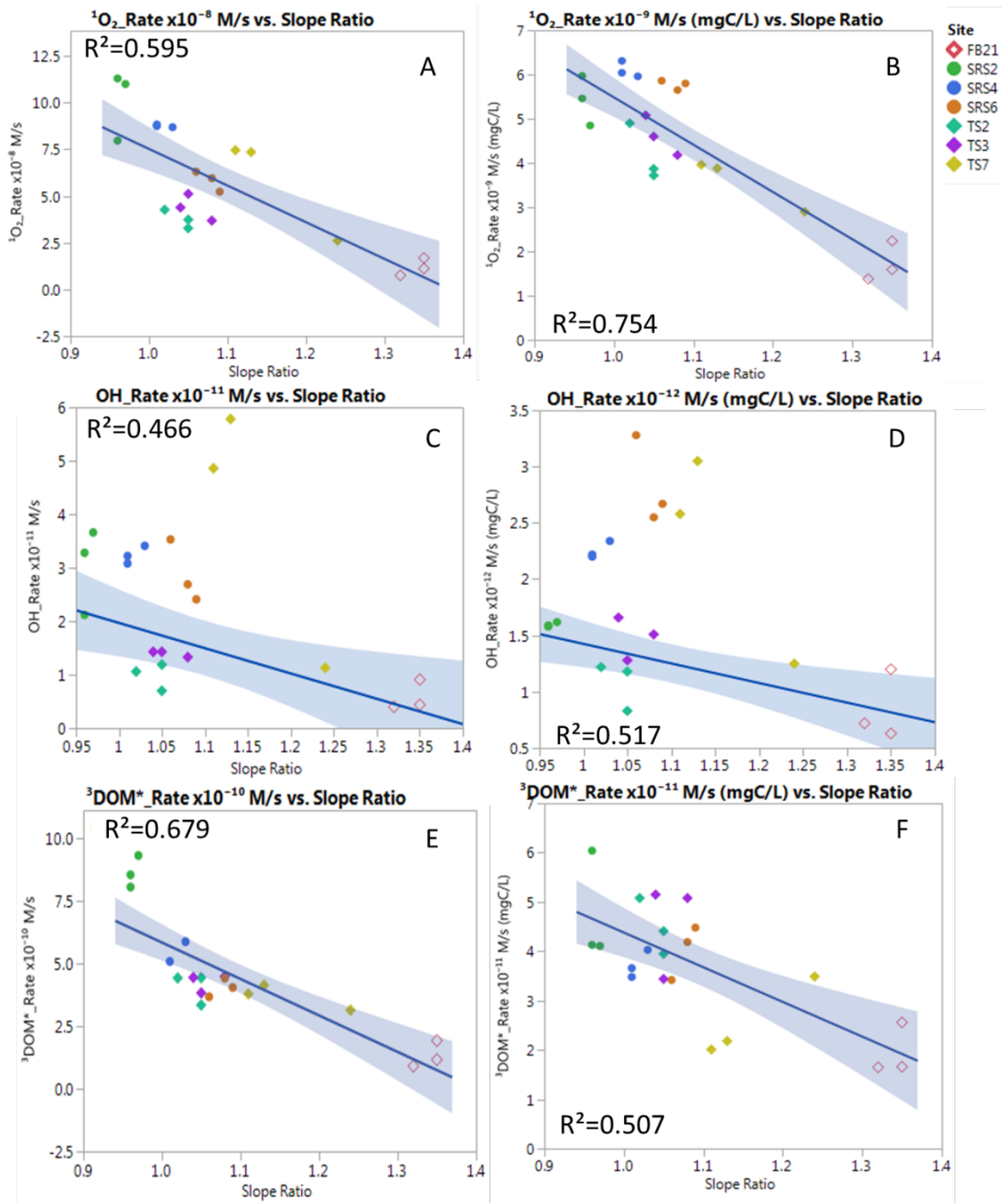

Figure 2-14. Reactive species formation rate and DOC normalized formation rate versus slope ratio. Fitting model was linear and the blue region represents the $95 \%$ confidence zone. The linear prediction in $\mathrm{C}$ and $\mathrm{D}$ was formed deprived of mangrove sites samples. Graph A, C, E represented singlet oxygen, hydroxyl radical, and excited triplet state DOM formation rate versus $\mathrm{S}_{\mathrm{R}}$ value respectively. $\mathrm{B}, \mathrm{D}, \mathrm{F}$ represented singlet oxygen, hydroxyl radical, excited triplet state DOM normalized formation rate versus $S_{R}$ value respectively. 
RS and redox potential (IP100)

As discussed in the previous section, the radical scavenging ability of DOM may affect RS production (Cory et al., 2009; Wenk et al., 2012; Page et al., 2014). The IP100 is an indicator of DOM free radical scavenging capacity. Comparing RS quantum yields and IP100 showed an inverse correlation between IP100 and ${ }^{1} \mathrm{O}_{2}$ and ${ }^{3} \mathrm{DOM}^{*}$ quantum yield (Figure 2-15 A and C). The inverse relationship indicates that higher radical scavenging ability inhibits RS production which agreed with previous research about the inhibition of excited triplet-induced transformation by phenolic compounds with antioxidant character (Wenk et al., 2012).

A possible explanation for the negative correlation between ${ }^{1} \mathrm{O}_{2}$ and ${ }^{3} \mathrm{DOM}^{*}$ quantum yield with IP100 is that the DOM which features the higher IP100 (free radical scavenging capacity) may have quench the ${ }^{1} \mathrm{O}_{2}$ in its microenvironment and lead to a lower ROS apparent quantum yield (Latch et al., 2006). Another possible explanation is that the DOC from methanol extract used in the IP100 method is different from the aqueous DOM. To answer this question, RS measurements using the DOC from methanol extract were performed in order to evaluate potential differences after SPE. Samples were prepared from the antioxidant activity measurement methanol DOM extract. An aliquot (3 ml) of each methanol DOM extract was dried with $\mathrm{N}_{2}$ gas and was also subject to vacuum in a freeze dryer for $2 \mathrm{~h}$ to ensure the complete dryness of the samples. Once dried, all the samples were re-dissolved with 40ml Milli-Q water. All the extracts presented a neutral $\mathrm{pH}(\mathrm{pH}=7)$ after methanol evaporation and re-dissolution in Milli-Q 
water. The results showed no significant difference between SPE-DOM and NDOM (Table S2 and S3). Therefore, the RS production profile seems indeed dependent on the presence of free radical scavenging activity of the DOM. Moreover, the SPE-DOM does not contain halides or other ionic ions and proved that halides or ionic strength influence on RS in this study were minor.

Comparing RS formation and IP100, no clear trend was observed except for the -OH normalized formation rate (Figure 2-16 D). SRS2 samples showed similar radical scavenging capacity as other freshwater marsh samples indicated that its normalized formation rate is mainly affected by molecular weight instead of radical scavenging ability. In general, samples from mangrove sites have high RS formation rate and DOC normalized formation rate. However, $\bullet \mathrm{OH}$ quantum yield is independent of IP100 (Figure 2-15 B).Therefore, in the natural aquatic environment, RS formation rates increased as DOC concentration increased which showed that the main role DOM plays is as a photosensitizer instead of a quencher. However, RS quantum yield would be affected by DOC composition and its redox potential. Thus, in the DOM microenvironment, DOM self-quenching for high aromatic compounds is a possible mechanism and needs additional research. 

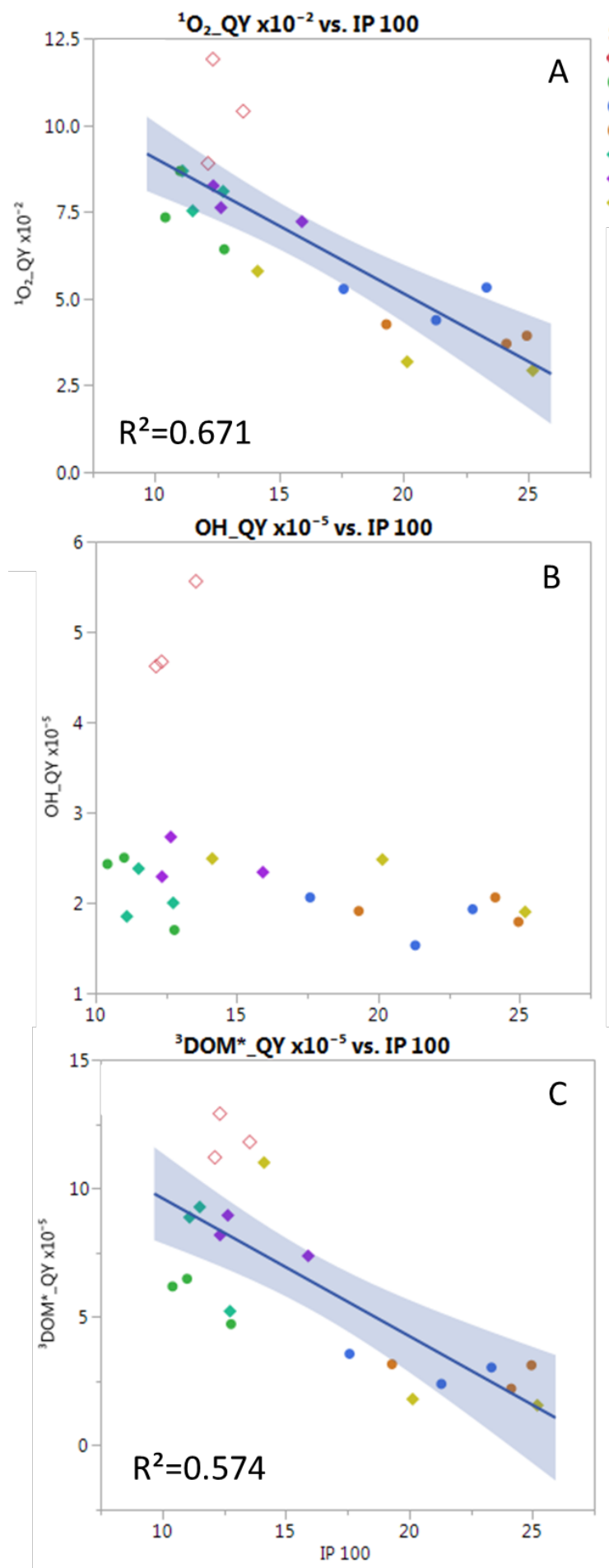

Figure 2-15. Reactive species quantum yields versus IP100. Fitting model was linear and the blue region represents the $95 \%$ confidence zone. A) Singlet oxygen; B) Hydroxyl radical; C) Excited triplet state DOM. 

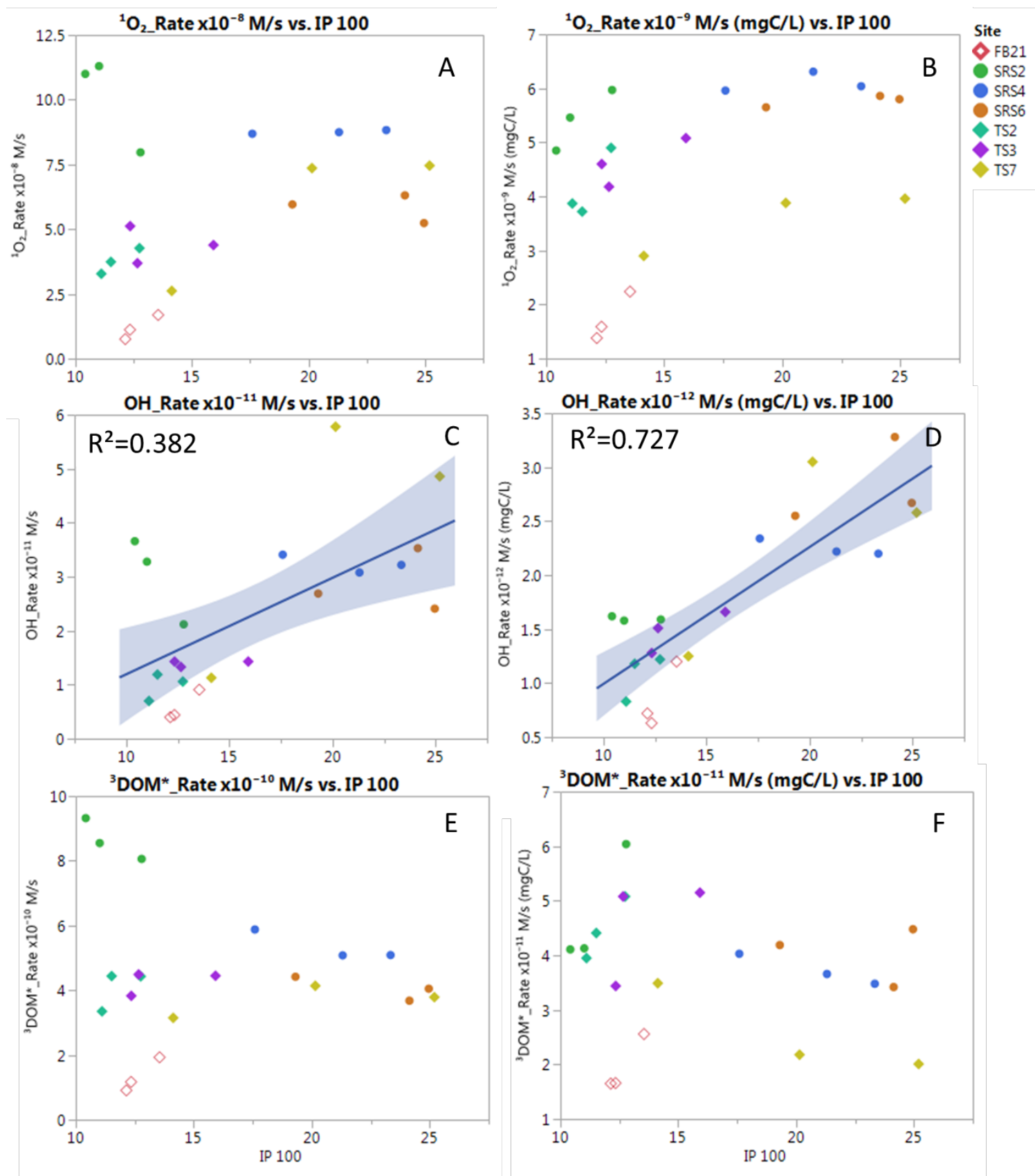

Figure 2-16. Reactive species formation rate and DOC normalized formation rate versus IP100. Graph A, C, E represented singlet oxygen, hydroxyl radical, and excited triplet state DOM formation rate versus HIX value respectively. B, D, F represented singlet oxygen, hydroxyl radical, excited triplet state DOM normalized formation rate versus HIX value respectively. The blue line in graph $\mathrm{C}$ and $\mathrm{D}$ is the linear fit and the blue shade is its $95 \%$ confidence zone. 


\section{Conclusion}

Quantum yield, formation rate and DOC normalized formation rate of singlet oxygen, triplet excited-state DOM and hydroxyl radical were determined in different subenvironments of the Florida Everglades. RS quantum yields were directly related to CDOM, SUVA, HIX, MW and IP100, and were clearly driven by the aromaticity of DOM which correlated with the relative abundance of humic-like DOM components. RS formation rates were directly related to DOC concentration, SUVA, HIX and molecular weight but were clearly driven by the DOC concentration. DOC concentration normalized RS formation rates showed more influence from HIX and molecular weight which related with DOM composition.

For singlet oxygen quantum yield, stronger correlations were observed with SUVA $\left(\mathrm{R}^{2}=0.85\right)$, and IP100 $\left(\mathrm{R}^{2}=0.67\right)$. Therefore, DOM with high aromaticity and high radical scavenging ability, the mangrove DOM, have low singlet oxygen quantum yield. The triplet excited-state DOM which is a precursor of singlet oxygen followed a similar trend for its quantum yield. Hydroxyl radical quantum yield showed the highest linear relation with $\mathrm{E} 2$ : $\mathrm{E} 3$ value $\left(\mathrm{R}^{2}=0.80\right)$ which indicated that molecular weight is the best proxy for $\bullet \mathrm{OH}$ production.

This study also proved that in the natural aquatic environment, although selfquenching for high aromatic compounds is a possible mechanism, DOM in general is a photosensitizer controlled by DOC or CDOM concentration instead of a quencher because the DOM formation rate has a more robust relation with DOC or CDOM 
concentration than with RS quantum yields. Moreover, halides or ionic strength have a minor influence on RS in the Everglades.

\section{References}

Aranami, Kazushi, and James W. Readman. 'Photolytic Degradation of Triclosan in Freshwater and Seawater.' Chemosphere 66, no. 6 (January 2007): 1052-56.

Balakrishnan, I., and Mummadi P. Reddy. 'Mechanism of Reaction of Hydroxyl Radicals with Benzene in the gamma. Radiolysis of the Aerated Aqueous Benzene System.' The Journal of Physical Chemistry 74, no. 4 (February 1, 1970): 850-55.

Brand-Williams, W., M. E. Cuvelier, and C. Berset. 'Use of a Free Radical Method to Evaluate Antioxidant Activity.' LWT - Food Science and Technology 28, no. 1 (1995): $25-30$.

Campbell, Sonia, Michael D David, Lee Ann Woodward, and Qing X Li. 'Persistence of Carbofuran in Marine Sand and Water.' Chemosphere 54, no. 8 (February 2004): 115561.

Canonica, Silvio, Bruno Hellrung, Pavel Müller, and Jakob Wirz. 'Aqueous Oxidation of Phenylurea Herbicides by Triplet Aromatic Ketones.' Environmental Science \& Technology 40, no. 21 (November 1, 2006): 6636-41.

Cawley, Kaelin M., J. Alexandra Hakala, and Yu-Ping Chin. 'Evaluating the Triplet State Photoreactivity of Dissolved Organic Matter Isolated by Chromatography and Ultrafiltration Using an Alkylphenol Probe Molecule.' Limnology and Oceanography: Methods 7, no. 6 (June 1, 2009): 391-98.

Cawley, Kaelin M., Julie A. Korak, and Fernando L. Rosario-Ortiz. 'Quantum Yields for the Formation of Reactive Intermediates from Dissolved Organic Matter Samples from the Suwannee River.' Environmental Engineering Science 32, no. 1 (October 31, 2014): 31-37.

Chambers, Randolph M., and Kristin A. Pederson. 'Variation in Soil Phosphorus, Sulfur, and Iron Pools among South Florida Wetlands.' Hydrobiologia 569, no. 1 (October 2006): $63-70$.

Chen, Meilian, Nagamitsu Maie, Kathleen Parish, and Rudolf Jaffé. 'Spatial and Temporal Variability of Dissolved Organic Matter Quantity and Composition in an Oligotrophic Subtropical Coastal Wetland.' Biogeochemistry 115, no. 1-3 (February 5, 2013): 167-83. 
Childers, D. L., Boyer, J. N., Davis, S. E., Madden, C. J., Rudnick, D. T., \& Sklar, F. H. (2006). Relating precipitation and water management to nutrient concentrations in the oligotrophic' upside-down' estuaries of the Florida Everglades. Limnology and Oceanography, 51(1), 602-616.

Coble, P. G., Green, S. A., Blough, N. V., \& Gagosian, R. B. (1990). Characterization of dissolved organic matter in the Black Sea by fluorescence spectroscopy.

Cooper. W. J., Zika. R. G., Petasne. R. G. and Fischer. A. M., in Influence of Aquatic Humic Substances on Fate and Treatment of Pollutants, ed. Suffet I H, MacCarthy P., American Chemical Society, 1989, pp. 333-362.

Cory, Rose M., James B. Cotner, and Kristopher McNeill. 'Quantifying Interactions between Singlet Oxygen and Aquatic Fulvic Acids.' Environmental Science \& Technology 43, no. 3 (February 1, 2009): 718-23.

Cory, R. M., K. H. Harrold, B. T. Neilson, and G. W. Kling. 'Controls on Dissolved Organic Matter (DOM) Degradation in a Headwater Stream: The Influence of Photochemical and Hydrological Conditions in Determining Light-Limitation or Substrate-Limitation of Photo-Degradation.' Biogeosciences 12, no. 22 (2015): 6669-85.

Davis, Stephen, Daniel Childers, John Day, David Rudnick, and Fred Sklar. 'Factors Affecting the Concentration and Flux of Materials in Two Southern Everglades Mangrove Wetlands.' Marine Ecology Progress Series, January 1, 2003. http://digitalcommons.fiu.edu/fce_lter_journal_articles/61.

De Laurentiis, Elisa, Sandro Buoso, Valter Maurino, Claudio Minero, and Davide Vione. 'Optical and Photochemical Characterization of Chromophoric Dissolved Organic Matter from Lakes in Terra Nova Bay, Antarctica. Evidence of Considerable Photoreactivity in an Extreme Environment.' Environmental Science \& Technology 47, no. 24 (December 17, 2013): 14089-98.

Dittmar, Thorsten, Boris Koch, Norbert Hertkorn, and Gerhard Kattner. 'A Simple and Efficient Method for the Solid-Phase Extraction of Dissolved Organic Matter (SPE-DOM) from Seawater.' Limnology and Oceanography: Methods 6, no. 6 (June 1, 2008): 230-35.

Dong, Mei Mei, Stephen P. Mezyk, and Fernando L. Rosario-Ortiz. 'Reactivity of Effluent Organic Matter (EfOM) with Hydroxyl Radical as a Function of Molecular Weight.' Environmental Science \& Technology 44, no. 15 (August 1, 2010): 5714-20.

Dong, Mei Mei, and Fernando L. Rosario-Ortiz. 'Photochemical Formation of Hydroxyl Radical from Effluent Organic Matter.' Environmental Science \& Technology 46, no. 7 (April 3, 2012): 3788-94. 
Fourqurean, J. W., Jones, R. D., \& Zieman, J. C. (1993). Process influencing water column nutrient characteristics and phosphorus limitation of phytoplankton biomass in Florida Bay, FL, USA: inferences from spatial distributions. Estuarine, Coastal and Shelf Science, 36(3), 295-314.

Friedman, Mendel, and Hella S. Jürgens. 'Effect of $\mathrm{pH}$ on the stability of plant phenolic compounds.' Journal of Agricultural and Food Chemistry 48.6 (2000): 2101-2110.

Fukushima, Masami, Kenji Tatsumi, and Seiya Nagao. 'Degradation Characteristics of Humic Acid during Photo-Fenton Processes.' Environmental Science \& Technology 35, no. 18 (September 1, 2001): 3683-90.

Glover, Caitlin M., and Fernando L. Rosario-Ortiz. 'Impact of Halides on the Photoproduction of Reactive Intermediates from Organic Matter.' Environmental Science \& Technology 47, no. 24 (December 17, 2013): 13949-56.

Gosselink, J. G., \& Turner, R. E. (1978). role of hydrology in freshwater wetland ecosystems. Freshwater wetlands.

Haag, Werner R., Jürg Hoigne', Ernst Gassman, and Andre'M. Braun. 'Singlet Oxygen in Surface Waters - Part I: Furfuryl Alcohol as a Trapping Agent.' Chemosphere 13, no. 5 (January 1, 1984a): 631-40.

Haag, Werner R., Ju“rg Hoigne', Ernst Gassman, and Andre'M. Braun. 'Singlet Oxygen in Surface Waters - Part II: Quantum Yields of Its Production by Some Natural Humic Materials as a Function of Wavelength.' Chemosphere 13, no. 5 (January 1, 1984b): 64150 .

Halliwell, B. 'How to Characterize a Biological Antioxidant.' Free Radical Research Communications 9, no. 1 (1990): 1-32.

Helms, John R., Aron Stubbins, Jason D. Ritchie, Elizabeth C. Minor, David J. Kieber, and Kenneth Mopper. 'Absorption Spectral Slopes and Slope Ratios as Indicators of Molecular Weight, Source, and Photobleaching of Chromophoric Dissolved Organic Matter.' Limnology and Oceanography 53, no. 3 (May 1, 2008): 955-69.

Huang, Dejian, Boxin Ou, and Ronald L. Prior. 'The Chemistry behind Radical scavenging ability Assays.' Journal of Agricultural and Food Chemistry 53, no. 6 (March 1, 2005): 1841-56.

Huguet, A., L. Vacher, S. Relexans, S. Saubusse, J. M. Froidefond, and E. Parlanti. 'Properties of Fluorescent Dissolved Organic Matter in the Gironde Estuary.' Organic Geochemistry 40, no. 6 (June 2009): 706-19. 
Housari, Fadi al, Davide Vione, Serge Chiron, and Stéphane Barbati. 'Reactive Photoinduced Species in Estuarine Waters. Characterization of Hydroxyl Radical, Singlet Oxygen and Dissolved Organic Matter Triplet State in Natural Oxidation Processes.' Photochemical \& Photobiological Sciences 9, no. 1 (January 1, 2010): 78-86.

Jaffe, Rudolf, Childers, Daniel, Boyer, Joseph, Fourqurean, James, and Trexler, Joel. 'Final Report for NSF Award \#9910514 (2000-2006).' Florida Coastal Everglades Long Term Ecological Research Florida International University, August 2007. http://dpanther.fiu.edu/dpService/dpPurlService/purl/FI14042504/00001.

Janssen, Elisabeth M.-L., Paul R. Erickson, and Kristopher McNeill. 'Dual Roles of Dissolved Organic Matter as Sensitizer and Quencher in the Photooxidation of Tryptophan.' Environmental Science \& Technology 48, no. 9 (May 6, 2014): 4916-24.

Ji, Yuefei, Chao Zeng, Corinne Ferronato, Jean-Marc Chovelon, and Xi Yang. 'NitrateInduced Photodegradation of Atenolol in Aqueous Solution: Kinetics, Toxicity and Degradation Pathways.' Chemosphere 88, no. 5 (July 2012): 644-49.

Jürg Hoigné, Bruce C. Faust, Werner R. Haag, Frank E. Scully, and Richard G. Zepp. 'Aquatic Humic Substances as Sources and Sinks of Photochemically Produced Transient Reactants.' In Aquatic Humic Substances, 219:363-81. Advances in Chemistry 219. American Chemical Society, 1988.

Larsen, Laurel G., George R. Aiken, Judson W. Harvey, Gregory B. Noe, and John P. Crimaldi. 'Using Fluorescence Spectroscopy to Trace Seasonal DOM Dynamics, Disturbance Effects, and Hydrologic Transport in the Florida Everglades.' Journal of Geophysical Research: Biogeosciences 115, no. G3 (September 1, 2010): G03001.

Latch, Douglas E., and Kristopher McNeill. 'Microheterogeneity of Singlet Oxygen Distributions in Irradiated Humic Acid Solutions.' Science 311, no. 5768 (March 24, 2006): 1743-47.

Lee, Eunkyung, Caitlin M. Glover, and Fernando L. Rosario-Ortiz. 'Photochemical Formation of Hydroxyl Radical from Effluent Organic Matter: Role of Composition.' Environmental Science \& Technology 47, no. 21 (November 5, 2013): 12073-80.

Mack, John, and James R. Bolton. 'Photochemistry of Nitrite and Nitrate in Aqueous Solution: A Review.' Journal of Photochemistry and Photobiology A: Chemistry 128, no. 1-3 (November 1999): 1-13.

Maie, Nagamitsu, Chengyong Yang, Toshikazu Miyoshi, Kathleen Parish, and Rudolf Jaffé. 'Chemical Characteristics of Dissolved Organic Matter in an Oligotrophic Subtropical Wetland/estuarine.' Limnology and Oceanography 50, no. 1 (January 1, 2005): 23-35. 
Maie, Nagamitsu, Rudolf Jaffé, Toshikazu Miyoshi, and Daniel L. Childers. 'Quantitative and Qualitative Aspects of Dissolved Organic Carbon Leached from Senescent Plants in an Oligotrophic Wetland.' Biogeochemistry 78, no. 3 (May 2006): 285-314.

doi:10.1007/s10533-005-4329-6.

Mopper, Kenneth, and Xianliang Zhou. 'Hydroxyl Radical Photoproduction in the Sea and Its Potential Impact on Marine Processes.' Science 250, no. 4981 (November 2, 1990): 661-64.

Mopper, Kenneth, and Christopher A. Schultz. 'Fluorescence as a Possible Tool for Studying the Nature and Water Column Distribution of DOC Components.' Marine Chemistry, Measurement of Dissolved Organic Carbon and Nitrogen in Natural Waters, 41, no. 1-3 (January 1993): 229-38. doi:10.1016/0304-4203(93)90124-7.

Mostafa, Simón, and Fernando L. Rosario-Ortiz. 'Singlet Oxygen Formation from Wastewater Organic Matter.' Environmental Science \& Technology 47, no. 15 (August 6, 2013): 8179-86.

Mostafa, Simón, Julie A. Korak, Kyle Shimabuku, Caitlin M. Glover, and Fernando L. Rosario-Ortiz. 'Relation between Optical Properties and Formation of Reactive Intermediates from Different Size Fractions of Organic Matter.' In Advances in the Physicochemical Characterization of Dissolved Organic Matter: Impact on Natural and Engineered Systems, 1160:159-79. ACS Symposium Series 1160. American Chemical Society, 2014.

Page, Sarah E., J. Robert Logan, Rose M. Cory, and Kristopher McNeill. 'Evidence for Dissolved Organic Matter as the Primary Source and Sink of Photochemically Produced Hydroxyl Radical in Arctic Surface Waters.' Environmental Science. Processes \& Impacts 16, no. 4 (April 2014): 807-22.

Parker, Kimberly M., Joseph J. Pignatello, and William A. Mitch. 'Influence of Ionic Strength on Triplet-State Natural Organic Matter Loss by Energy Transfer and Electron Transfer Pathways.' Environmental Science \& Technology 47, no. 19 (October 1, 2013): 10987-94. doi:10.1021/es401900j.

Riley, J. P., \& Chester, R. (1971). Introduction to marine chemistry.

Vaughan, Pamela P., and Neil V. Blough. 'Photochemical Formation of Hydroxyl Radical by Constituents of Natural Waters.' Environmental Science \& Technology 32, no. 19 (October 1, 1998): 2947-53.

Voelker, Bettina M., François M. M. Morel, and Barbara Sulzberger. 'Iron Redox Cycling in Surface Waters: Effects of Humic Substances and Light.' Environmental Science \& Technology 31, no. 4 (April 1, 1997): 1004-11. 
Peuravuori, Juhani, and Kalevi Pihlaja. 'Molecular Size Distribution and Spectroscopic Properties of Aquatic Humic Substances.' Analytica Chimica Acta 337, no. 2 (January 20, 1997): 133-49.

Rice-Evans, C. A., N. J. Miller, and G. Paganga. 'Structure-Antioxidant Activity Relationships of Flavonoids and Phenolic Acids.' Free Radical Biology \& Medicine 20, no. 7 (1996): 933-56.

Romera-Castillo, Cristina, and Rudolf Jaffé. 'Free Radical Scavenging (antioxidant Activity) of Natural Dissolved Organic Matter.' Marine Chemistry 177, Part 4 (December 20, 2015): 668-76.

Senesi, N., T. M. Miano, M. R. Provenzano, and G. Brunetti. 'Characterization, Differentiation, and Classification of Humic Substances by Fluorescence Spectroscopy.' Soil Science (USA), 1991.

Takeda, Kazuhiko, Hiroshi Takedoi, Shuhei Yamaji, Keiichi Ohta, and Hiroshi Sakugawa. 'Determination of Hydroxyl Radical Photoproduction Rates in Natural Waters.' Analytical Sciences 20, no. 1 (2004): 153-58.

Timko, Stephen A., Cristina Romera-Castillo, Rudolf Jaffé, and William J. Cooper. 'Photo-Reactivity of Natural Dissolved Organic Matter from Fresh to Marine Waters in the Florida Everglades, USA.' Environmental Science: Processes \& Impacts 16, no. 4 (March 27, 2014): 866-78.

Turro, Nicholas J., V. Ramamurthy, and Juan C. Scaiano. Principles of Molecular Photochemistry: An Introduction. University Science Books, 2009.

Vione, Davide, Gianpaolo Falletti, Valter Maurino, Claudio Minero, Ezio Pelizzetti, Mery Malandrino, Roberto Ajassa, Romeo-Iulian Olariu, and Cecilia Arsene. 'Sources and Sinks of Hydroxyl Radicals upon Irradiation of Natural Water Samples.' Environmental Science \& Technology 40, no. 12 (June 1, 2006): 3775-81.

Warneck, Peter, and Christa Wurzinger. 'Product Quantum Yields for the 305-Nm Photodecomposition of Nitrate in Aqueous Solution.' The Journal of Physical Chemistry 92, no. 22 (November 1, 1988): 6278-83.

Wei, Shu-Dong, Hai-Chao Zhou, and Yi-Ming Lin. 'Antioxidant Activities of Extract and Fractions from the Hypocotyls of the Mangrove Plant Kandelia Candel.' International Journal of Molecular Sciences 11, no. 10 (October 21, 2010): 4080-93.

Weishaar, James L., George R. Aiken, Brian A. Bergamaschi, Miranda S. Fram, Roger Fujii, and Kenneth Mopper. 'Evaluation of Specific Ultraviolet Absorbance as an Indicator of the Chemical Composition and Reactivity of Dissolved Organic Carbon.' Environmental Science \& Technology 37, no. 20 (October 15, 2003): 4702-8. 
Wenk, Jannis, and Silvio Canonica. 'Phenolic Antioxidants Inhibit the Triplet-Induced Transformation of Anilines and Sulfonamide Antibiotics in Aqueous Solution.'

Environmental Science \& Technology 46, no. 10 (May 15, 2012): 5455-62.

William J. Cooper, Rod G. Zika, Robert G. Petasne, and Anne M. Fischer. 'SunlightInduced Photochemistry of Humic Substances in Natural Waters: Major Reactive Species.' In Aquatic Humic Substances, 219:333-62. Advances in Chemistry 219. American Chemical Society, 1988.

Zepp, Richard G., N. Lee Wolfe, G. L. Baughman, and Reginald C. Hollis. 'Singlet Oxygen in Natural Waters.' Nature 267, no. 5610 (June 2, 1977): 421-23.

Zepp, Richard G., George L. Baughman, and Patricia F. Schlotzhauer. 'Comparison of Photochemical Behavior of Various Humic Substances in Water: I. Sunlight Induced Reactions of Aquatic Pollutants Photosensitized by Humic Substances.' Chemosphere 10, no. 1 (1981): 109-17.

Zsolnay, Adam, Erik Baigar, Miguel Jimenez, Bernd Steinweg, and Flavia Saccomandi. 'Differentiating with Fluorescence Spectroscopy the Sources of Dissolved Organic Matter in Soils Subjected to Drying.' Chemosphere 38, no. 1 (January 1999): 45-50. 


\section{Appendix}

Table S1. Dataset

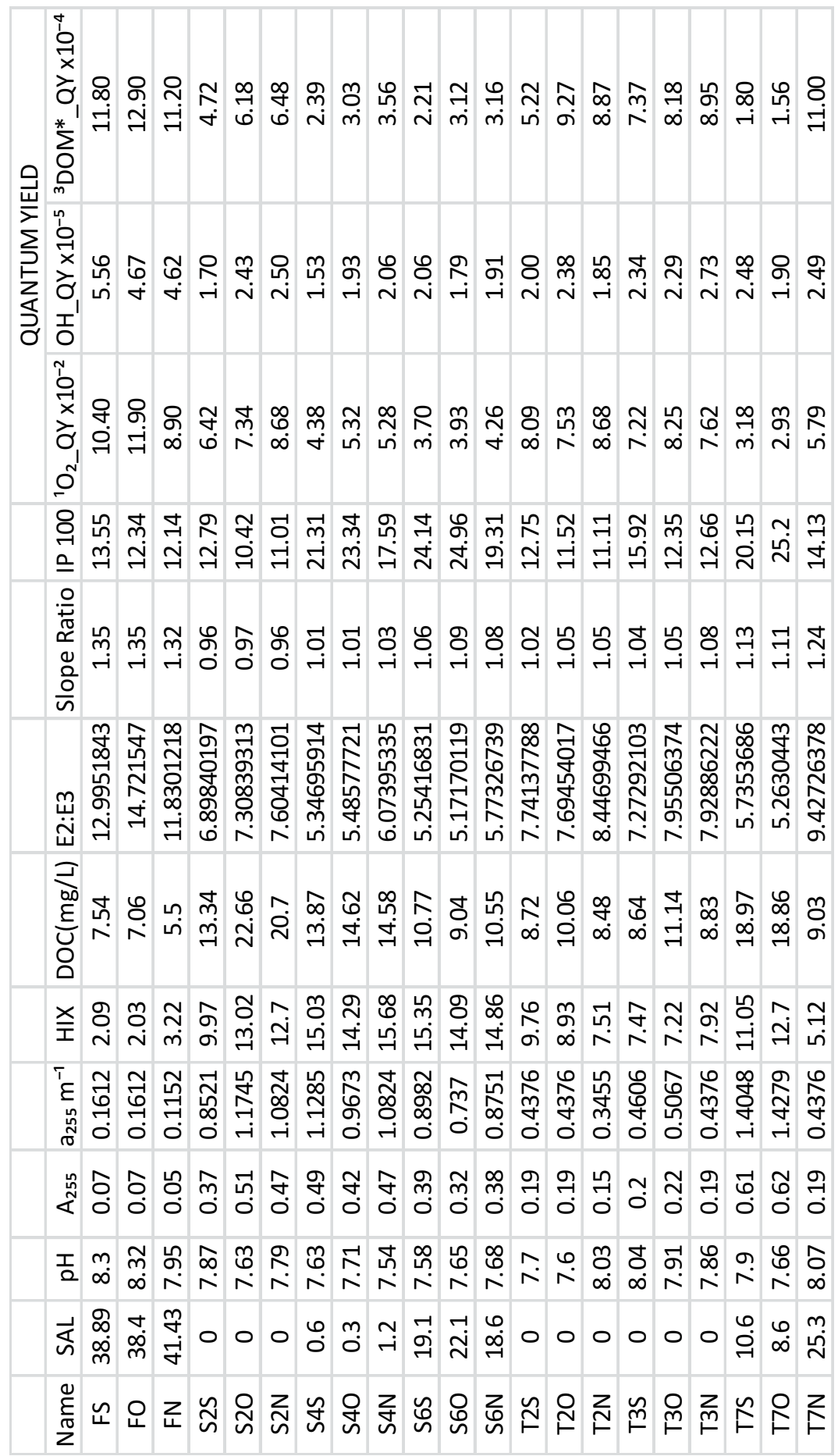




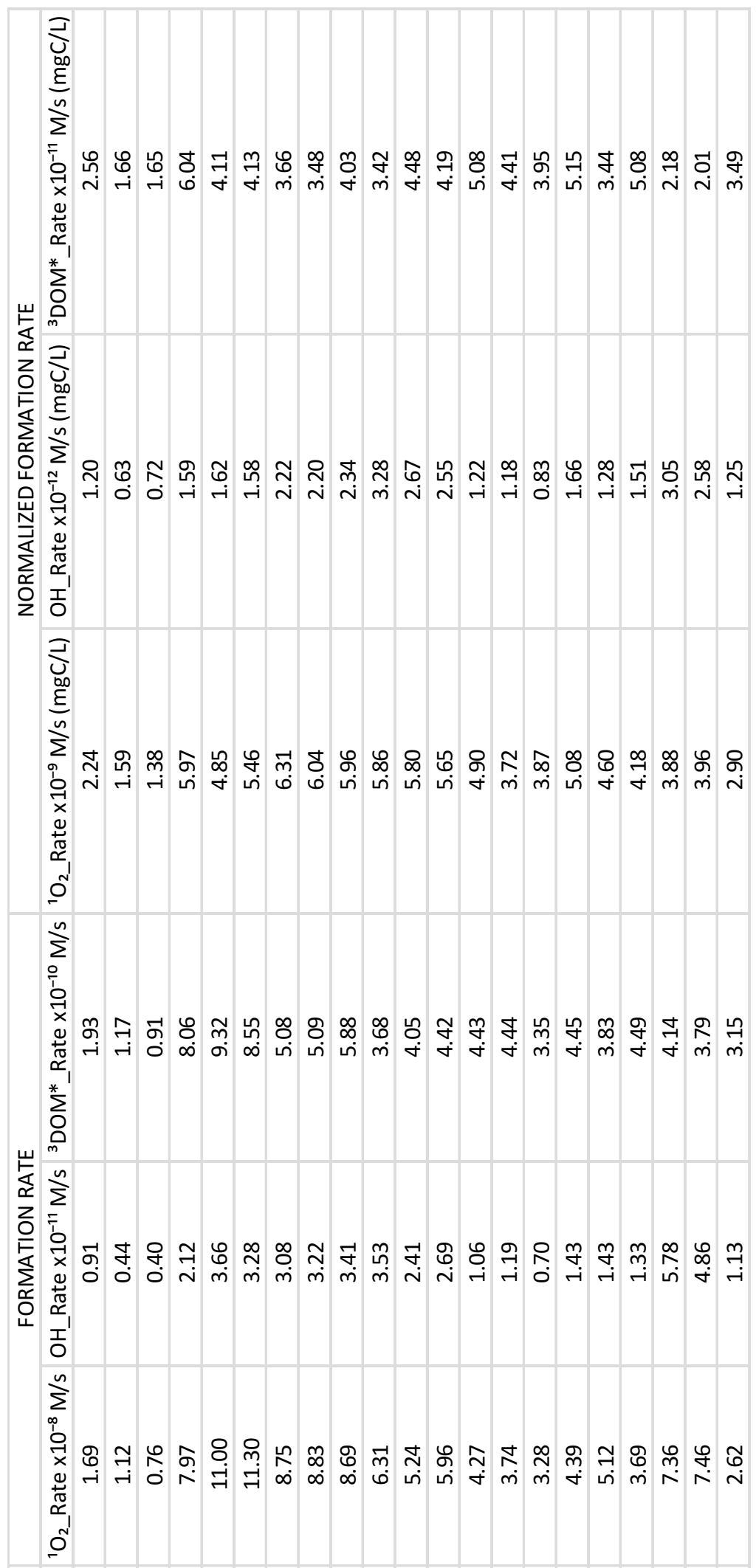


Table S2. Reactive species quantum yields for surface water (whole water) and surface water extract (isolates)

\begin{tabular}{|c|c|c|c|c|c|c|c|c|}
\hline & \multicolumn{3}{|c|}{ Isolates QY's } & \multicolumn{4}{c|}{ Whole Water QY's } \\
\hline Sample & E2/E3 & SO & TMP & OH & E2/E3 & SO & TMP & OH \\
\hline FB21_1030 & 12.90 & $8.12 \mathrm{E}-02$ & $2.27 \mathrm{E}+02$ & $4.61 \mathrm{E}-05$ & 15.34 & $1.19 \mathrm{E}-01$ & $3.62 \mathrm{E}+02$ & $4.67 \mathrm{E}-05$ \\
\hline SRS2_1015 & 7.16 & $7.73 \mathrm{E}-02$ & $1.49 \mathrm{E}+02$ & $2.56 \mathrm{E}-05$ & 7.30 & $7.34 \mathrm{E}-02$ & $1.61 \mathrm{E}+02$ & $2.43 \mathrm{E}-05$ \\
\hline SRS4_1007 & 5.49 & $4.94 \mathrm{E}-02$ & $6.23 \mathrm{E}+01$ & $2.10 \mathrm{E}-05$ & 5.55 & $5.32 \mathrm{E}-02$ & $8.04 \mathrm{E}+01$ & $1.93 \mathrm{E}-05$ \\
\hline SRS6_1007 & 5.04 & $4.08 \mathrm{E}-02$ & $7.29 \mathrm{E}+01$ & $2.05 \mathrm{E}-05$ & 5.33 & $3.93 \mathrm{E}-02$ & $8.07 \mathrm{E}+01$ & $1.79 \mathrm{E}-05$ \\
\hline SRS6_1104 & 5.04 & $5.57 \mathrm{E}-02$ & $7.89 \mathrm{E}+01$ & $2.43 \mathrm{E}-05$ & 5.83 & $4.26 \mathrm{E}-02$ & $8.77 \mathrm{E}+01$ & $1.91 \mathrm{E}-05$ \\
\hline TS2_1015 & 7.85 & $8.19 \mathrm{E}-02$ & $2.06 \mathrm{E}+02$ & $2.26 \mathrm{E}-05$ & 8.34 & $7.53 \mathrm{E}-02$ & $2.53 \mathrm{E}+02$ & $2.38 \mathrm{E}-05$ \\
\hline TS3_1016 & 7.79 & $7.64 \mathrm{E}-02$ & $2.05 \mathrm{E}+02$ & $1.79 \mathrm{E}-05$ & 7.98 & $8.25 \mathrm{E}-02$ & $2.25 \mathrm{E}+02$ & $2.29 \mathrm{E}-05$ \\
\hline TS7_1009 & 5.05 & $3.36 \mathrm{E}-02$ & $4.25 \mathrm{E}+01$ & $1.94 \mathrm{E}-05$ & 5.27 & $2.93 \mathrm{E}-02$ & $4.15 \mathrm{E}+01$ & $1.90 \mathrm{E}-05$ \\
\hline
\end{tabular}

Table S3. Linear Fit of Data in Table S2 (w/ intercept $=0)$

\begin{tabular}{|c|c|c|c|c|}
\hline & $\mathrm{E} 2 / \mathrm{E} 3$ & ${ }^{1} \mathrm{O}_{2}$ & ${ }^{3} \mathrm{DOM}^{*}$ & $\mathrm{OH}$ \\
\hline Slope & 1.10 & 1.06 & 1.28 & 0.98 \\
\hline $\mathrm{R}^{2}$ & 1.00 & 0.96 & 0.97 & 0.99 \\
\hline
\end{tabular}



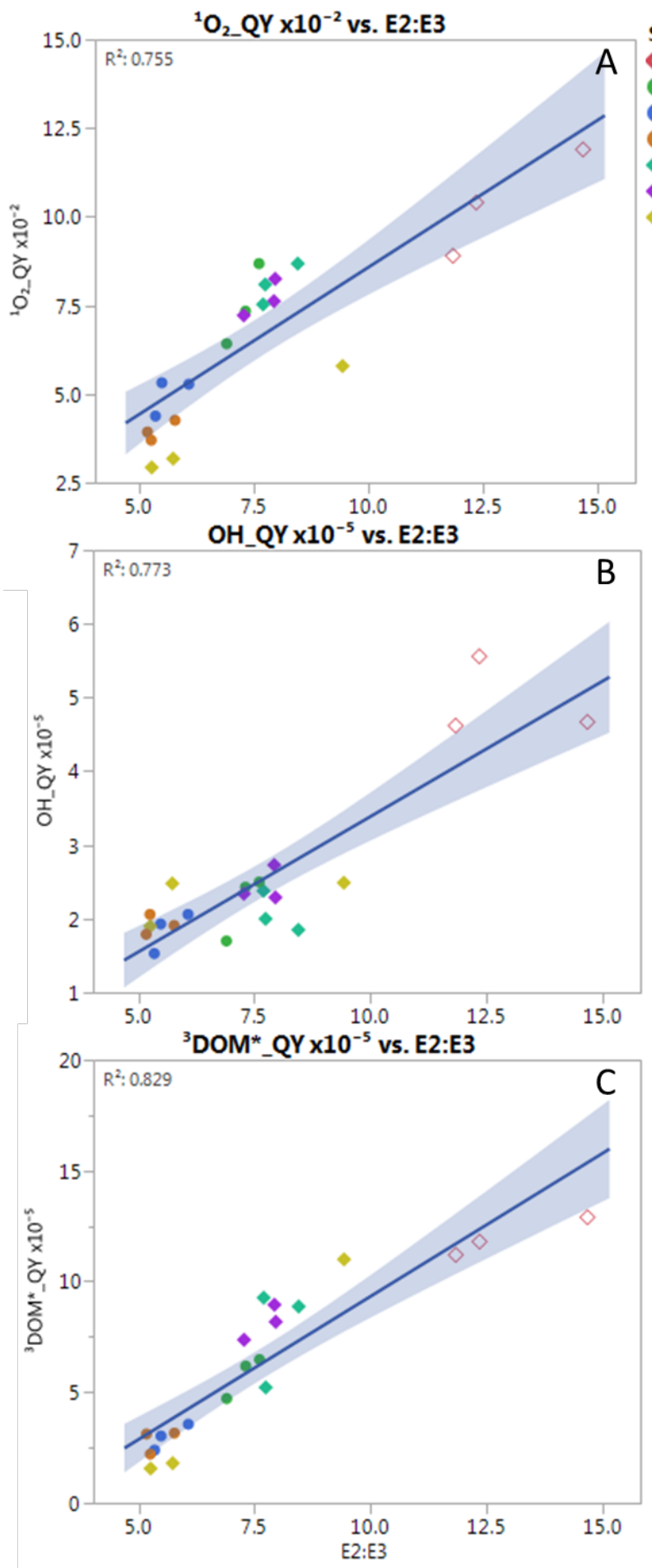

Figure S1. Reactive species quantum yields versus E2:E3 ratio. Fitting model was linear and the blue region represents the 95\% confidence zone. A) Singlet oxygen; B) Hydroxyl radical; C) Excited triplet state DOM. 

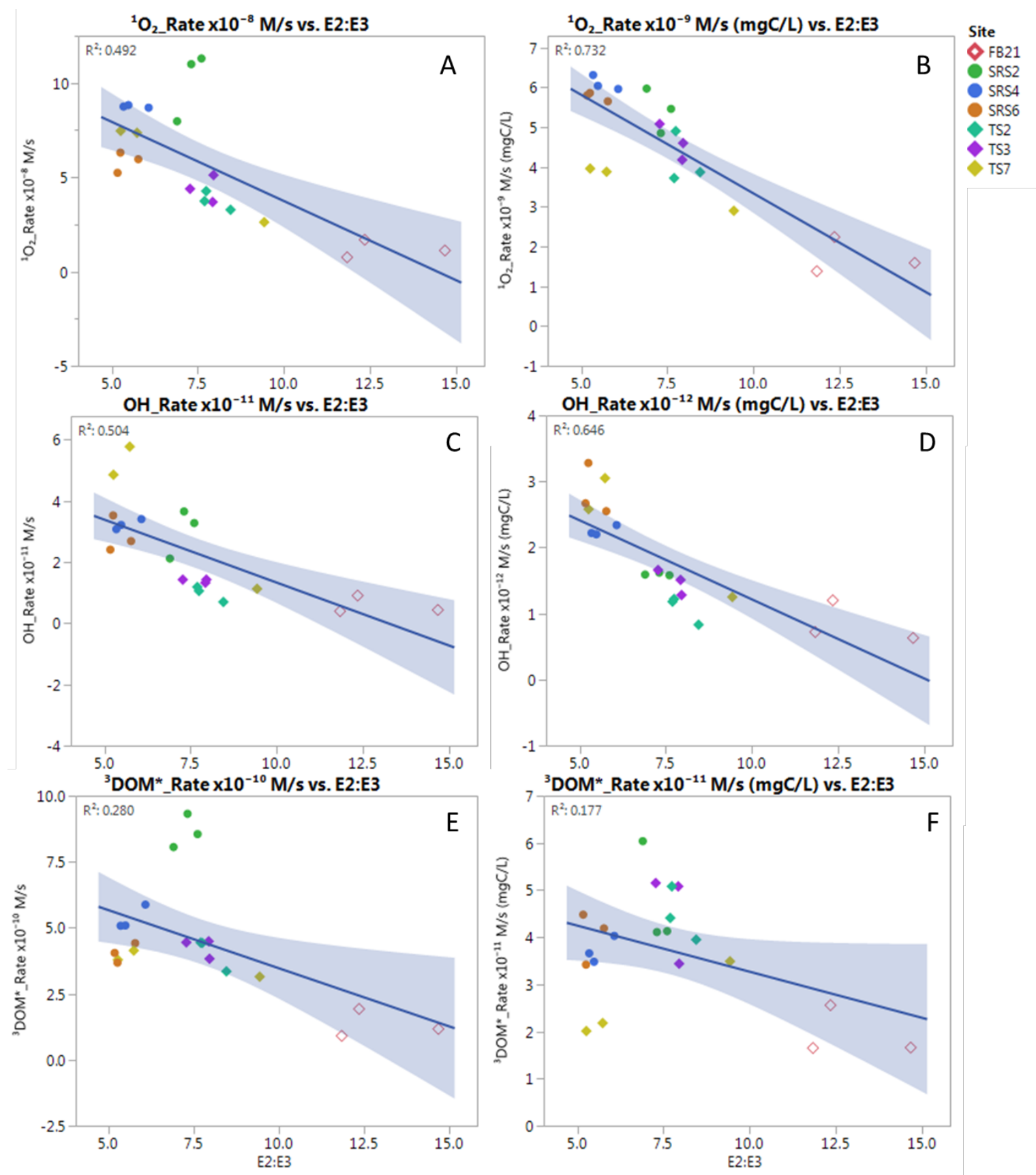

Figure S2. Reactive species formation rate and DOC normalized formation rate versus E2:E3 ratio. Fitting model was linear and the blue region represents the $95 \%$ confidence zone. Graph A, $\mathrm{C}$, E represented singlet oxygen, hydroxyl radical, and excited triplet state DOM formation rate versus E2:E3 value respectively. B, D, F represented singlet oxygen, hydroxyl radical, excited triplet state DOM normalized formation rate versus E2:E3 value respectively. 